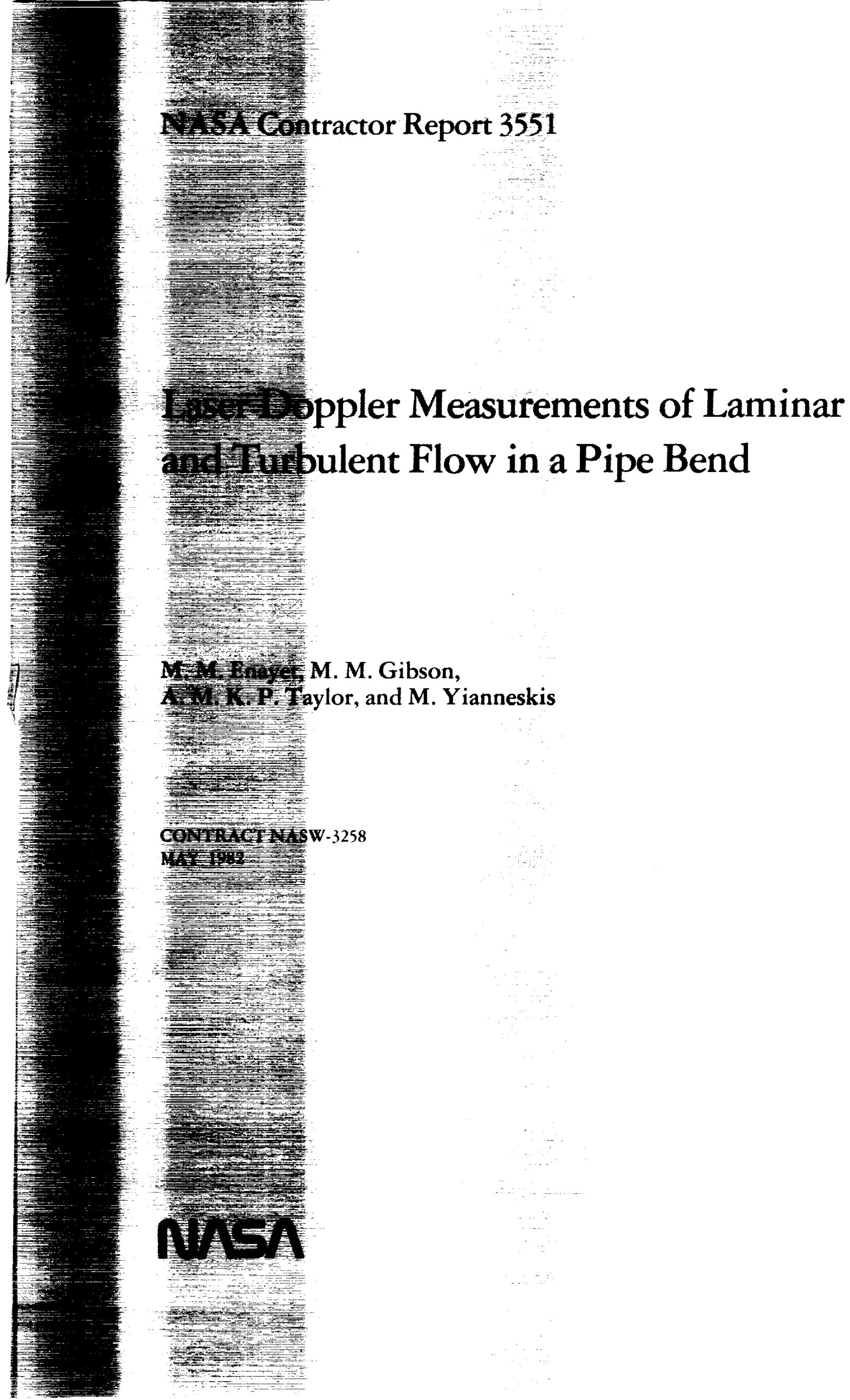




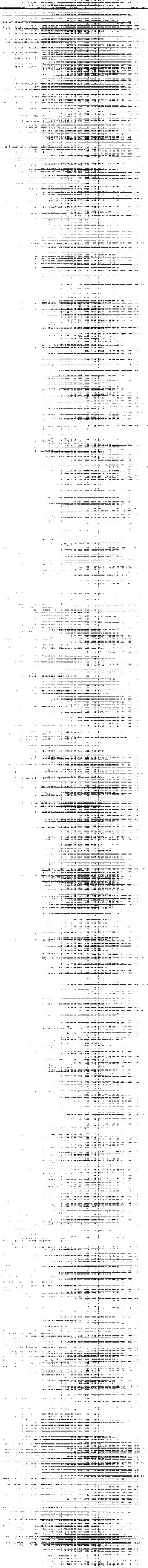


NASA Contractor Report 3551

\section{Laser Doppler Measurements of Laminar and Turbulent Flow in a Pipe Bend}

M. M. Enayet, M. M. Gibson,

A. M. K. P. Taylor, and M. Yianneskis

Imperial College of Science and Technology

London, England

Prepared for

NASA Headquarters

under Contract NASW-3258

\section{N/SA \\ National Aeronautics \\ and Space Administration}

Scientific and Technical Information Otfice 
1 


\section{TABLE OF CONTENTS}

SUMMARY

$\underline{\text { Page }}$

1. INTRODUCTION

2. EXPERIMENTAL ARRANGEMENT

2.1 THE TEST BEND

2.2 INSTRUMENTATION AND SIGNAL PROCESSING

2.3 SCOPE AND ACCURACY OF THE MEASUREMENTS

3. RESULTS AND DISCUSSION 6

3.1 FLOW VISUALIZATION 6

3.2 LAMINAR FLOW MEASUREMENTS 6

3.3 TURBULENT FLOW MEASUREMENTS 7

4. CLOSURE 18

APPENDIX $\rightarrow$ TABULATED DATA FOR REYNOLDS NUMBER 500 MEASUREMENTS 10

APPENDIX 2 TABULATED DATA FOR REYNOLDS NUMBER 1093 MEASUREMENTS 16

APPENDIX 3 TABULATED DATA FOR REYNOLDS NUMBER 43000 MEASUREMENTS 22

$\begin{array}{llll}\text { APPENDIX } 4 & 4 & \text { DEFINITION OF SYMBOLS } & 39\end{array}$

$\begin{array}{ll}\text { REFERENCES } & 40\end{array}$

$\begin{array}{ll}\text { FIGURES } & 41\end{array}$ 
1 
Laser-Doppler measurements are reported for laminar and turbulent flow through a ninety-degree bend of circular cross section with mean radius of curvature equal to 2.8 times the diameter. The measurements were made in crossstream planes 0.58 diameters upstream of the bend inlet plane, in 30,60 , and 75 degree planes in the bend and in planes one and six diameters downstream of the exit plane. Three sets of data were obtained: for laminar flow at Reynolds numbers of 500 and 1093 and for turbulent flow at the maximum obtainable Reynolds number of 43000 . The results show the development of strong pressure driven secondary flows in the form of a pair of counter rotating vortices in the streamwise direction. The strength and character of the secondary flows were found to depend on the thickness and nature of the inlet boundary layers: inlet conditions which could not be varied independently of Reynolds number. The quantitative anemometer measurements are supported by flow visualisation studies. Refractive index matching at the fluid-wall interface was not used; the measurements consist therefore of streamwise components of mean and fluctuating velocities only supplemented by wall pressure measurements for the turbulent flow. The displacement of the laser measurement volume due to refraction is allowed for in simple geometrical calculations. The results are intended for use as benchmark data for calibrating flow calculation methods.

This research was supported by contracts from the CEGB Central Electricity Research Laboratories, London, England, and from the NASA Lewis Research Center, Cleveland, Ohio, U.S.A. 


\section{INTRODUCTION}

As a fluid flows through a straight pipe or duct and into a bend the pressure, which in the straight section is uniform across the flow, must adjust in the bend to counter centrifugal forces. The pressure is greatest at the outer wall farthest from the centre of curvature and least at the inner wall nearest the centre of curvature and the cross-stream pressure gradient in the bend has two well known effects on the flow. At the bend inlet the boundary layer on the outer wall experiences the effects of a positive streamwise pressure gradient which may in a tight bend be strong enough to produce local separation; conversely, the inner wall boundary layer is accelerated. The reverse occurs at the pipe exit where local pressure gradients of the opposite sign appear as the flow adjusts to uniform pressure conditions downstream. Inside the bend the presence of side wall boundary layers ensures that the conditions for radial equilibrium cannot be satisfied exactly over the entire field. The slow moving fluid in these layers is forced inwards towards the centre of curvature and continuity ensures that the high speed fluid near the axis is driven outwards. The result is a secondary flow superimposed on the main flow.

If the bend is of circular cross section, or its height is not too much greater than its width measured in the radial direction, the effect of the secondary flow is to displace the region of maximum velocity from the centre towards the outer wa11. If, however, the boundary layers are thin and the secondary flow is weak the velocity distribution in the inviscid central core will approximate to that of a free vortex with velocity increasing towards the centre of curvature. The effects of longitudinal curvature on the boundary layers on the inner and outer walls also tend to counteract the effects of pressure-driven secondary flow. In the inner boundary layer the shear stress is reduced by curvature and the boundary layer grows relatively slowly. In the outer boundary layer the shear stress is increased and the layer is retarded and thickened. Thus in the flow in a high narrow curved channel, where the secondary flows are weak and confined to the edge zones, the region of maximum velocity is found closer to the inner wall (1). The effects of curvature on laminar boundary layers are weak in ducts of moderate aspect ratio and are masked by the secondary flow; the fractional change in shear stress is of order $\delta / R$ (where $\delta \equiv$ boundary layer thickness and $\mathrm{R} \equiv$ radius of curvature). The effects of curvature on the turbulence in turbulent boundary layer flow are an order of magnitude greater (2) and may be large enough to counteract the effects of secondary flow and to play a significant role in determining the flow structure.

The presence and origin of secondary flow in bends have long been known and understood although obvious measurement difficulties associated with probe explorations have hindered detailed investigation and have largely restricted experiments to flow visualization studies and overall pressure loss measurements. The former (3) show that a laminar boundary layer in a ninetydegree pipe bend is deflected through about 45 degrees while the deflexion of a turbulent layer does not exceed 30 degrees as might be inferred from the different inlet profiles. Work done prior to 1970, which consists almost entirely of wall pressure measurements and pressure probe surveys of the outlet 
plane, is summarized and reviewed by Ward-Smith (4). These data provide a basis for empirical pressure drop correlations but are necessarily too limited to be used for the validation of flow calculation methods. The development of these methods to the point where they can be used as standard design tools has, fortunately, been paralleled by the development of the laser Doppler anemometer which, by obviating the need for probe insertion, has made possible more detailed measurement of complex flows including those in bends. Humphrey et al (5) report measurements of the longitudinal velocity component in laminar flow through a strongly curved duct of square cross section. This work is extended in (6) to the measurement in turbulent flow of two components of mean velocity, two components of turbulent energy and one shear stress component; similar measurements are also reported in (7) for laminar and turbulent flow with thin inlet boundary layers.

The problem of flow in a round pipe, which is the subject of the present contribution, presents additional measurement difficulties and has consequently received less attention. Rowe (8) reports total-pressure measurements in a mildly curved pipe bend while laser-Doppler measurements appear to be limited to the laminar flow experiment described by Agrawal et a) (9). The difficulties arise because in off-diameter planes the laser beams are refracted at the fluid-wall interface unless care is taken to match the refractive indices. If this is not done the measurements will be limited to longitudinal components of mean and fluctuating velocity. The measurement volume is displaced but to a position which can be located quite accurately by simple calculation (10).

In the present paper we report measurements of laminar and turbulent flow in and downstream of a tight 90-degree pipe bend. The results, which complement and extend those of $(5,6,7)$ are seen as a useful contribution to the 'data bank' available for the further testing and development of numerical flow calculation methods. sions.

Professor J.H. Whitelaw contributed valuable advice in numerous discus-

\section{EXPERIMENTAL ARRANGEMENT}

\subsection{The test bend}

The geometry and dimensions of the test bend are shown in Figure 1. The dimensions are similar to those of the square-sectioned bend of $(6,7)$ with radius of curvature equal to 2.8 times the internal diameter. The bend was machined accurately from two halves of a rectangular plexiglass block split in the plane of symetry. It was thus possible to maintain a tolerance of $\pm 0.7 \mathrm{~mm}$ on the internal diameter and to minimise refraction problems at the external, air-plexiglass, interface by the retention of a rectangular external 
section. The bend was fixed in the horizontal plane downstream of a straight tube of the same diameter $(48 \mathrm{~mm})$ and $240 \mathrm{~mm}$ long; a second straight tube, $480 \mathrm{~mm}$ long, was fitted downstream. Photographs of the overall arrangement are shown in Figure 2.

Figure 3 shows diagrammatically the closed circuit water flow rig in which the bend was fitted immediately downstream of a contraction fitted to the plenum chamber. The flow rate was constantly monitored using Fischer and Porter precision flowmeters. The maximum obtainable Reynolds number, $\frac{4}{\pi} \frac{\dot{m}}{v d}$, was 43000 . For the turbulent flow measurements the water was seeded with minute quantities of milk in order to increase the scattering particle concentration and, consequently, the particle arrival rate (11).

\subsection{Instrumentation and signal processing}

The optical arrangement, which is similar to that described by Taylor et al (7), is shown diagrammatically in Figure 4. The light beam generated by a $5 \mathrm{~mW}$ helium-neon laser is focussed on to a radial diffraction grating, collimated in order to reduce spherical aberration and then focussed to form the scattering volume at the point of measurement in the bend. Measurements in the vertical plane were made in the straight pipe sections at each end of the bend. For these the light beam was turned through 90 deg using a mirror which was optically flat to within one tenth of the wavelength of light.

Forward scattered light collected by the objective lens is focussed on and passes through a pinhole to an EMI 9658 photomultiplier, the output from which is processed in a Cambridge Consultants $\mathrm{CCOl}$ frequency tracking demodulator and associated equipment shown in the block diagram of Figure 5 . The principal characteristics of the laser-Doppler anemometer are given in Table 1 below.

\section{Table 1}

Optical Characteristics of the Laser Doppler Anemometer

Focal length of imaging lens

Half-angle of beam intersection

Fringe separation (1ine-pair spacing)

Number of fringes in measuring volume

Intersection volume diameter calculated at

$1 / e^{2}$ intensity

Intersection volume length calculated at

$$
1 / \mathrm{e}^{2} \text { intensity }
$$

Photomultiplier pinhole diameter

Transfer constant
$300 \mathrm{~mm}$

$9.11^{\circ}$

$1.9 \mu \mathrm{m}$

84

$0.167 \mathrm{~mm}$

$1.391 \mathrm{~mm}$

$0.50 \mathrm{~mm}$

$0.500 \mathrm{MHz}_{\mathrm{ms}}^{-1}$

4 


\subsection{Scope and accuracy of the measurements}

Refraction of the laser beam at the water-plexiglass interface not only displaces the measurement volume by an amount which can be readily calculated but also, and more importantly, prevents the measurement of cross-section velocity components. The method employed successfully for the latter in the rectangular bend experiments $(6,7)$ fails for the round pipe because, unless the refractive indices of the fluid and pipe wall are equal, the twin laser beams entering the pipe in a plane at 45 degrees to the axis cannot converge. Consideration has been given to the use of fluids other than water which would allow the indices to be equalized. Unfortunately it turns out that such fluids either possess highly unpleasant or toxic properties or are so viscous that it is difficult to realize Reynolds numbers high enough for turbulent flow. A case in point is the experiment described by Agrawal et al (9) where the use of a glycerine-water mixture to match the indices limited the investigation to laminar flow. Since the main objective of the present work is the study of turbulent bend flow, the limitation on the scope of the measurements to streamwise velocities only has had to be accepted at this stage.

There is no difficulty in measuring the streamwise velocities or in calculating the displaced position of the measurement volume. The measurements are made at points along the optical axis which is refracted at the pipe wall at an angle to the plane of symmetry to which it was originally parallel. A straightforward calculation produces the beam trajectories shown in Figure 6 . The actual location of the measurement points along the optical axis is obtained by applying the correction described by Boadway and Karahan (10) for the effects of refraction due to the bend curvatures. These two corrections have been applied independently to the results presented here. It was also found that signal quality was only slightly impaired by refraction and that measurements were feasible for points in the flow distant more than one tenth of the radius from the wall in the vertical plane.

Estimated measurement errors are summarized in Table 2. Corrections were not applied for the effects of finite transit time and instrument noise broadening. Systematic errors of up to 2.5 per cent are mainly associated with velocity gradient effects near the walls and have been included in the table.

Table 2

Measurement errors

$\begin{array}{lcc}\text { Quantity } & \text { Systematic error } & \text { Random error } \\ x & \pm 0.5 \mathrm{~mm} & \pm 0.02 \mathrm{~mm} \\ y, z & \pm 0.2 \mathrm{~mm} & \pm 0.02 \mathrm{~mm} \\ \theta & \pm 0.30 & \pm 0.170 \\ B & \pm 0.05^{\circ} & \mathrm{nil} \\ U_{B} \text { (laminar) } & \pm 0.8 \% & \pm 0.8 \% \\ U_{B} \text { (turbulent) } & \pm 1.5 \% & \pm 0.5 \% \\ U / U_{B} & \text { up to } 2.5 \% & \pm 1.5 \% \\ u^{\prime} / U_{B} & \text { up to } 3 \% & \text { up to } \pm 3 \%\end{array}$


The measurements were made in cross-stream planes 0.58 diameters upstream of the bend inlet plane, in 30,60, and 75 degree planes in the bend and in planes at one and six diameters downstream of the exit plane. Three sets of data were obtained: for laminar flow at Reynolds numbers of 500 and 1093 and for turbulent flow at the maximum obtainable Reynolds number of 43000 .

\section{RESULTS AND DISCUSSION}

\subsection{Flow visualization}

Observation of hydrogen bubble paths in low speed flow revealed no unusual features such as the local separation reported in (5) for fully developed flow through the square section bend. The visual observations were entirely consistent with large scale secondary flow patterns detected by laser Doppler anemometry. Hydrogen bubbles were generated in the flow by a thin wire electrode inserted through static pressure tappings, the trajectories were photographed with typical results shown in Figure 7 . Figures 7.1 and 7.2 show bubble paths at the 15 and 30 degree stations where the inward movement of low velocity fluid in the upper part of the bend is clearly visible. The secondary flow appears to be directed inward at a greater angle at the 15 degree station than further downstream at 30 degrees. The corresponding outward movement of the core flow is shown by the distinct trace from the electrode tip. Figure 7.3 shows the hydrogen bubble sheet generated near the outer wall at the 30 degree station; the flow here is upward and along the wall toward the inside of the bend.

\subsection{Laminar flow measurements}

The results of velocity measurements at a Reynolds number of 500 , mean velocity $10.5 \mathrm{~mm} \mathrm{~s} \mathrm{~s}^{-1}$, are presented graphically in Figures 8 and 9 . The data are tabulated in Appendix 1. Figure 8 shows the inlet conditions: horizontal and vertical velocity profiles 0.58 diameters upstream of the bend. The boundary layer thickness is about $0.27 \mathrm{~d}$ so that there is a significant potential core. The apparent slight asymmetry shown in the results is within the estimated error band. Contours of the streamwise velocity in four crossstream planes are presented in Figure 9 and show the effects of strong secondary flow which displaces the region of maximum velocity to the outside of the bend. The secondary flow develops gradually: in the 30 degree plane the only visible effect is a thickening of the shear layer on the inside of the bend. By 60 degrees the secondary flow has become almost fully developed as is shown by the distortion of the contours. The fourth set of contours, in the plane one diameter downstream, shows that the secondary motion persists without significant decay to this distance. 
The effects of doubling the mean velocity and Reynolds number to $23 \mathrm{~mm} \mathrm{~s}-1$ and 1093 respectively are shown in Figures 10 and 11 . The data are tabulated in Appendix 2. The inlet boundary layers are reduced in thickness by about fifteen per cent to $0.23 \mathrm{~d}$, the transverse pressure gradient is increased and the secondary flow is intensified. The peak velocity in the 30 degree plane is displaced from the plane of symmetry but remains closer to the centreline. This displacement, which persists downstream, has also been observed in the flow in a square bend (7). The shape of the contours near the outside of the bend reflect scatter in the data attributable mainly to difficulties in locating accurately the measurement volume near the wall and partly, perhaps, to slight asymmetry in the flow.

In neither case do the measurements show any unexpected feature: the secondary flow superposed on the main motion is essentially as described qualitatively in references (1) and (3); it develops gradually and persists downstream after the removal of the transverse pressure gradient responsible for its generation in the bend. The strength and location of the pressure driven secondary flow depend on the inlet conditions and the Reynolds number which could not be varied independently in the present experiments. The stronger secondary flow observed at $\mathrm{Re}=1093$ must be attributable mainly to the increased centrifugal forces and transverse pressure gradient rather than to the relatively small changes noted in the initial conditions. The present contribution is of quantitative velocity data in the bend: these are considered to be accurate enough to be useful in checking the numerical accuracy of flow prediction methods.

\subsection{Turbulent flow measurements}

At the maximum flow velocity of $0.92 \mathrm{~m} \mathrm{~s}^{-1}$, Reynolds number 43000 , the inlet boundary layers are turbulent. The static pressure variation on the bend wall is large enough to be measured accurately with the results shown in Figure 12. At the bend inlet the negative pressure gradient on the inner wall is roughly twice the positive gradient on the outside. These initial gradients resulting from the change from straight to curved flow disappear at about 25 degrees so that in the mid-section of the bend $\left(25^{\circ}<\theta<75^{\circ}\right)$ a quasi equlibrium condition is reached with approximately uniform pressure on the inner and outer walls. The transition to straight flow downstream is signalled by the appearance of strong gradients for $\theta>75 \mathrm{deg}$. The overall pressure drop is about $0.3 \rho U_{B}^{2}$.

Laser Doppler measurements of the mean and r.m.s. fluctuation of the streamwise velocity at inlet are shown in Figure 13 and contours of these quantities at downstream stations in Figures 14 and 15 . Numerical values are tabulated in Appendix 3. The inlet boundary layers of Figure 13 are much thinner, $0.09 \mathrm{~d}$, than in the two laminar flows investigated and the presence of a large central region of uniform velocity flow influences significantly the development of secondary flow downstream. The mean velocity contours presented in Figure 14 show that by the 30 degree plane the potential core has adjusted to the cross-stream pressure gradient imposed by the bend and the region of 
maximum velocity has been displaced toward the inside. The results also differ from the corresponding laminar flow measurements in that the thickness of the outer wall boundary layer is increased relative to that on the inside of the bend due mainly to the effects of the potential flow adjustment and the wall pressure gradients of opposite sign but also, quite possibly, to the effects of longitudinal curvature on the turbulence structure. In the 60 degree plane distortion of the contours suggests the presence of strong secondary flow largely confined to the region of steep velocity gradients near the inner wa11. This secondary flow grows with distance through the bend and by the 75 degree plane extends over and beyond the inner half of the section. The removal of the transverse pressure gradient in the straight flow downstream results in a shift of the velocity maximum toward the outside. A large secondary flow, comparable with those observed in the laminar flow experiments, now extends over the entire flow area and persists in the plane six diameters downstream of the bend where, however, the transverse velocity gradients have decayed to about one half of their values one diameter downstream.

The contours of turbulence intensity presented in Figure 15 are consistent with those of the mean velocity. As is to be expected high values of the velocity fluctuation are associated with steep mean velocity gradients and with the distortion of the symmetrical inlet flow.

These results may be compared with the measurements made by Humphrey, Whitelaw and Yee (6) in a tight bend of square cross-section. The inlet boundary layers of that flow were substantially thicker than in the present flow and contained stress driven secondary flows towards the corners. As a result the pressure driven secondary flow in the bend extended over the entire flow area as in the two laminar flows of the present study.

\section{CLOSURE}

The measurements show, as expected, the presence in bend flow of strong cross-stream flows produced by the inward motion of slow moving fluid in a radial pressure gradient. The strength of the secondary flow is influenced by the initial inlet flow conditions: when the inlet boundary layers are thin, as in the turbulent flow case reported here, the initial flow adjustment is an inward shift of the velocity peak in the potential core. The secondary flow then develops initially in the inside of the bend. For all cases the secondary flow takes some time to develop and its effects are still increasing by the exit and persist downstream.

The effects of refraction at the doubly curved fluid-wall interface prevent the measurement of cross-stream velocity components. The investigation of flows in the round bend to the same level of detail as has been achieved 
previously in square bends will require refractive index matching. For the streamwise velocity measurements reported here simple geometrical corrections allow for the displacement of the measurement volume by refraction.

The laminar flow data may be used to check the numerical accuracy of flow prediction methods; the turbulent flow measurements provide the additional information needed to validate mathematical models of turbulence. 


\section{Appendix 1}

Tabulated Data for Reynolds Number 500 Measurements

All velocities normalised with the bulk velocity, $U_{B}=0.0105 \mathrm{~m} / \mathrm{s}$. Symbols as defined in Figures 1 and 6.

\begin{tabular}{|c|l|l|l|l|l|l|}
\hline$x / d$ & $y / r$ & $z / r$ & $U / U_{B}$ & $y / r$ & $z / r$ & $U / U_{B}$ \\
\hline \multirow{5}{*}{0.58} & 0.9 & 0 & 0.509 & 0 & -0.9 & 0.539 \\
& 0.8 & & 0.865 & & -0.8 & 0.820 \\
& 0.7 & & 1.167 & & -0.7 & 1.106 \\
& 0.6 & & 1.393 & & -0.6 & 1.335 \\
& 0.5 & & 1.546 & & -0.5 & 1.484 \\
& 0.4 & & 1.603 & & -0.4 & 1.595 \\
& 0.3 & & 1.648 & & -0.3 & 1.655 \\
& 0.2 & & 1.66 & & -0.2 & 1.673 \\
& 0.1 & & 1.664 & & -0.1 & 1.681 \\
& 0.0 & & 1.663 & & 0.0 & 1.687 \\
& -0.1 & & 1.658 & & 0.1 & 1.682 \\
& -0.2 & & 1.66 & & 0.2 & 1.678 \\
& -0.3 & & 1.648 & & 0.3 & 1.667 \\
& -0.4 & & 1.607 & & 0.4 & 1.639 \\
& -0.5 & & 1.55 & & 0.5 & 1.552 \\
& -0.6 & & 1.408 & & 0.6 & 1.419 \\
& -0.7 & & 1.18 & & 0.7 & 1.167 \\
& -0.8 & & 0.873 & & 0.8 & 0.847 \\
& -0.9 & & 0.505 & & 0.9 & 0.482 \\
& & & & & & \\
\hline
\end{tabular}




\begin{tabular}{|c|c|c|}
\hline$\stackrel{2}{\infty}^{\infty}$ & 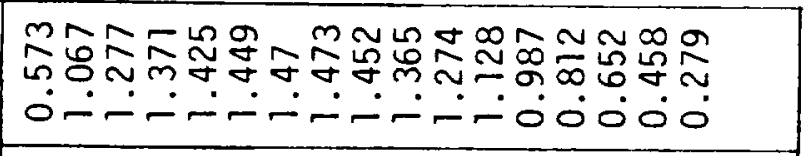 & 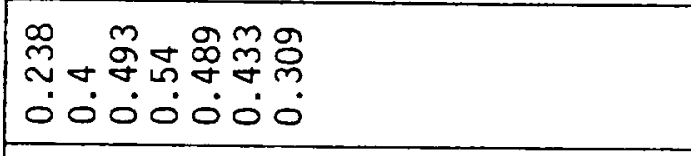 \\
\hline$\leqslant$ & 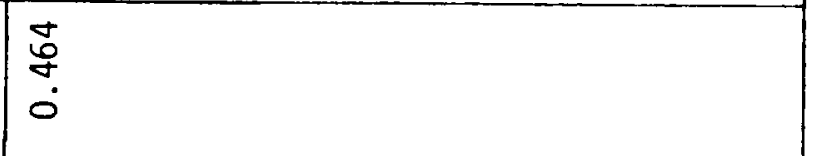 & 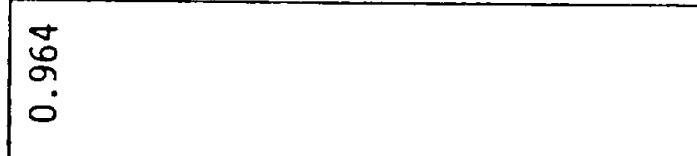 \\
\hline 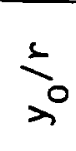 & 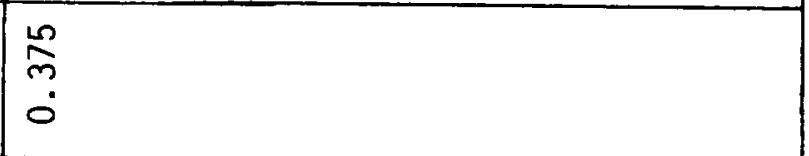 & $\begin{array}{c}\tilde{o} \\
\tilde{\infty} \\
0\end{array}$ \\
\hline$\sum^{\infty}$ & 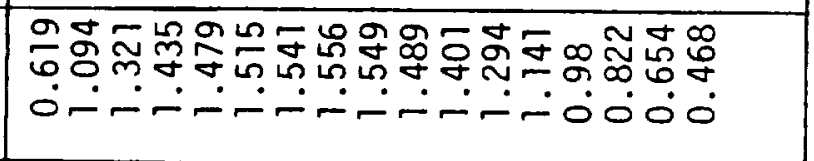 & 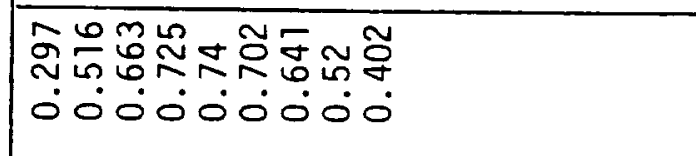 \\
\hline$\stackrel{5}{i}$ & $\bar{m}_{0}^{m}$ & $\begin{array}{ll} \\
\bar{\sigma} \\
\vdots \\
\end{array}$ \\
\hline 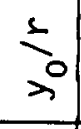 & 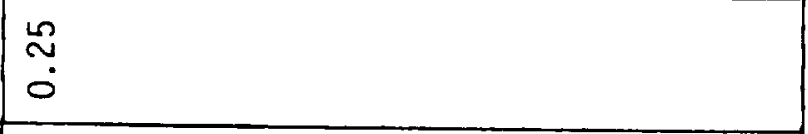 & $\begin{array}{l}n \\
0 \\
0\end{array}$ \\
\hline$\sum^{\infty}$ & 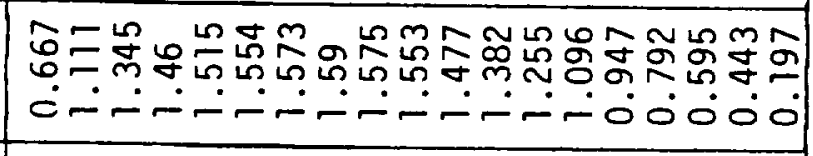 & 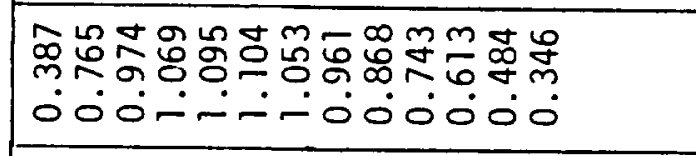 \\
\hline$\stackrel{\Sigma}{\vdots-1}$ & 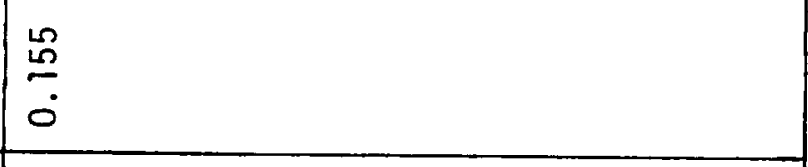 & $\begin{array}{l}\infty \\
\stackrel{\infty}{0} \\
\vdots \\
0\end{array}$ \\
\hline 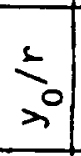 & $\stackrel{2}{\cong}$ & \begin{tabular}{|l|l|}
$\frac{6}{6}$ \\
0 \\
0 \\
0
\end{tabular} \\
\hline $2^{\infty}$ & 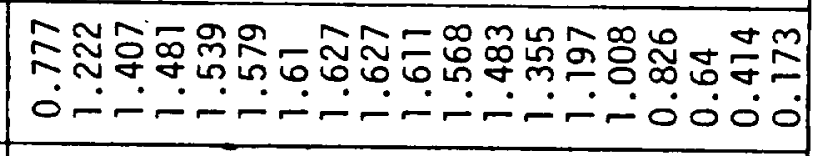 & 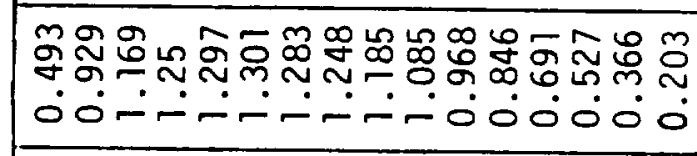 \\
\hline 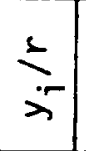 & 0 & $\begin{array}{ll}\tilde{0} \\
\dot{0} \\
0\end{array}$ \\
\hline 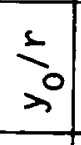 & 0 & $\ddot{0}$ \\
\hline$\vdots$ & 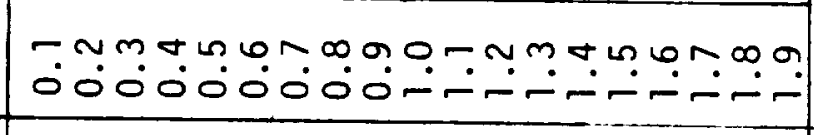 & 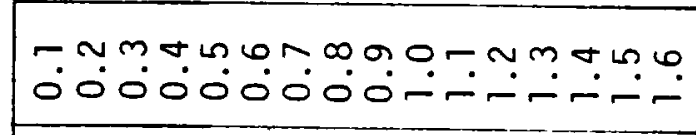 \\
\hline$\odot$ & io & 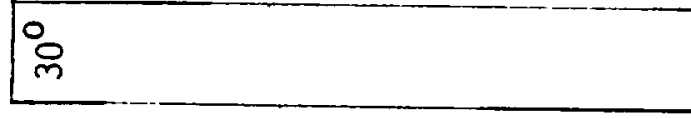 \\
\hline
\end{tabular}




\begin{tabular}{|c|c|}
\hline$\sum^{\infty}$ & 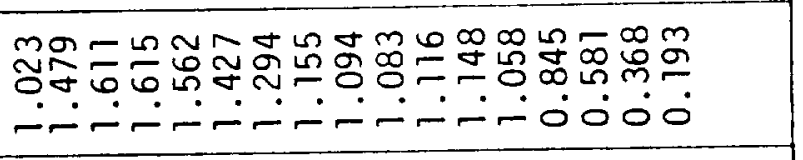 \\
\hline$\neq$ & $\begin{array}{l}\dot{G} \\
\dot{q} \\
\dot{0}\end{array}$ \\
\hline$\neq 0$ & $\underset{\substack{n \\
m}}{0}$ \\
\hline$\stackrel{2}{\Sigma}^{\infty}$ & 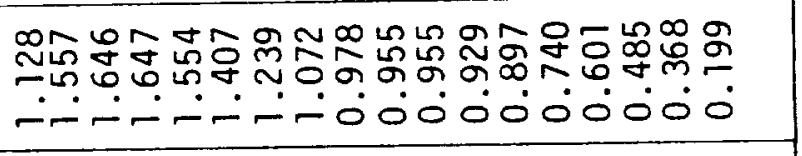 \\
\hline$\div$ & $\stackrel{\circ}{m}$ \\
\hline$\leqslant$ & 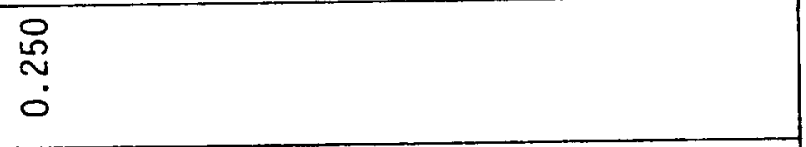 \\
\hline$\sum^{\infty}$ & 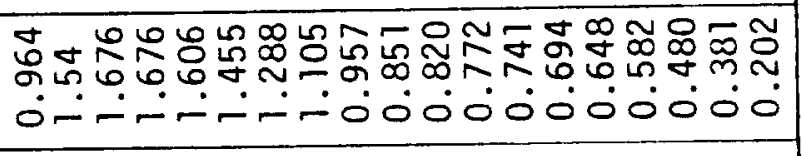 \\
\hline 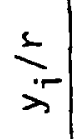 & $\stackrel{n}{\stackrel{n}{0}}$ \\
\hline$\leqslant$ & $\stackrel{\stackrel{\sim}{\cong}}{\circ}$ \\
\hline$\sum^{\infty}$ & 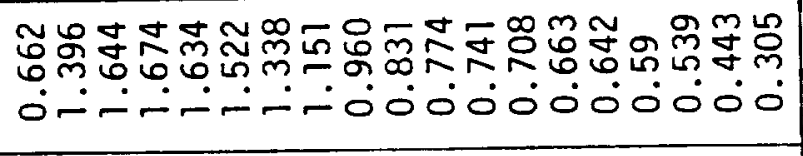 \\
\hline \pm & 0 \\
\hline $\begin{array}{l} \pm \\
>0\end{array}$ & 0 \\
\hline$\frac{5}{2}$ & 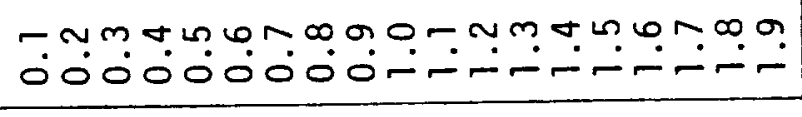 \\
\hline ه & 8 \\
\hline
\end{tabular}

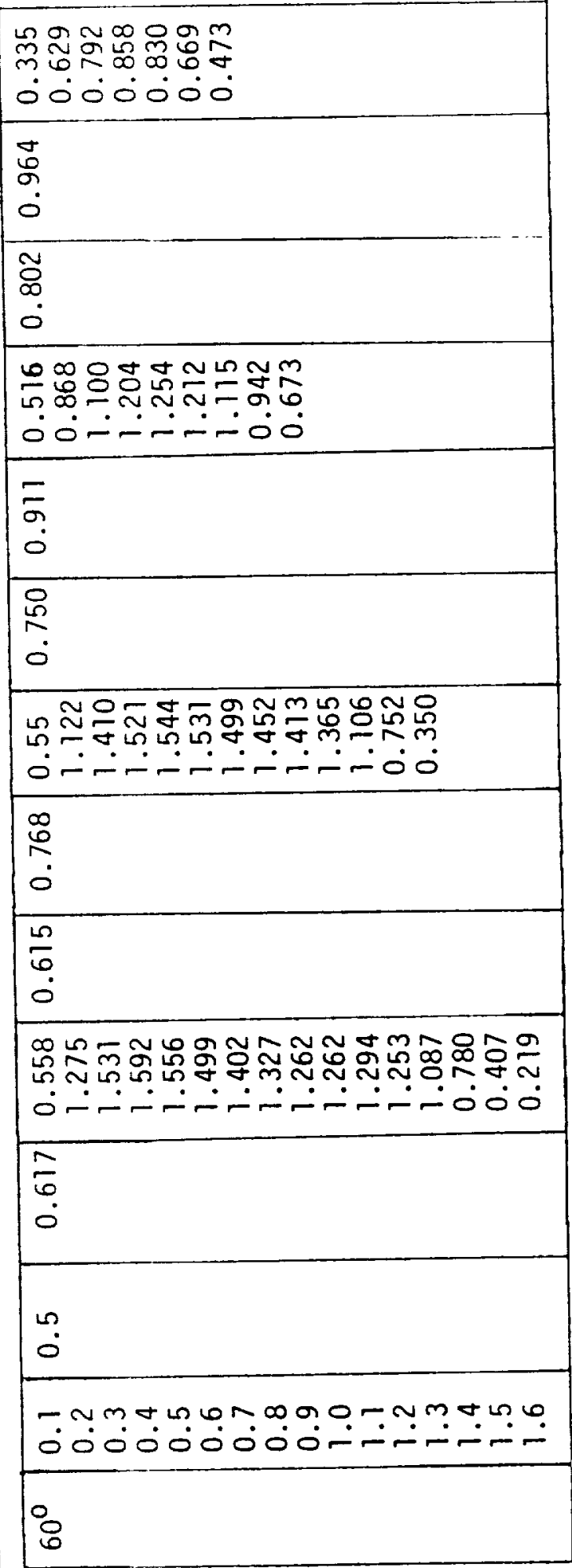




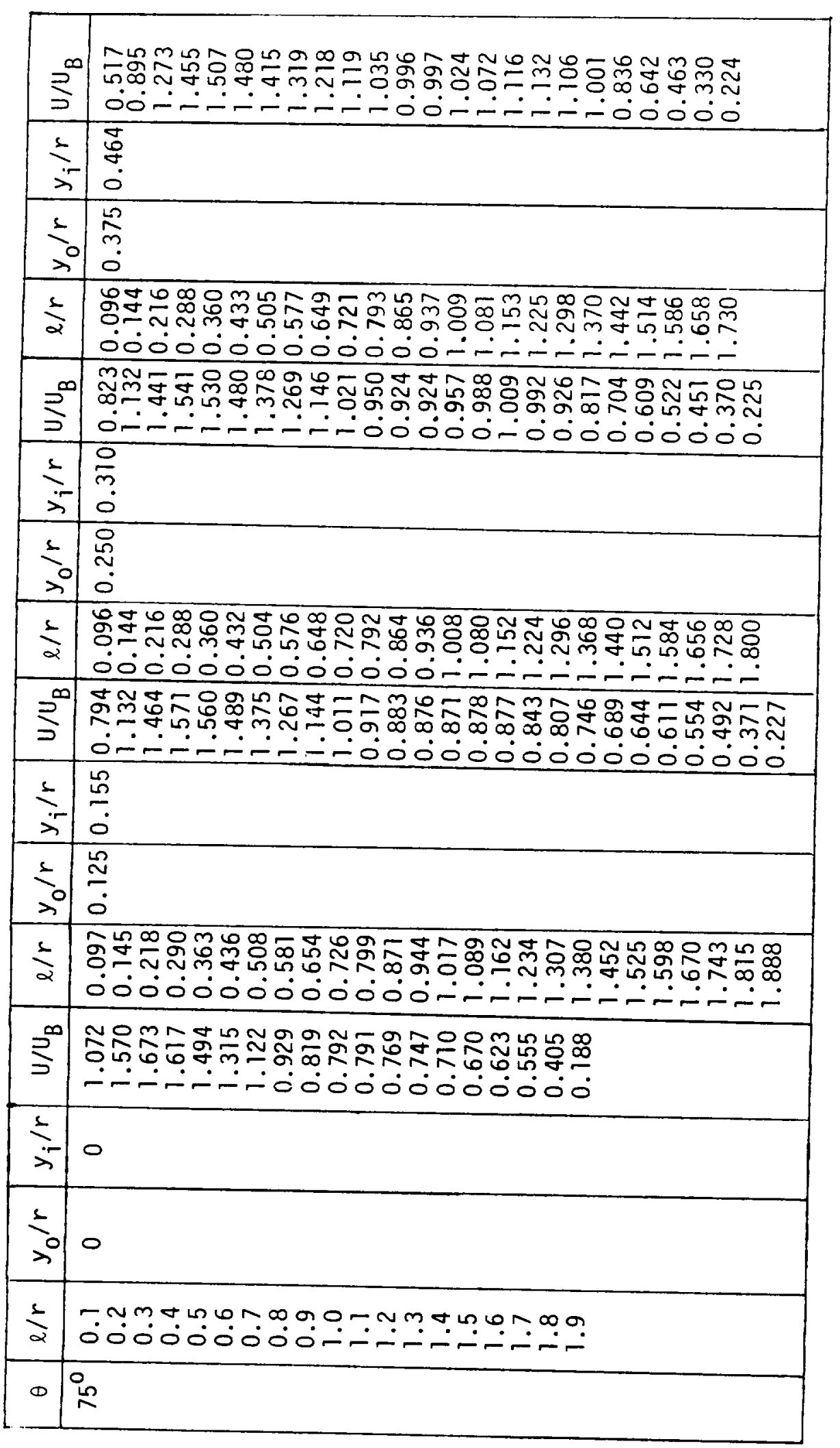




\begin{tabular}{|c|c|}
\hline$\sum^{\infty}$ & 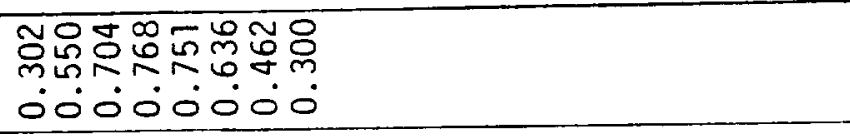 \\
\hline 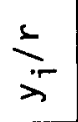 & 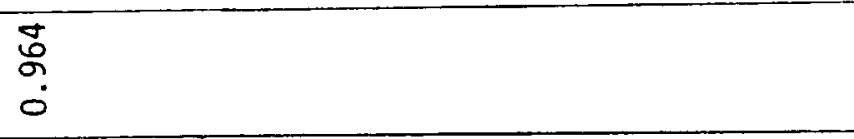 \\
\hline 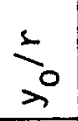 & \\
\hline$\frac{s}{\alpha}$ & 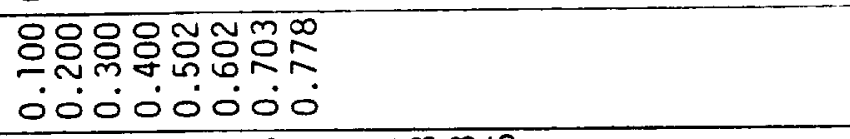 \\
\hline$\sum^{\infty}$ & 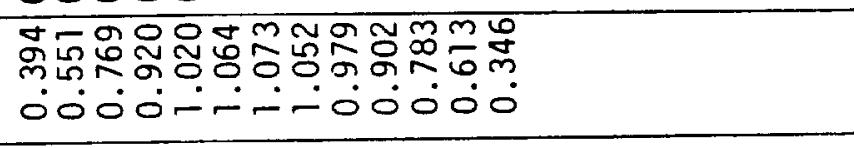 \\
\hline$\dot{i}$ & $\bar{\sigma}$ \\
\hline$\leqslant$ & 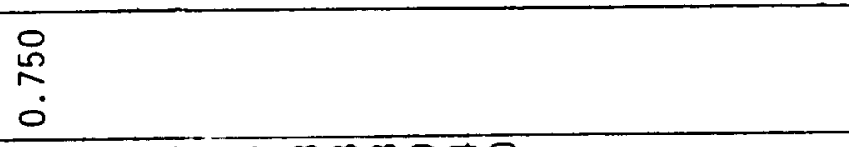 \\
\hline$\stackrel{5}{\alpha}$ & 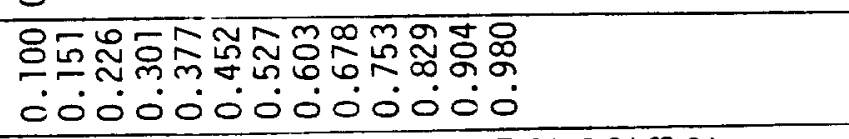 \\
\hline$\sum^{\infty}$ & 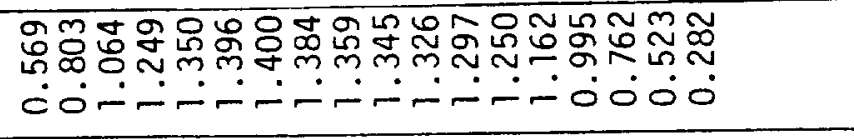 \\
\hline 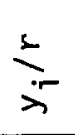 & $\begin{array}{l}\infty \\
\stackrel{\infty}{\circ} \\
\dot{0}\end{array}$ \\
\hline$\leqslant$ & $\begin{array}{l}10 \\
0 \\
0 \\
0\end{array}$ \\
\hline$\frac{\xi}{\alpha}$ & 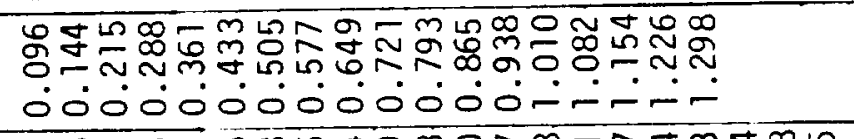 \\
\hline$\sum^{\infty}$ & 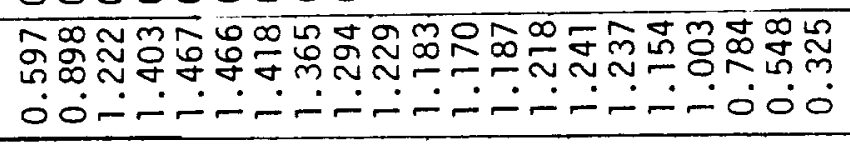 \\
\hline$\stackrel{5}{i}$ & $\begin{array}{lll}\bar{\sigma} \\
\dot{0} \\
0\end{array}$ \\
\hline 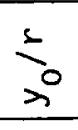 & $\begin{array}{ll} \\
0 \\
0 \\
0 \\
\end{array}$ \\
\hline 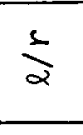 & 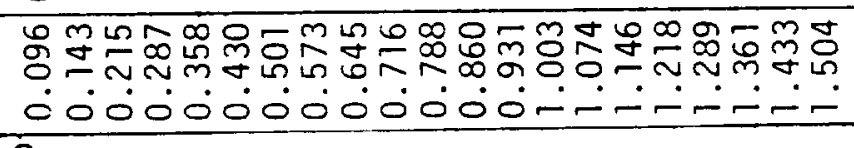 \\
\hline D & in \\
\hline
\end{tabular}



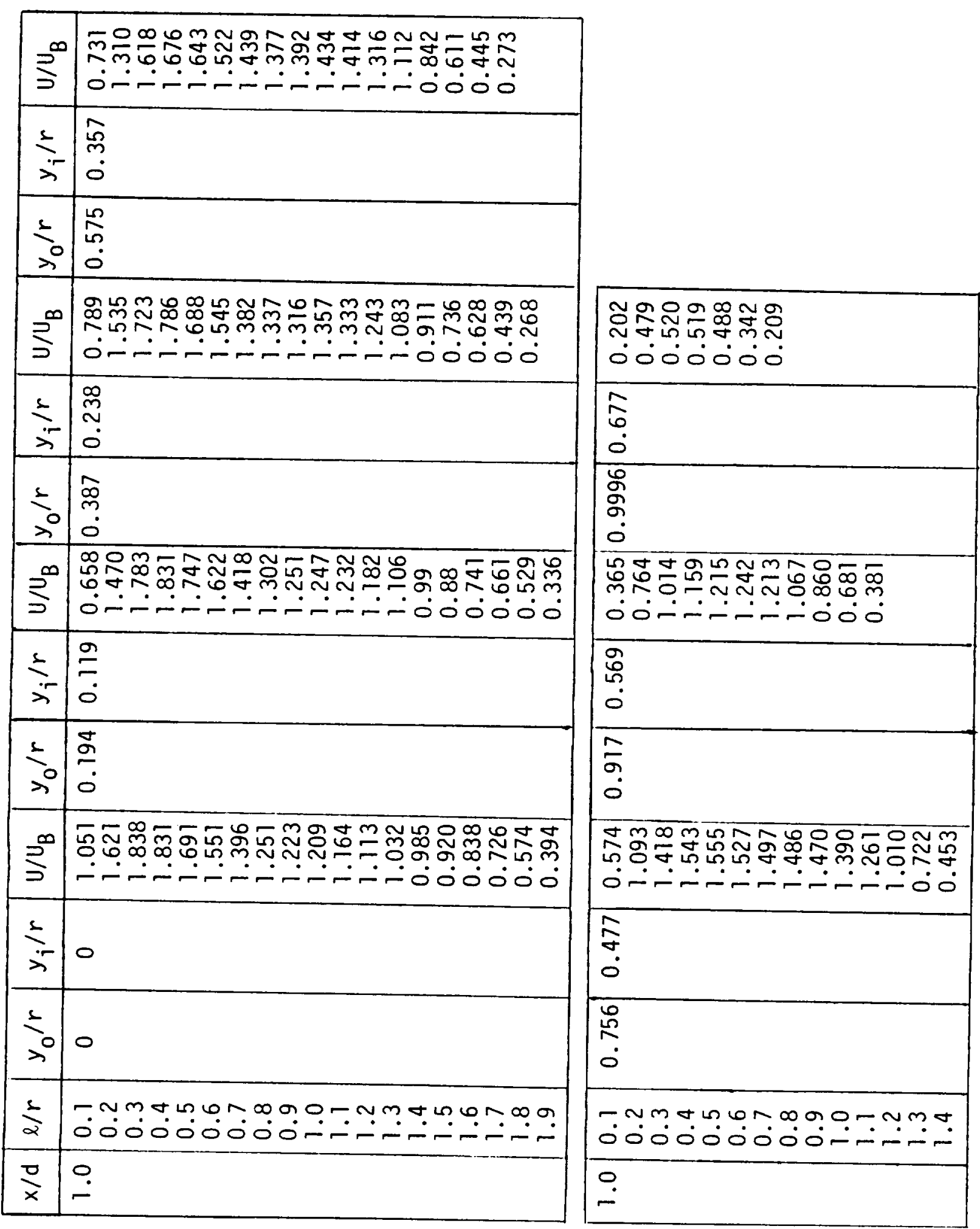


\section{Appendix 2}

\section{Tabulated Data for Reynolds Number 1093 Measurements}

All velocities normalised with the bulk velocity, $U_{B}=0.023 \mathrm{~m} / \mathrm{s}$. Symbols as defined in Figures 1 and 6.

\begin{tabular}{|c|c|c|ccc|c|}
\hline$x / d$ & $y / r$ & $z / r$ & $U / U_{B}$ & $y / r$ & $z / r$ & $U / U_{B}$ \\
\hline \multirow{6}{*}{-0.58} & 0.9 & 0 & 0.422 & 0 & -0.9 & \\
& 0.8 & & 0.878 & & -0.8 & 0.926 \\
& 0.7 & & 1.169 & -0.7 & 1.157 \\
& 0.6 & & 1.353 & -0.6 & 1.353 \\
& 0.5 & & 1.424 & -0.5 & 1.406 \\
& 0.4 & & 1.460 & -0.4 & 1.470 \\
& 0.3 & & 1.477 & -0.3 & 1.477 \\
& 0.2 & & 1.477 & -0.2 & 1.483 \\
& 0.1 & & 1.472 & -0.1 & 1.488 \\
& -0.1 & & 1.477 & 0.0 & 1.488 \\
& -0.2 & & 1.472 & 0.1 & 1.488 \\
& -0.3 & & 1.465 & 0.2 & 1.488 \\
& -0.4 & & 1.477 & 0.3 & 1.483 \\
& -0.5 & & 1.477 & 0.4 & 1.488 \\
& -0.6 & & 1.447 & 0.5 & 1.440 \\
& -0.7 & & 1.383 & 0.6 & 1.371 \\
& -0.8 & & 1.251 & 0.7 & 1.198 \\
& -0.9 & & 0.931 & 0.8 & 0.865 \\
& -1.0 & & 0.457 & 0.9 & \\
& & & & & \\
\hline 676
\end{tabular}




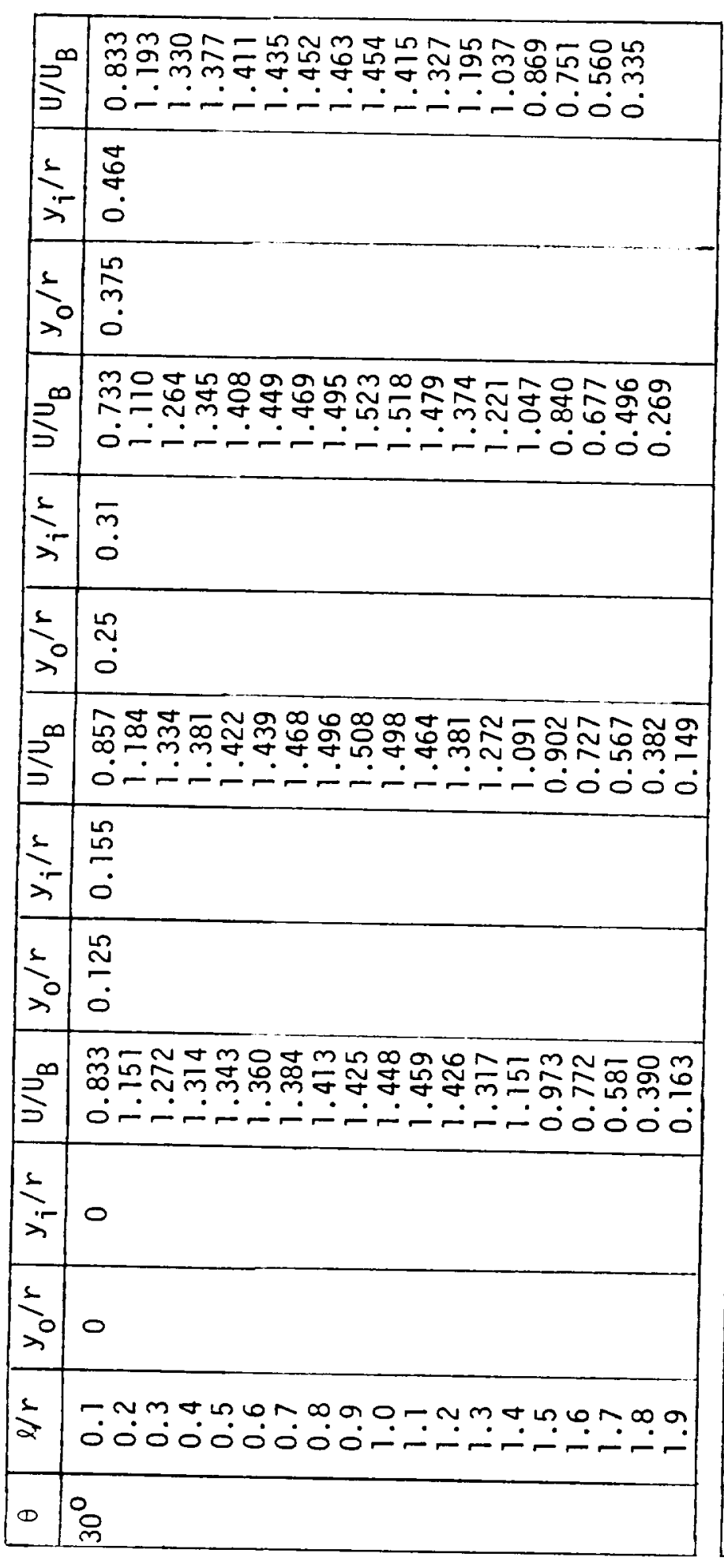

\begin{tabular}{|c|c|}
\hline & 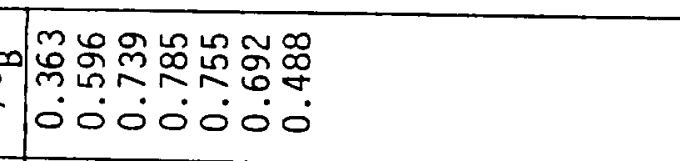 \\
\hline & $\mid$ \\
\hline & $\tilde{D}_{\substack{0 \\
0 \\
0}}^{0}$ \\
\hline & 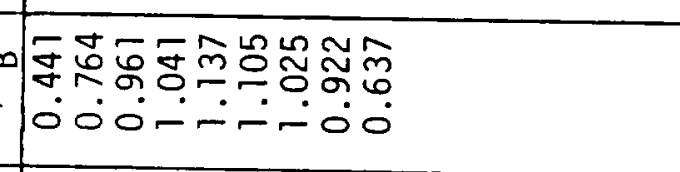 \\
\hline & E \\
\hline & $\mid \begin{array}{l}0 \\
0 \\
0 \\
0\end{array}$ \\
\hline & 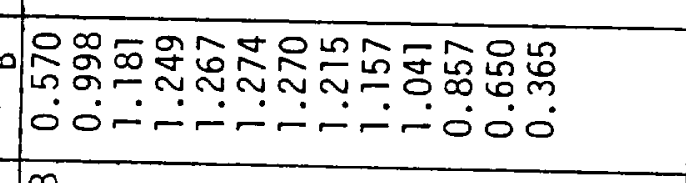 \\
\hline & $\begin{array}{l}\infty \\
\infty \\
0 \\
0 \\
\end{array}$ \\
\hline & $\begin{array}{lll}\mu \\
\frac{1}{0} \\
0 \\
0\end{array}$ \\
\hline & 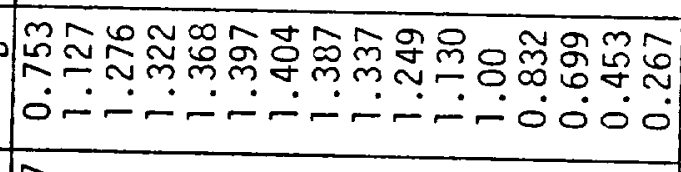 \\
\hline & $\frac{1}{0}$ \\
\hline & \\
\hline & - ஸ̣m \\
\hline & \\
\hline
\end{tabular}




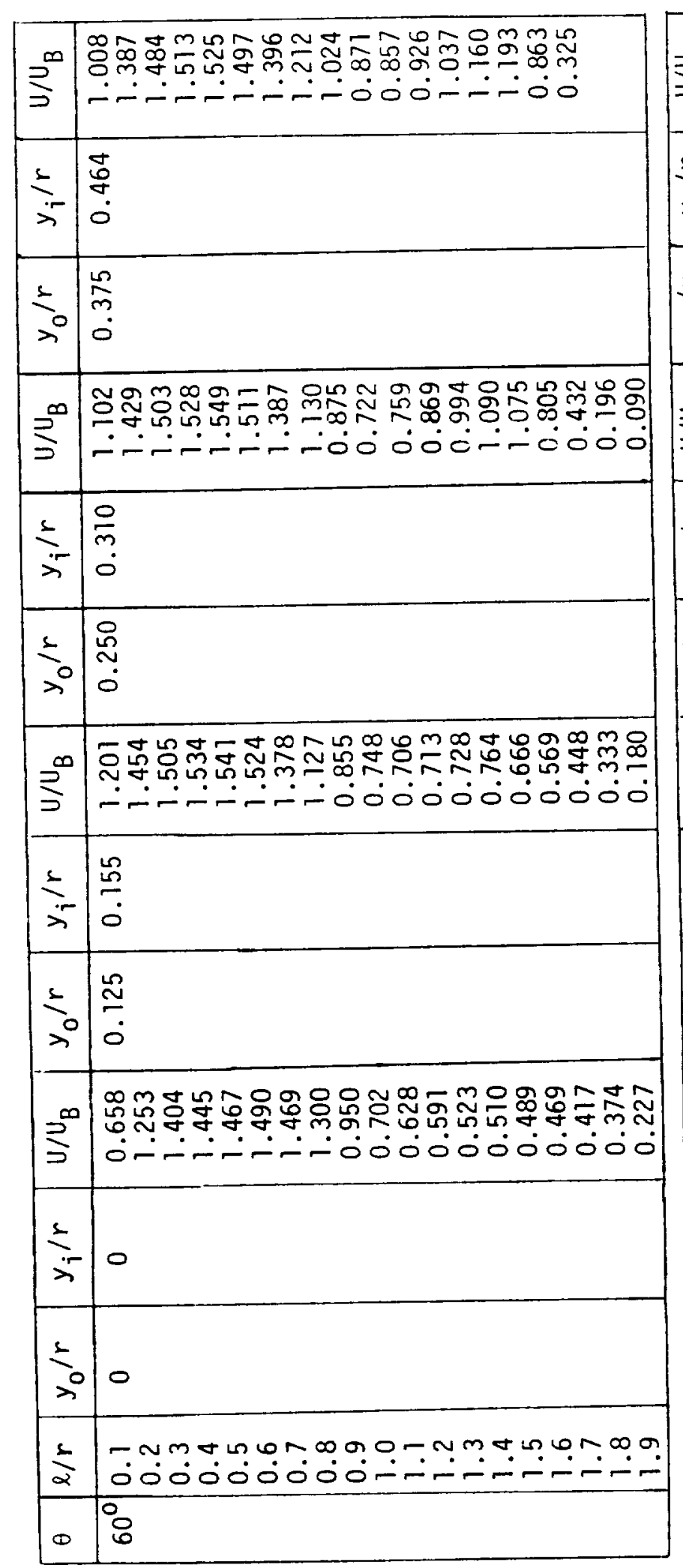

\begin{tabular}{|c|c|}
\hline$\sum^{\infty}$ & 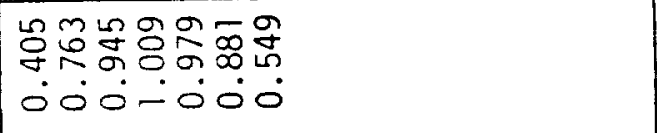 \\
\hline \pm & $\begin{array}{l}\forall \\
\mathscr{0} \\
0 \\
0\end{array}$ \\
\hline$\underbrace{}_{>}$ & $\tilde{O}$ \\
\hline$\sum^{\infty}$ & 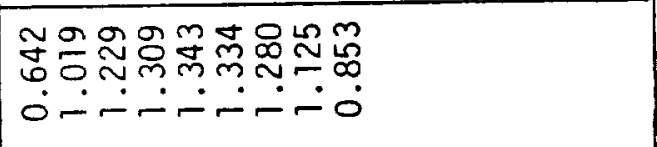 \\
\hline$\stackrel{+}{i}$ & $\overline{\bar{\sigma}}$ \\
\hline$\stackrel{-}{>0}$ & 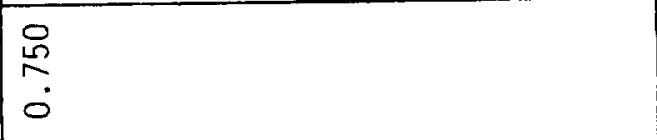 \\
\hline$\sum^{\infty}$ & 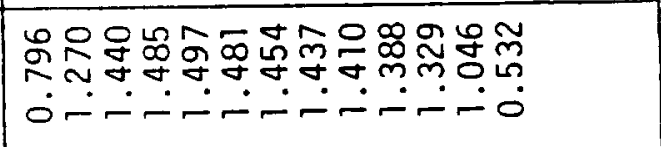 \\
\hline \pm & 孪 \\
\hline$\frac{1}{2}$ & $\begin{array}{l}\frac{n}{6} \\
\dot{0}\end{array}$ \\
\hline$\stackrel{\infty}{2}^{\infty}$ & 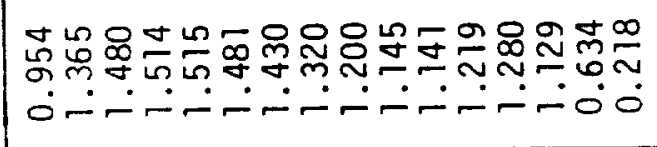 \\
\hline$\stackrel{-}{x}$ & $\frac{1}{6}$ \\
\hline$\sum_{2}^{\circ}$ & $\begin{array}{l}8 \\
8 \\
0 \\
0\end{array}$ \\
\hline$\frac{1}{2}$ & 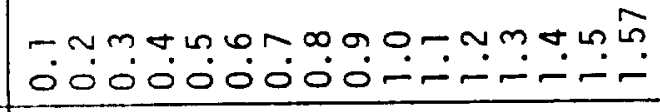 \\
\hline (1) & 8 \\
\hline
\end{tabular}




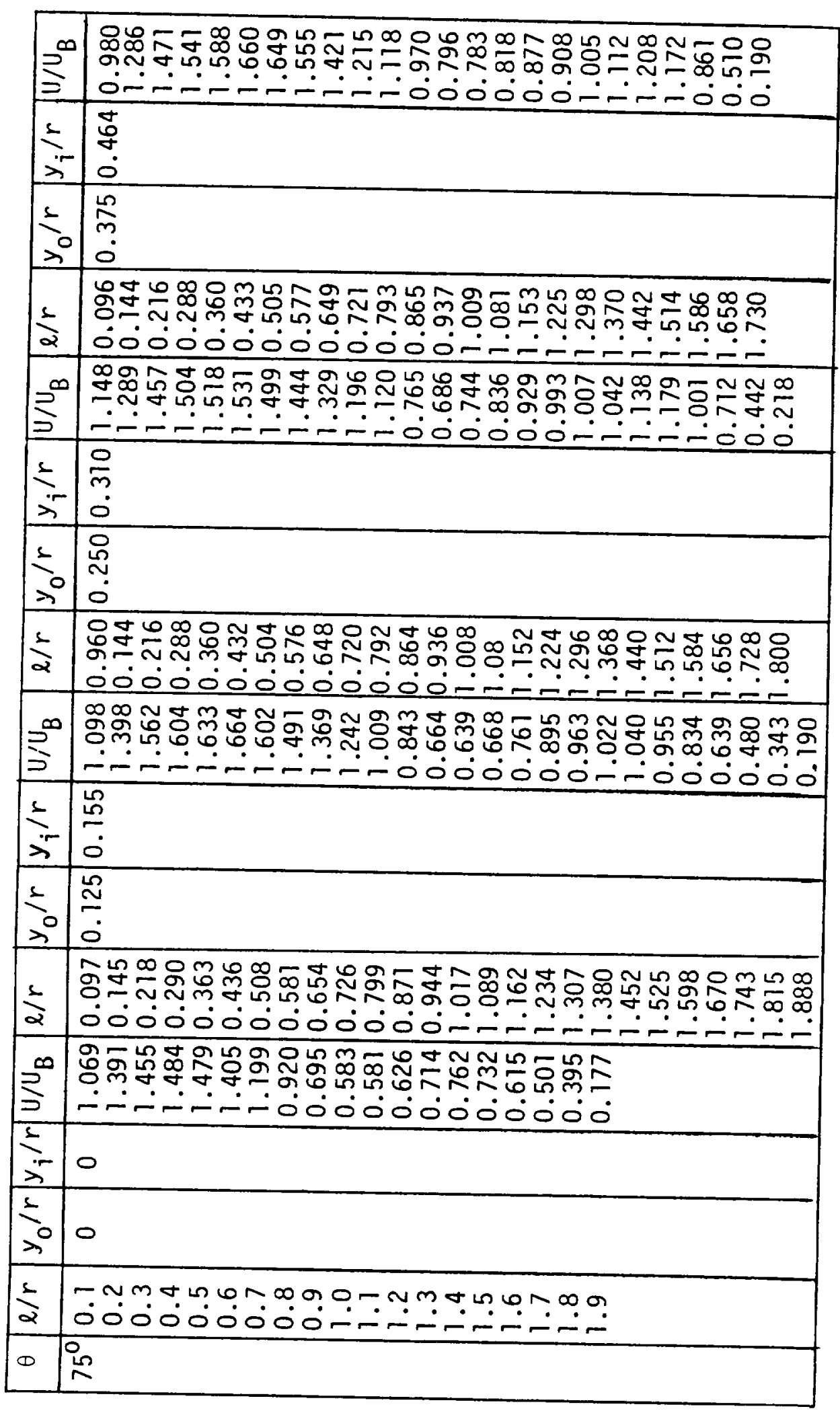




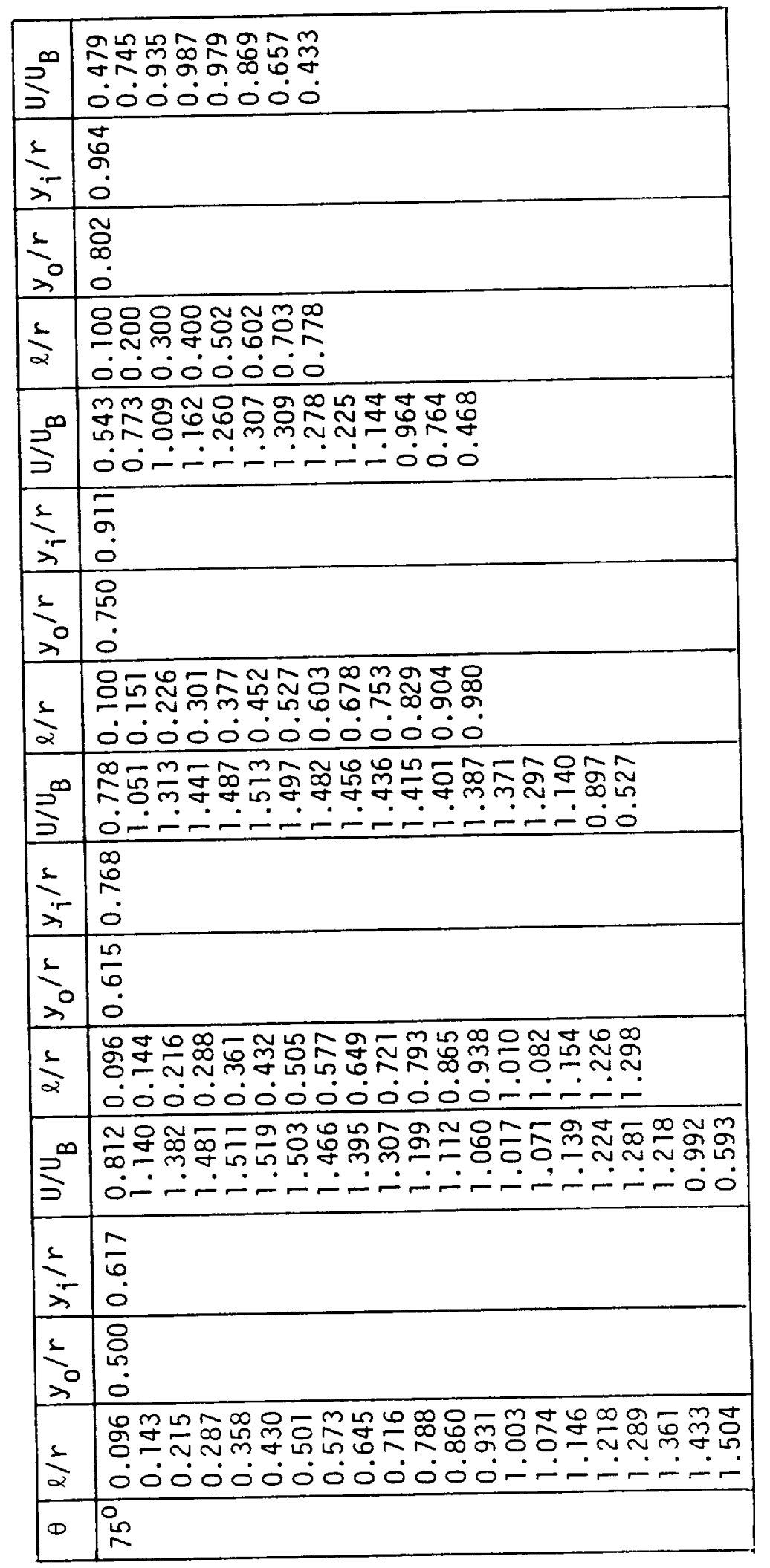




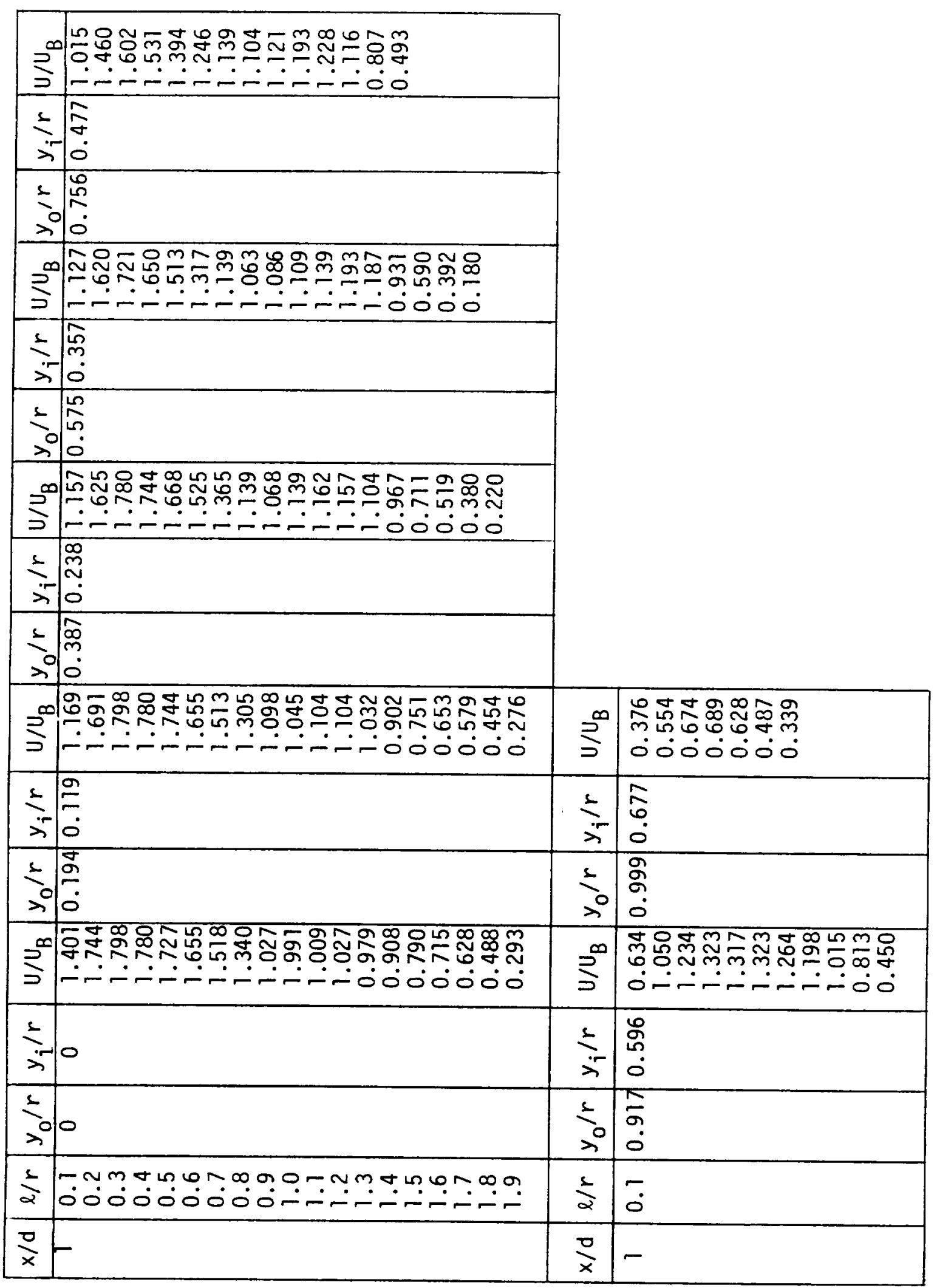




\section{Appendix 3}

Tabulated Data for Reynolds Number 43000 Measurements

All velocities normalised with the bulk velocity, $U_{B}=0.92 \mathrm{~m} / \mathrm{s}$. Symbols as defined in Figures 1 and 6.

\begin{tabular}{|c|c|c|c|c|c|c|c|c|}
\hline$x / d$ & $y / r$ & $z / r$ & $U / U_{B}$ & $\left(u^{\prime} / U_{B}\right) \times 10^{2}$ & $y / r$ & $z / r$ & $U / U_{B}$ & $\left(u^{\prime} / U_{B}\right) \times 10^{2}$ \\
\hline \multirow{3}{*}{-.58} & 0.9 & 0 & 0.985 & 7.44 & 0 & -0.9 & 0.976 & 6.74 \\
& 0.8 & & 1.105 & 3.30 & & -0.8 & 1.086 & 3.56 \\
& 0.7 & & 1.133 & 1.25 & & -0.7 & 1.125 & 1.288 \\
& 0.6 & & 1.137 & 0.93 & & -0.6 & 1.135 & 0.896 \\
& 0.5 & & 1.138 & 0.91 & & -0.5 & 1.135 & 0.798 \\
& 0.4 & & 1.137 & 0.86 & & -0.4 & 1.135 & 0.728 \\
& 0.3 & & 1.138 & 0.87 & & -0.3 & 1.138 & 0.680 \\
& 0.2 & & 1.138 & 0.82 & & -0.2 & 1.132 & 0.664 \\
& 0.1 & & 1.137 & 0.72 & & -0.1 & 1.136 & 0.634 \\
& 0.0 & & 1.139 & 0.70 & & 0.0 & 1.138 & 0.617 \\
& -0.1 & & 1.138 & 0.71 & & 0.1 & 1.136 & 0.598 \\
& -0.2 & & 1.142 & 0.69 & & 0.2 & 1.138 & 0.656 \\
& -0.3 & & 1.142 & 0.70 & & 0.3 & 1.134 & 0.709 \\
& -0.4 & & 1.142 & 0.74 & & 0.4 & 1.130 & 0.751 \\
& -0.5 & & 1.142 & 0.75 & & 0.5 & 1.136 & 0.814 \\
& -0.6 & & 1.138 & 0.94 & & 0.6 & 1.136 & 0.794 \\
& -0.7 & & 1.137 & 1.36 & & 0.7 & 1.130 & 1.085 \\
& -0.8 & & 1.111 & 3.01 & & 0.8 & 1.095 & 3.560 \\
& -0.9 & & 0.988 & 6.75 & & 0.9 & 0.953 & 8.030 \\
\hline
\end{tabular}




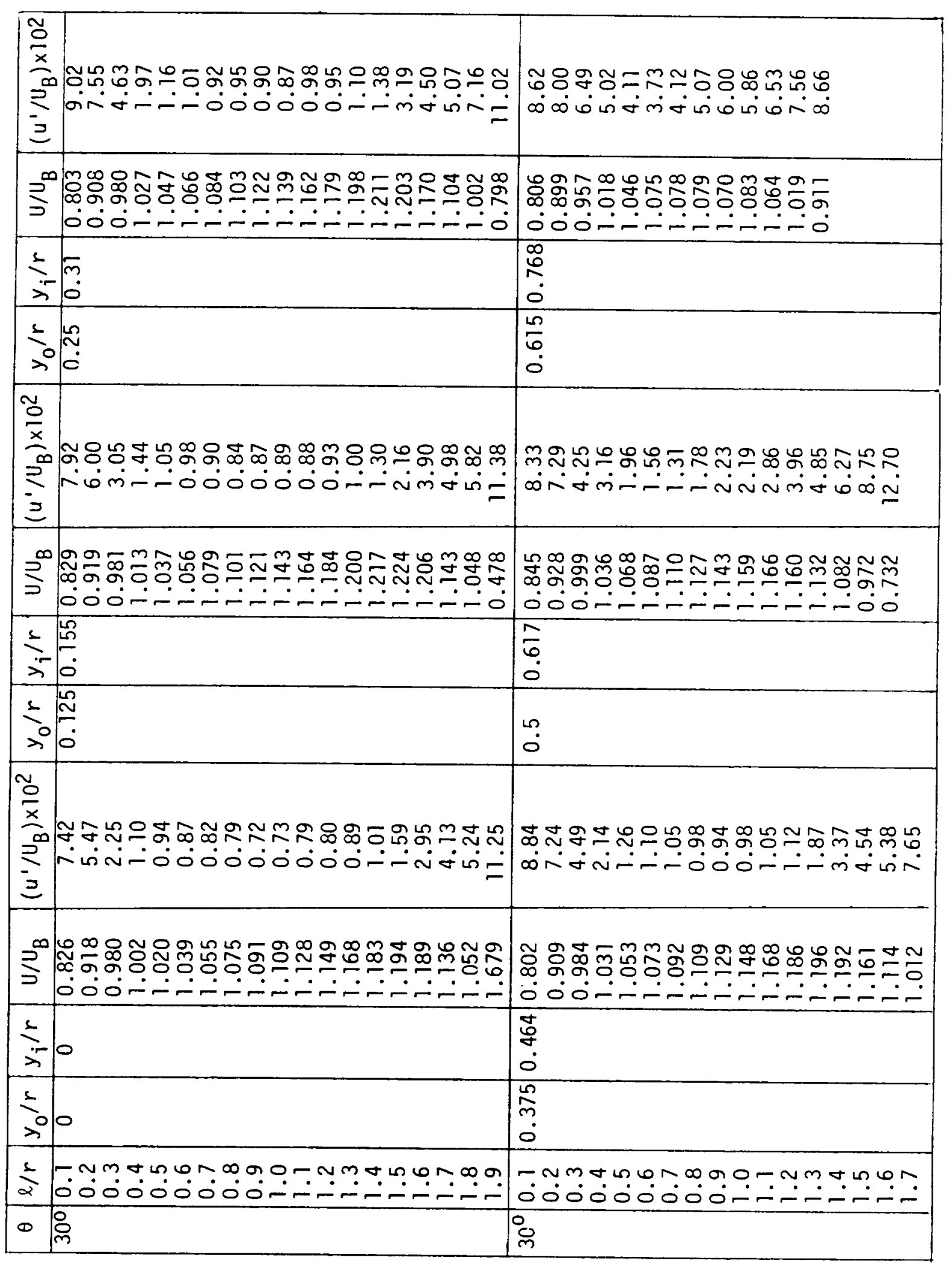




\begin{tabular}{|c|c|}
\hline $\begin{array}{l}\frac{0}{x} \\
\frac{0}{x} \\
\sum \\
\vdots \\
z\end{array}$ & 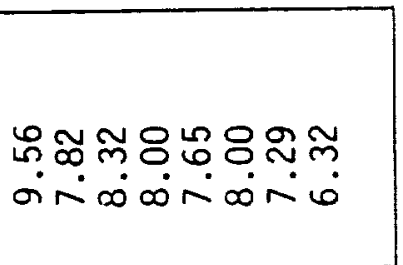 \\
\hline$\stackrel{\rho}{\Xi}^{\infty}$ & 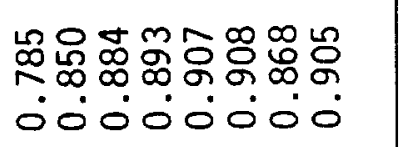 \\
\hline$\frac{1}{i}$ & $\begin{array}{l}\dot{H} \\
\mathscr{0} \\
0\end{array}$ \\
\hline 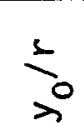 & $\begin{array}{l}\tilde{\delta} \\
\infty \\
0 \\
0\end{array}$ \\
\hline 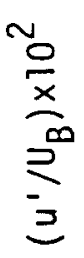 & 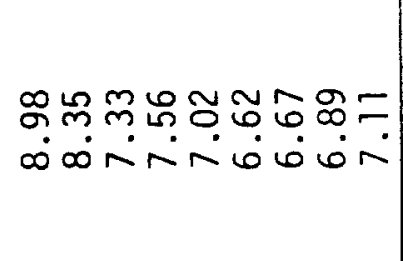 \\
\hline$\sum^{\infty}$ & 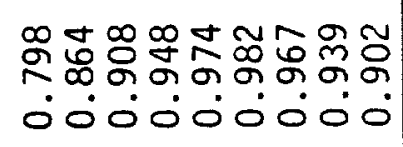 \\
\hline$\stackrel{5}{i}$ & $\bar{\sigma}$ \\
\hline 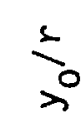 & $\frac{g}{i}$ \\
\hline$\frac{1}{2}$ & ت ب் \\
\hline$\Phi$ & O \\
\hline
\end{tabular}




\begin{tabular}{|c|c|}
\hline 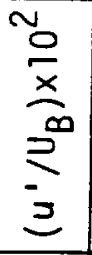 & 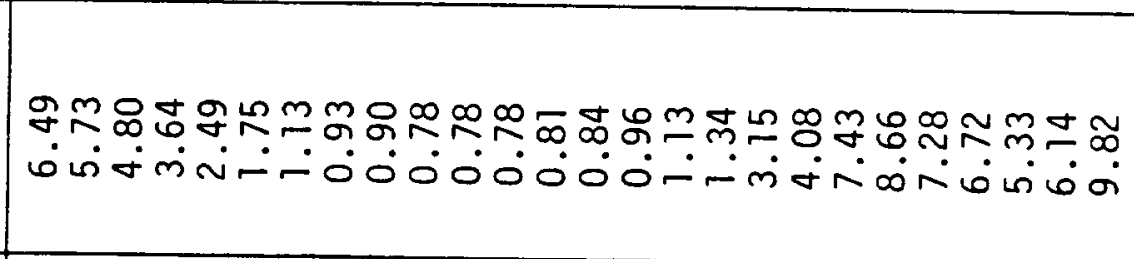 \\
\hline$\sum^{\infty}$ & 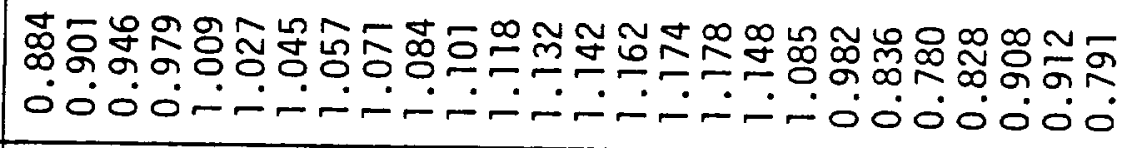 \\
\hline$\doteq$ & $\begin{array}{l}\stackrel{L}{\Omega} \\
\stackrel{2}{0} \\
0\end{array}$ \\
\hline 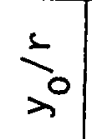 & $\stackrel{2}{\dddot{N}}$ \\
\hline$\frac{\xi}{2}$ & 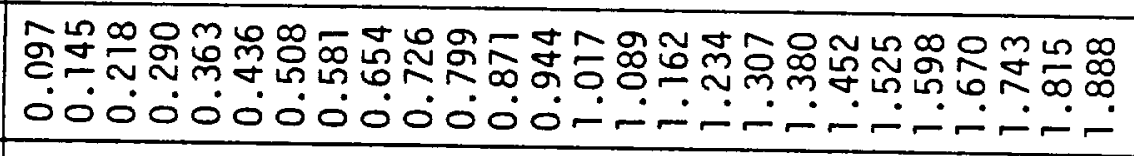 \\
\hline $\begin{array}{l}\frac{v}{0} \\
\frac{0}{x} \\
\sum^{\infty} \\
\vdots \\
\vdots\end{array}$ & 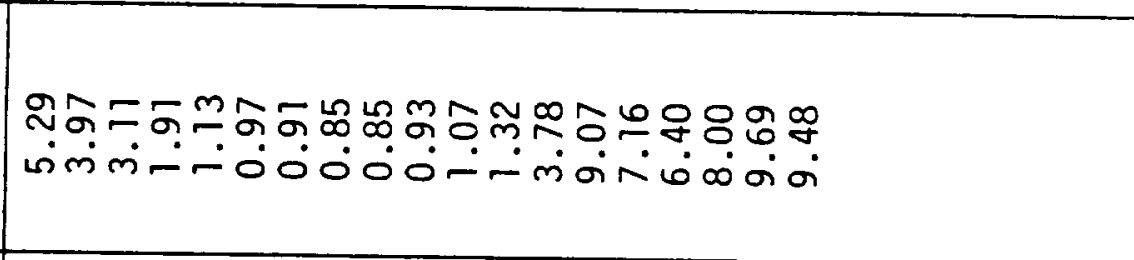 \\
\hline$\stackrel{2}{ }^{\infty}$ & 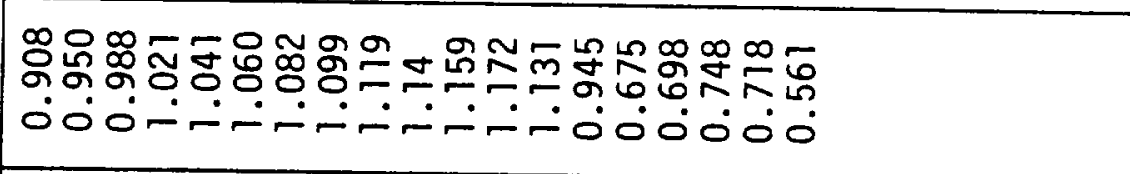 \\
\hline 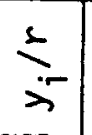 & 0 \\
\hline$\leqslant$ & 0 \\
\hline$\frac{\xi}{\alpha}$ & 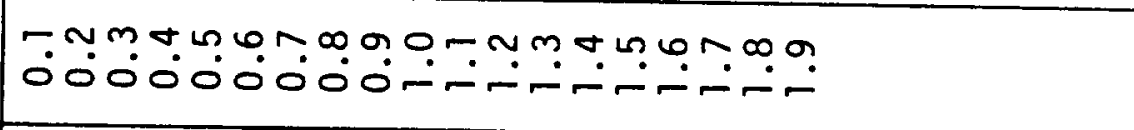 \\
\hline 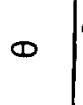 & : \\
\hline
\end{tabular}




\begin{tabular}{|c|c|}
\hline $\begin{array}{l}\underset{0}{x} \\
\underset{x}{\infty} \\
\sum \\
\sum\end{array}$ & 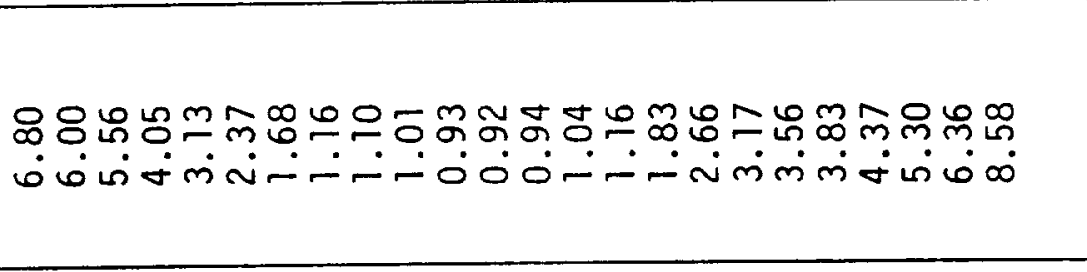 \\
\hline$\stackrel{\infty}{2}$ & 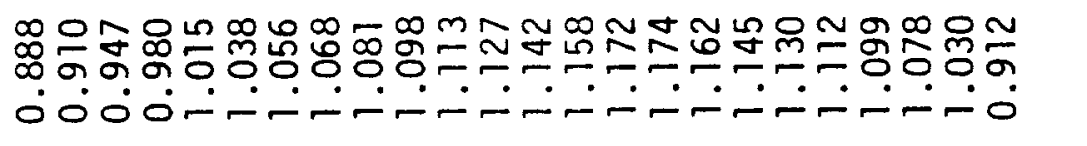 \\
\hline$\stackrel{5}{i}$ & 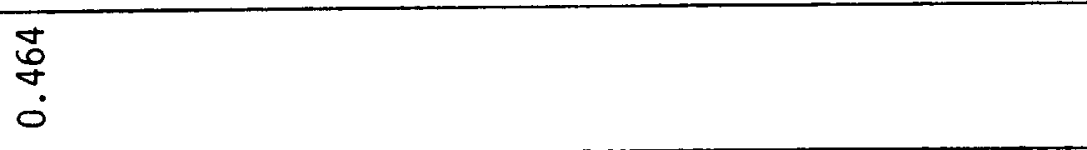 \\
\hline$\stackrel{2}{i}$ & 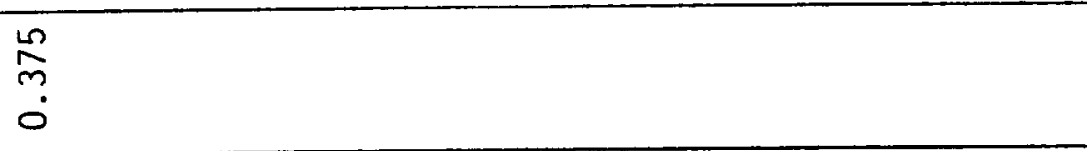 \\
\hline$\frac{1}{2}$ & 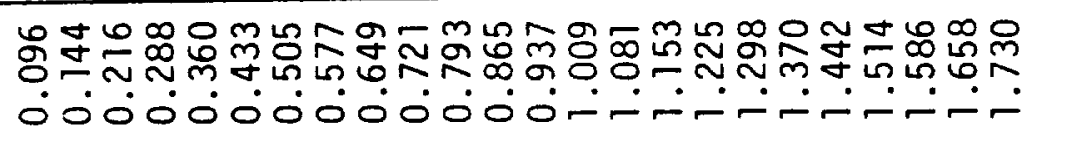 \\
\hline $\begin{array}{l}\frac{0}{x} \\
\frac{\infty}{x} \\
\sum \\
\equiv\end{array}$ & 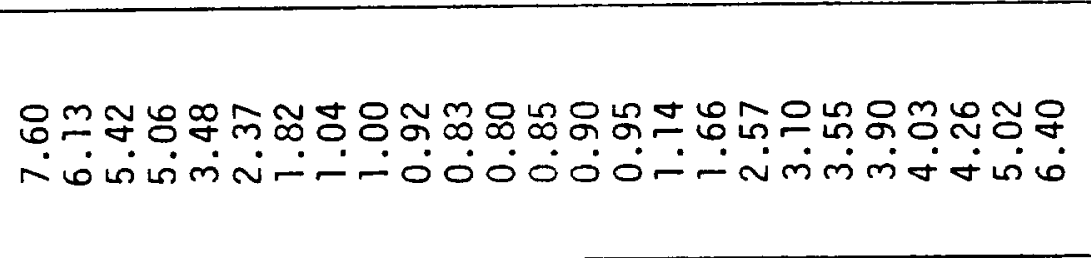 \\
\hline$\stackrel{\infty}{\risingdotseq}$ & 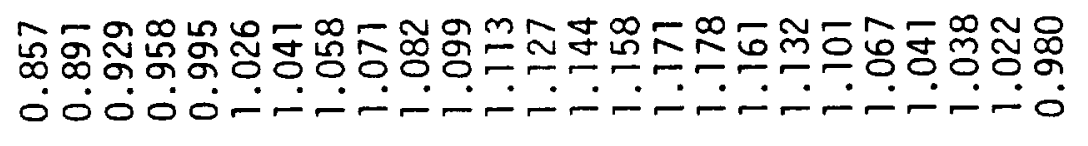 \\
\hline$\stackrel{-1}{i}$ & $\bar{m}$ \\
\hline$\stackrel{+}{i}$ & $\stackrel{n}{\dddot{0}}$ \\
\hline$\stackrel{s}{\alpha}$ & 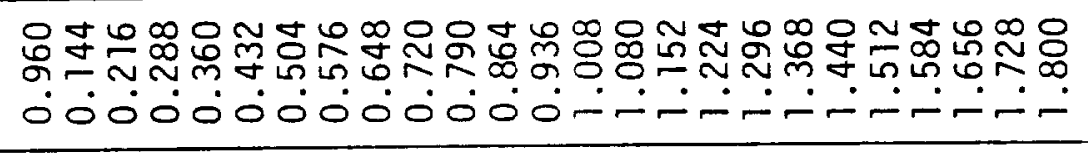 \\
\hline$\Phi$ & 8 \\
\hline
\end{tabular}




\begin{tabular}{|c|c|}
\hline 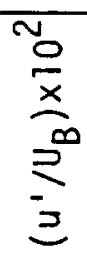 & 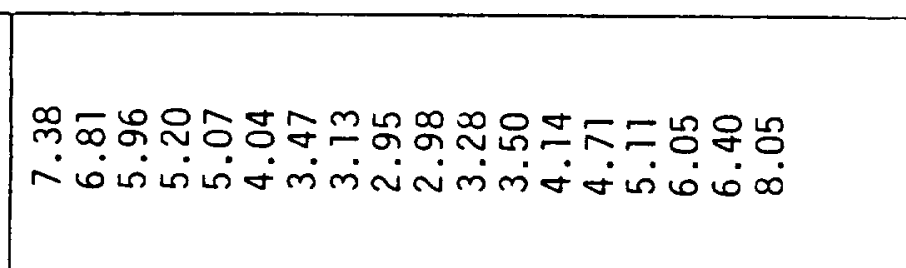 \\
\hline$\stackrel{2}{3}^{\infty}$ & 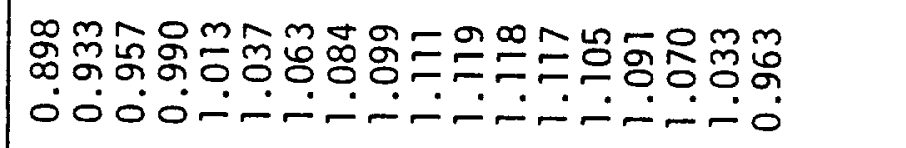 \\
\hline$\stackrel{5}{i}$ & $\begin{array}{l}\infty \\
\stackrel{\infty}{\infty} \\
\dot{0}\end{array}$ \\
\hline 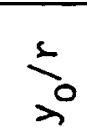 & $\begin{array}{l}\frac{n}{0} \\
0 \\
0 \\
0\end{array}$ \\
\hline$\frac{1}{\alpha}$ & 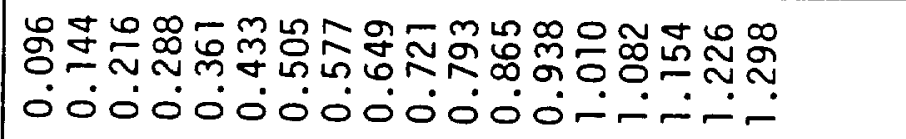 \\
\hline 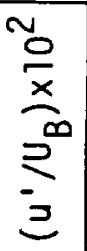 & 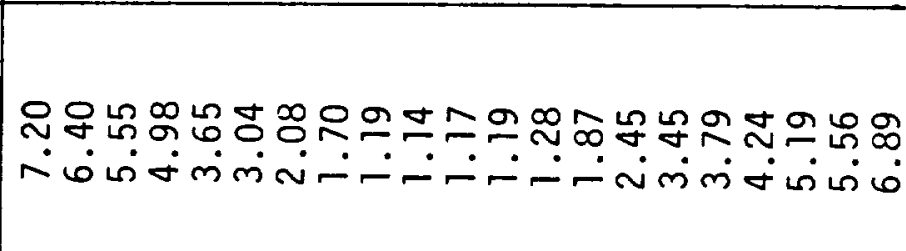 \\
\hline$\sum^{\infty}$ & 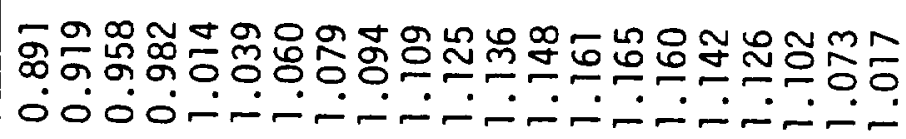 \\
\hline$\stackrel{\leftarrow}{\doteqdot}$ & $\begin{array}{l}\tilde{\sigma} \\
\dot{\sigma} \\
0\end{array}$ \\
\hline \pm 0 & $\begin{array}{l}\stackrel{\circ}{\circ} \\
\stackrel{0}{0}\end{array}$ \\
\hline$\frac{\xi}{\alpha}$ & 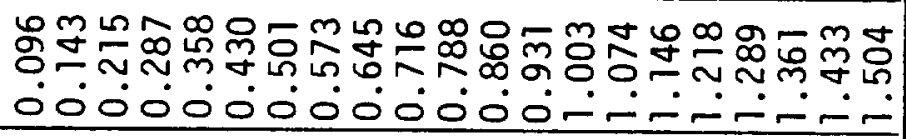 \\
\hline$\odot$ & 8 \\
\hline
\end{tabular}




\begin{tabular}{|c|c|}
\hline 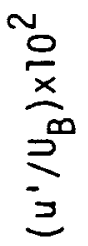 & 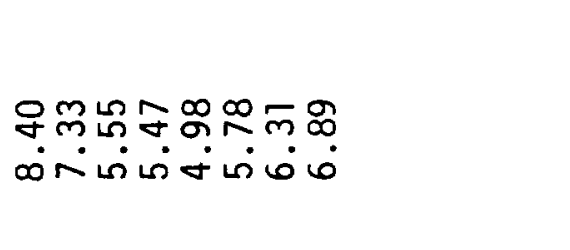 \\
\hline$\sum^{\infty}$ & 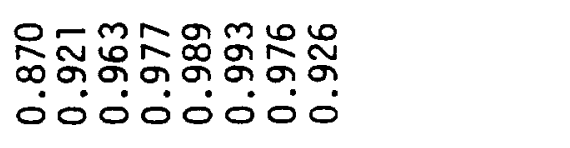 \\
\hline 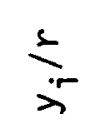 & $\begin{array}{l}\dot{H} \\
\text { ğ } \\
\dot{0}\end{array}$ \\
\hline$\leqslant$ & $\begin{array}{c}\widetilde{o} \\
\check{\infty} \\
\vdots\end{array}$ \\
\hline$\frac{1}{\alpha}$ & 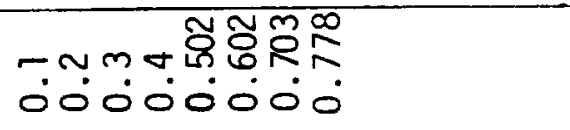 \\
\hline 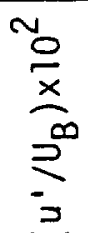 & 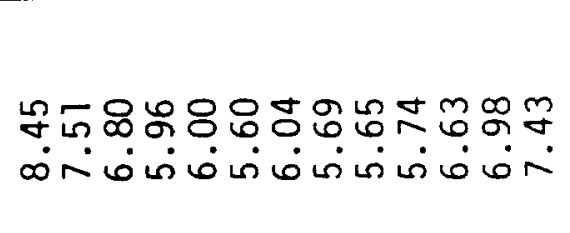 \\
\hline$\sum^{\infty}$ & 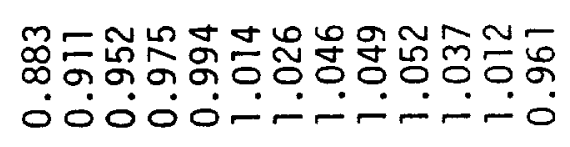 \\
\hline$\stackrel{5}{i}$ & $\bar{\sigma}$ \\
\hline$\neq$ & $\stackrel{\stackrel{n}{R}}{\dot{0}}$ \\
\hline$\frac{5}{2}$ & 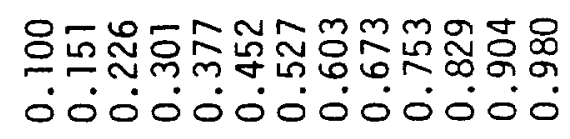 \\
\hline$\Phi$ & $\stackrel{8}{8}$ \\
\hline
\end{tabular}




\begin{tabular}{|c|c|}
\hline $\begin{array}{l}\mathfrak{O}_{0} \\
\frac{x}{\infty} \\
\sum^{\infty} \\
\Xi\end{array}$ & 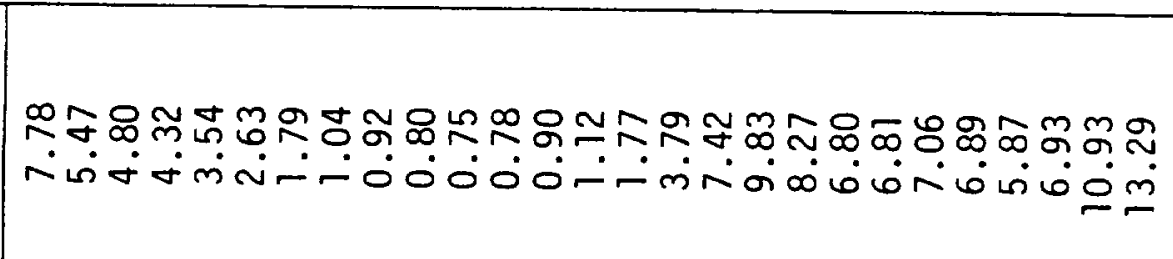 \\
\hline$\sum^{\infty}$ & 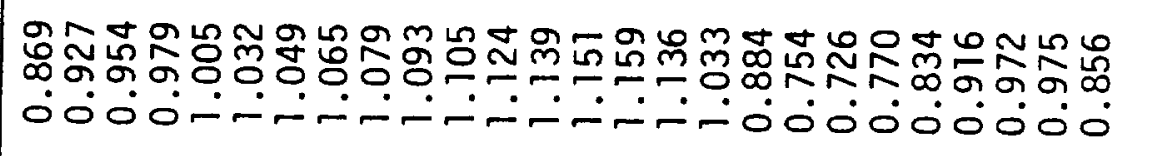 \\
\hline 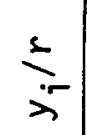 & $\stackrel{\stackrel{\leftrightarrow}{\circ}}{\dot{0}}$ \\
\hline$\approx$ & $\stackrel{\stackrel{\sim}{\cong}}{\dot{0}}$ \\
\hline$\frac{1}{\alpha}$ & 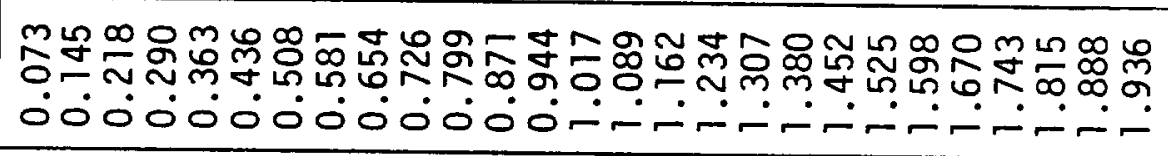 \\
\hline $\begin{array}{l}\frac{0}{0} \\
\frac{x}{\infty} \\
\sum^{\infty} \\
\vdots \\
\Sigma\end{array}$ & 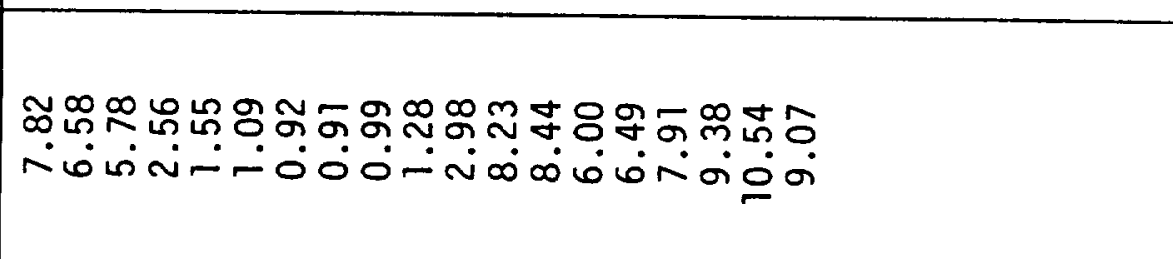 \\
\hline$\stackrel{2}{\infty}^{\infty}$ & 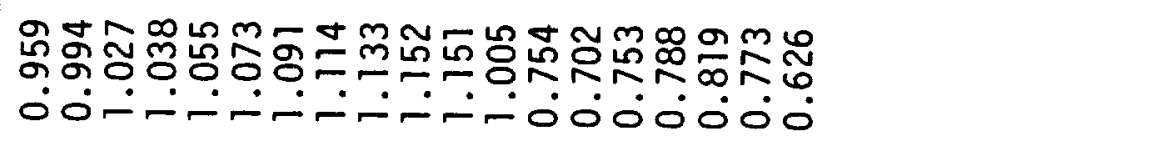 \\
\hline 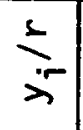 & 0 \\
\hline$\neq 0$ & 0 \\
\hline$\frac{\partial}{\alpha}$ & 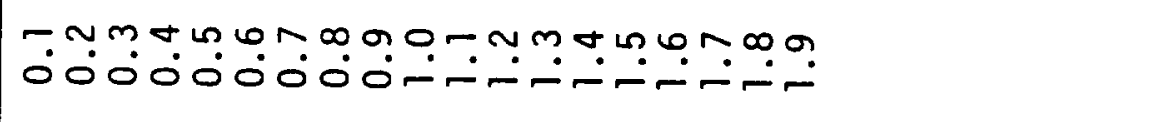 \\
\hline 0 & 许 \\
\hline
\end{tabular}




\begin{tabular}{|c|c|}
\hline $\begin{array}{l}\frac{N}{\infty} \\
\frac{x}{\infty} \\
\sum \\
\sum\end{array}$ & 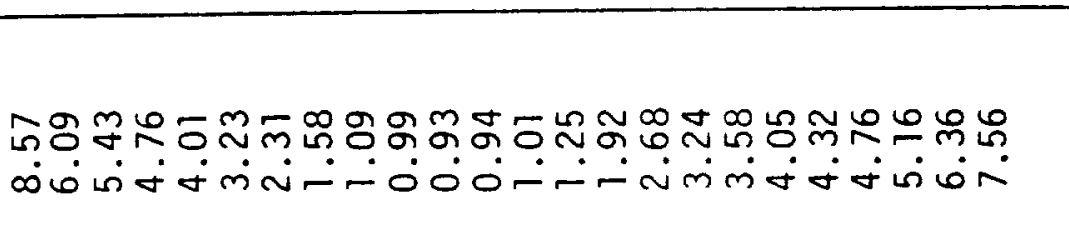 \\
\hline$\sum^{\infty}$ & 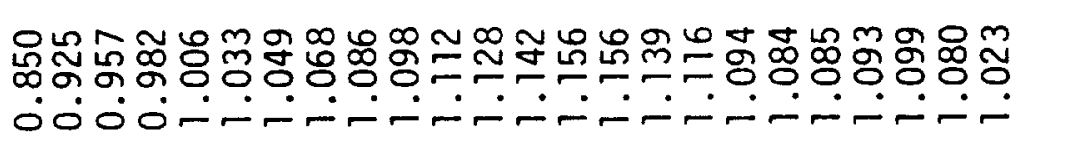 \\
\hline$\stackrel{+}{i}$ & $\begin{array}{l}\dot{J} \\
\dot{\sigma} \\
\dot{0}\end{array}$ \\
\hline 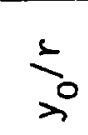 & $\stackrel{\substack{n \\
\hdashline}}{0}$ \\
\hline$\frac{1}{2}$ & 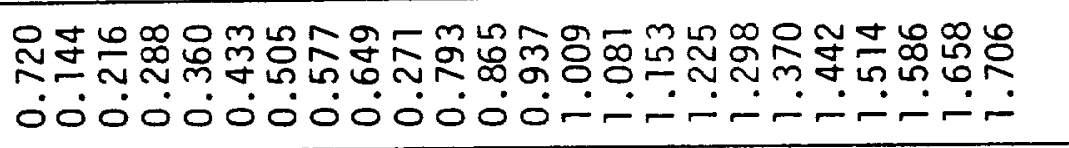 \\
\hline$\frac{\substack{0 \\
x}}{\underbrace{\infty}_{0}}$ & 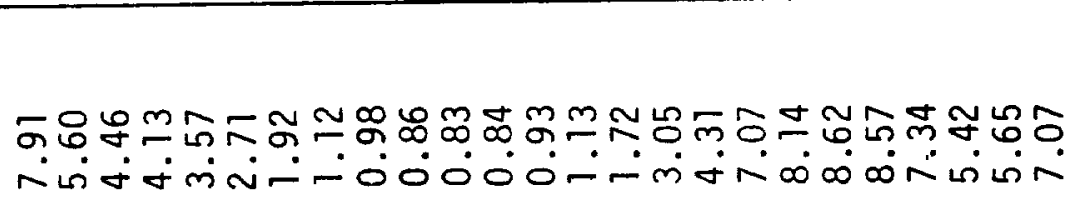 \\
\hline$\stackrel{2}{\infty}^{\infty}$ & 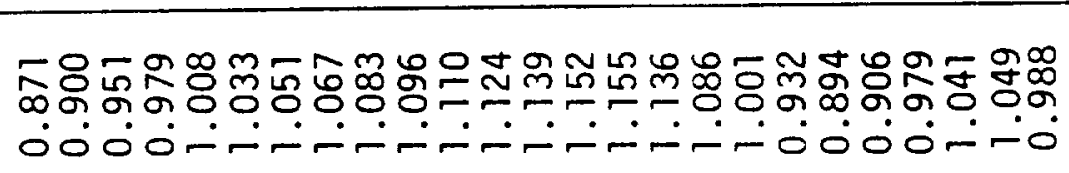 \\
\hline$\stackrel{5}{i}$ & $\bar{j}$ \\
\hline$\leqslant$ & $\stackrel{2}{\stackrel{2}{0}}$ \\
\hline$\frac{\delta}{\alpha}$ & 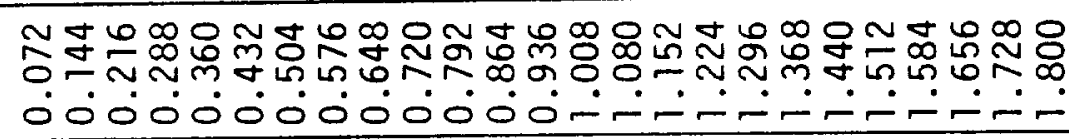 \\
\hline 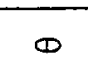 & in \\
\hline
\end{tabular}




\begin{tabular}{|c|c|}
\hline 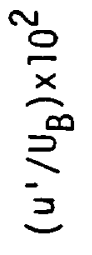 & 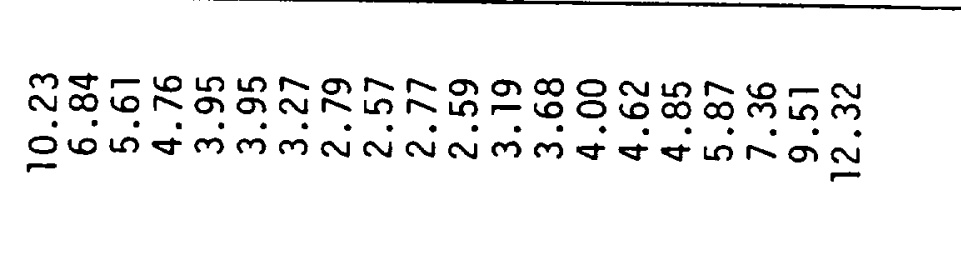 \\
\hline$\stackrel{2}{I}^{\infty}$ & 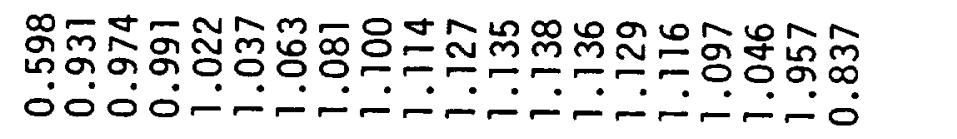 \\
\hline 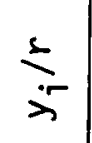 & $\begin{array}{l}\infty \\
\stackrel{\infty}{\circ} \\
\dot{0}\end{array}$ \\
\hline$\neq$ & 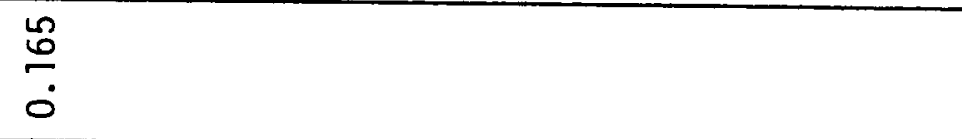 \\
\hline$\frac{1}{\alpha}$ & 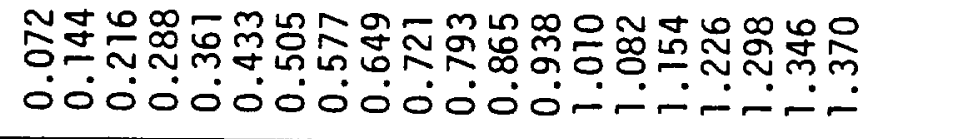 \\
\hline 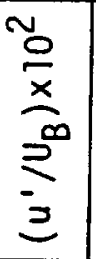 & 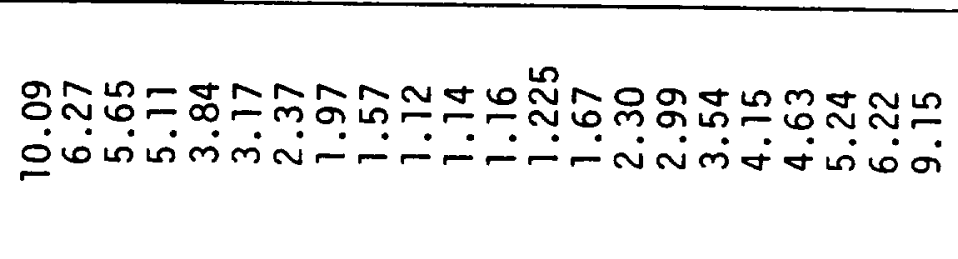 \\
\hline$\sum^{\infty}$ & 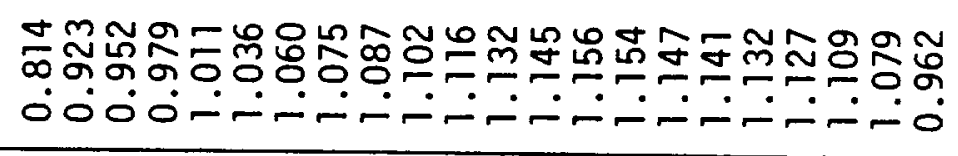 \\
\hline 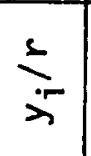 & $\frac{1}{6}$ \\
\hline$\neq 0$ & مّ \\
\hline$\frac{5}{\alpha}$ & 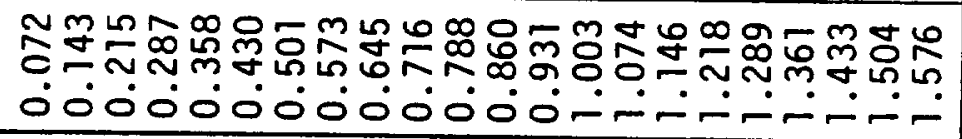 \\
\hline$\infty$ & in \\
\hline
\end{tabular}




\begin{tabular}{|c|c|}
\hline 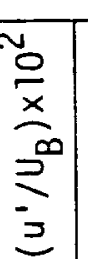 & 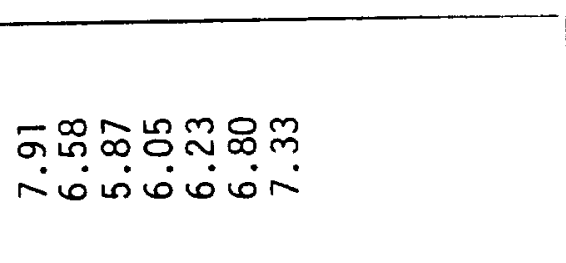 \\
\hline$\stackrel{2}{S}^{\infty}$ & 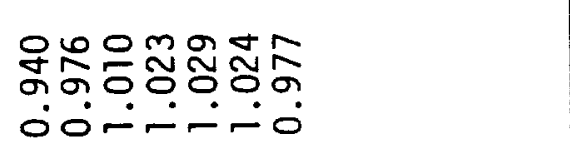 \\
\hline$\stackrel{5}{i}$ & 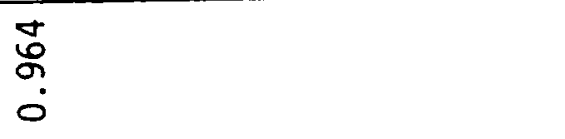 \\
\hline 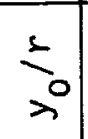 & 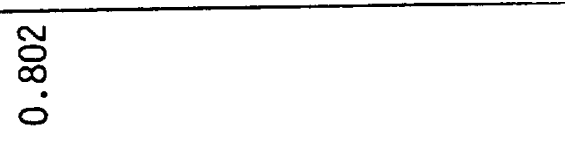 \\
\hline$\frac{5}{2}$ & 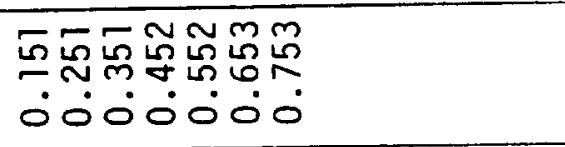 \\
\hline $\begin{array}{l}\frac{0}{0} \\
x \\
\sum^{\infty} \\
\vdots \\
\vdots\end{array}$ & 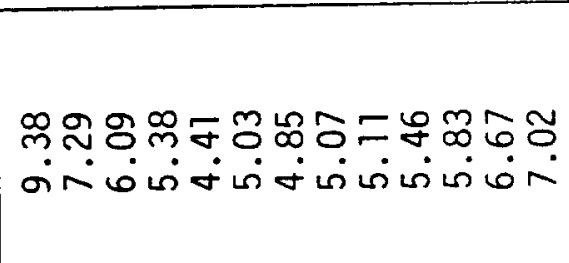 \\
\hline$\gtrless^{\infty}$ & 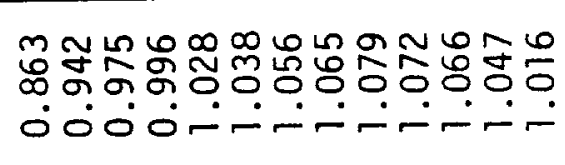 \\
\hline$\stackrel{+}{i}$ & Б̄ \\
\hline \pm & $\stackrel{n}{\circ}$ \\
\hline$\leqslant$ & 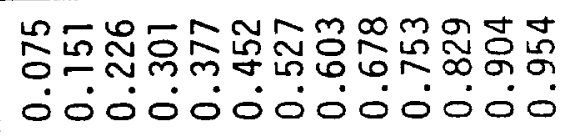 \\
\hline 0 & in \\
\hline
\end{tabular}




\begin{tabular}{|c|c|}
\hline $\begin{array}{l}\frac{N}{0} \\
\frac{0}{x} \\
\sum \\
\sum \\
\sum\end{array}$ & 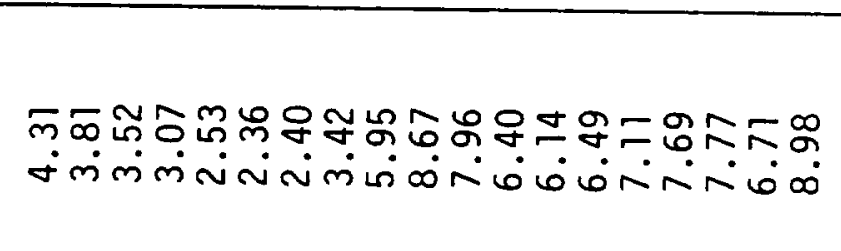 \\
\hline$\sum^{\infty}$ & 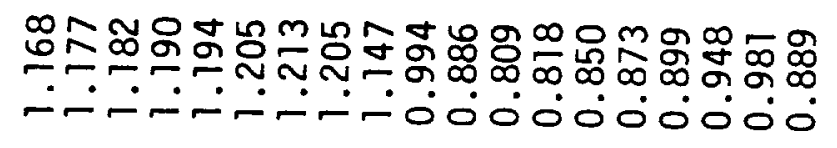 \\
\hline$\stackrel{-}{i}$ & $\frac{\sigma}{\check{E}}$ \\
\hline$\leqslant$ & 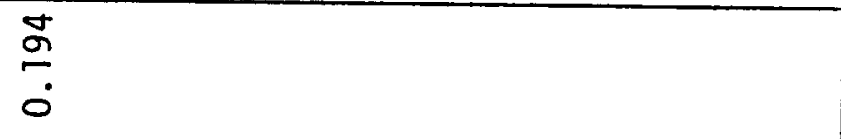 \\
\hline $\begin{array}{l}\frac{\tilde{0}}{x} \\
\frac{x}{\infty} \\
\sum^{\infty} \\
j\end{array}$ & 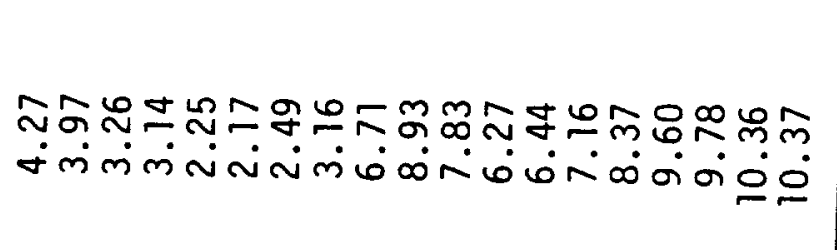 \\
\hline$\sum^{\infty}$ & 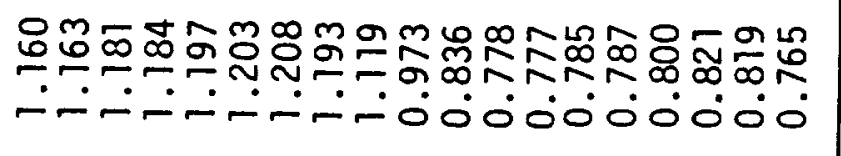 \\
\hline 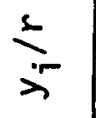 & 0 \\
\hline$\leqslant$ & 0 \\
\hline$\frac{\xi}{\alpha}$ & 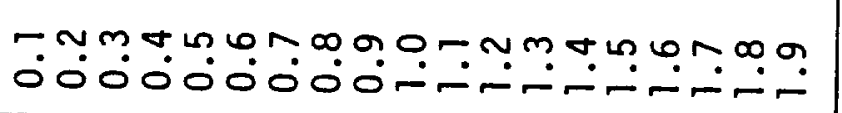 \\
\hline$\frac{\bar{x}}{x}$ & $\stackrel{\circ}{\circ}$ \\
\hline
\end{tabular}




\begin{tabular}{|c|c|}
\hline $\begin{array}{c}\underset{0}{0} \\
\frac{x}{\infty} \\
\sum^{\infty} \\
\vdots\end{array}$ & 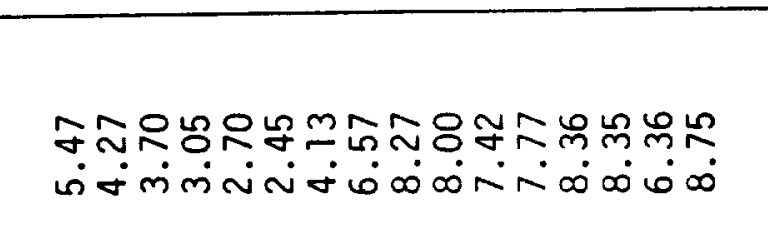 \\
\hline$\stackrel{\infty}{3}$ & 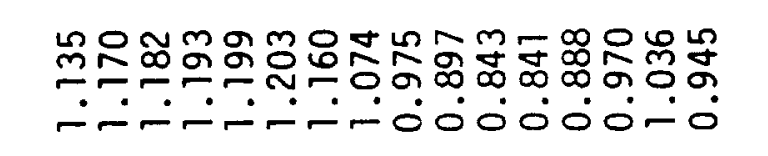 \\
\hline 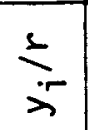 & 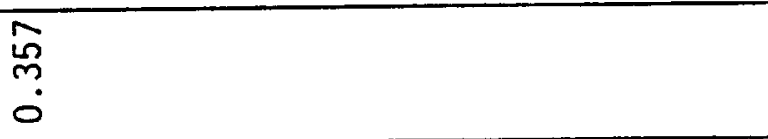 \\
\hline 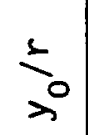 & 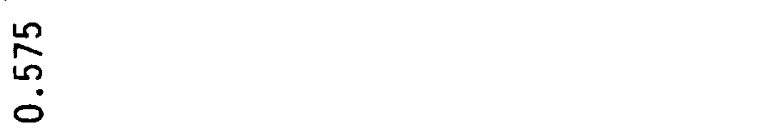 \\
\hline $\begin{array}{l}\frac{n}{0} \\
\frac{0}{x} \\
\sum \\
\sum \\
\sum\end{array}$ & 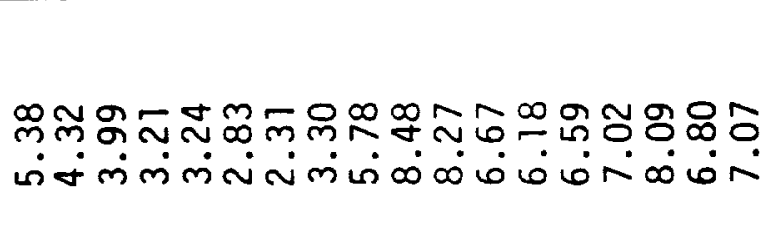 \\
\hline$\sum^{\infty}$ & 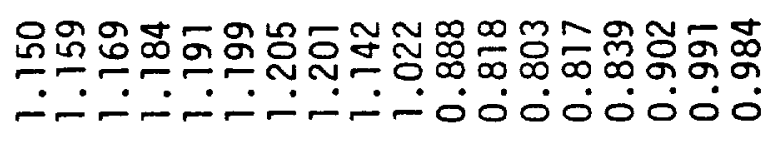 \\
\hline 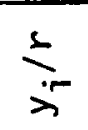 & $\begin{array}{l}\infty \\
\tilde{m} \\
\vdots \\
0\end{array}$ \\
\hline$\leqslant$ & $\begin{array}{c}\hat{\infty} \\
\stackrel{p}{0} \\
0\end{array}$ \\
\hline$\frac{5}{\alpha}$ & ப்றல் \\
\hline$\frac{\Gamma}{x}$ & $\stackrel{\circ}{-}$ \\
\hline
\end{tabular}




\begin{tabular}{|c|c|}
\hline 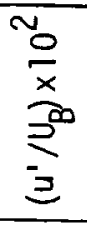 & 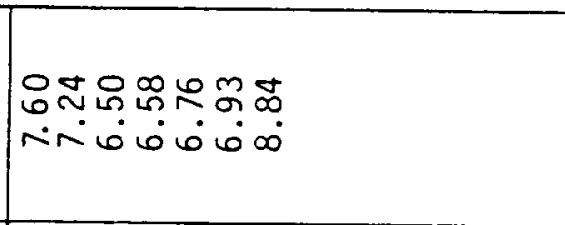 \\
\hline$\stackrel{2}{ }^{\infty}$ & 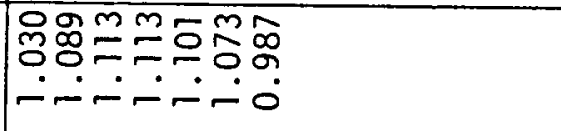 \\
\hline 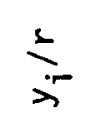 & 会 \\
\hline$\leqslant$ & $\begin{array}{l}0 \\
\circ \\
o \\
0 \\
\end{array}$ \\
\hline $\begin{array}{l}\frac{0}{0} \\
\frac{0}{x} \\
\sum^{\infty} \\
z\end{array}$ & 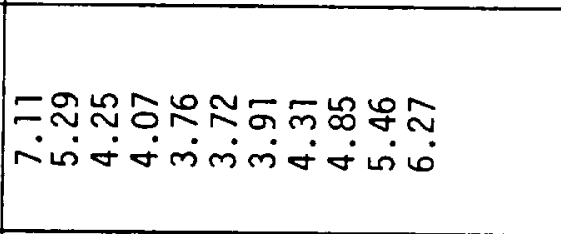 \\
\hline$\sum^{\infty}$ & 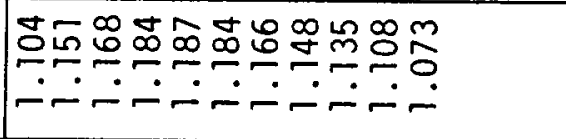 \\
\hline 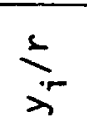 & $\begin{array}{l}\mathscr{S}_{0}^{\circ} \\
\text { in. } \\
0 \\
0\end{array}$ \\
\hline \pm & $\frac{1}{\sigma}$ \\
\hline 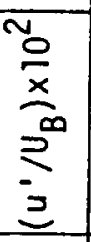 & 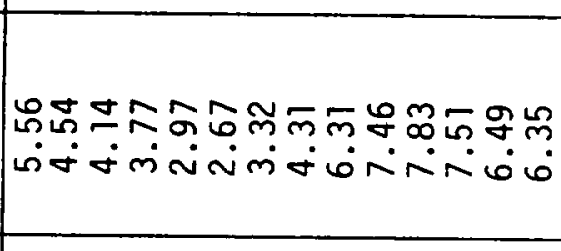 \\
\hline$\sum^{\infty}$ & 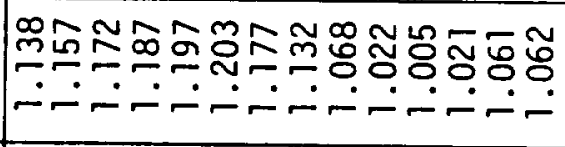 \\
\hline 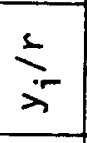 & $\stackrel{\hat{\sigma}}{\sigma}$ \\
\hline$\leqslant$ & 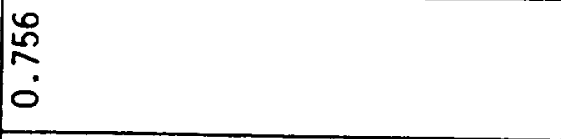 \\
\hline$\$$ & - Nmono: \\
\hline$\frac{\pi}{x}$ & $\ddot{0}$ \\
\hline
\end{tabular}




\begin{tabular}{|c|c|}
\hline 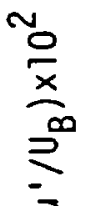 & 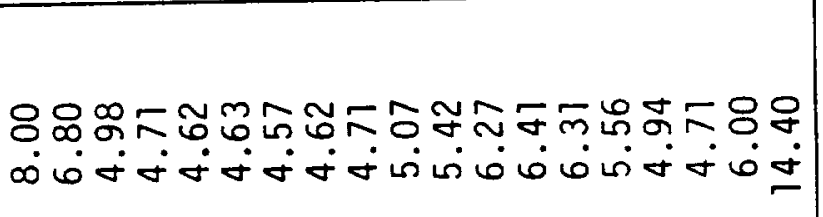 \\
\hline$\sum^{\infty}$ & 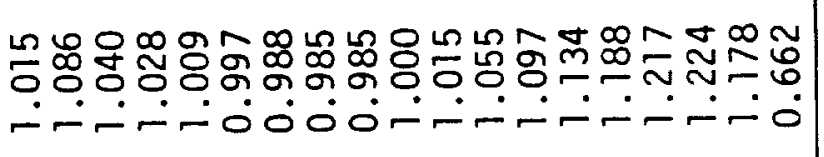 \\
\hline$\stackrel{5}{i}$ & $\frac{\sigma}{\sigma}$ \\
\hline$\leqslant$ & $\begin{array}{l}\dot{g} \\
\stackrel{0}{0}\end{array}$ \\
\hline 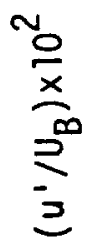 & 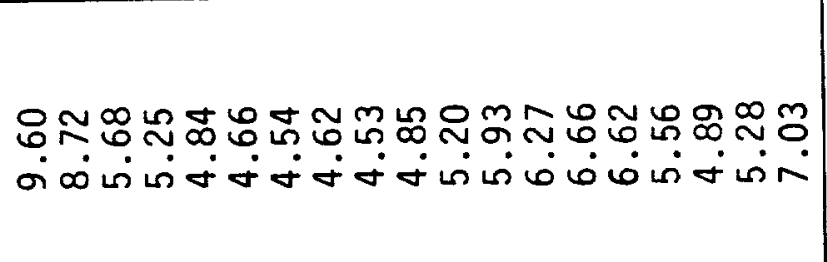 \\
\hline$\sum^{\infty}$ & 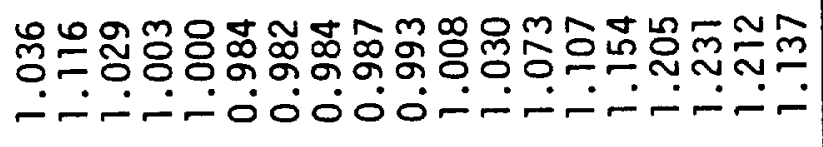 \\
\hline 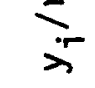 & 0 \\
\hline$>$ & 0 \\
\hline$\frac{1}{2}$ & 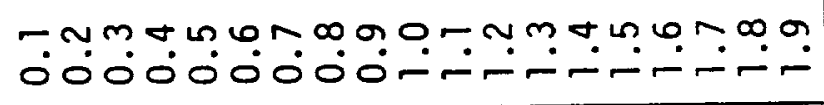 \\
\hline$\frac{\partial}{x}$ & $\stackrel{\circ}{\circ}$ \\
\hline
\end{tabular}




\begin{tabular}{|c|c|}
\hline 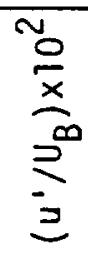 & 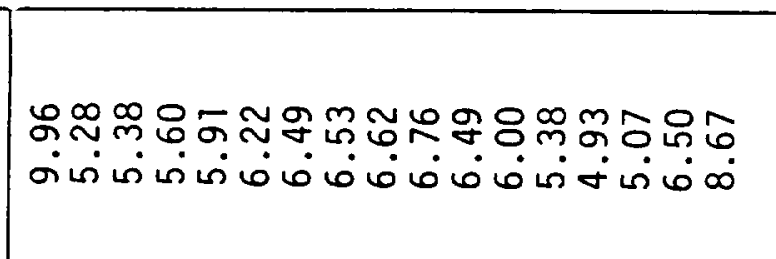 \\
\hline$\sum^{\infty}$ & 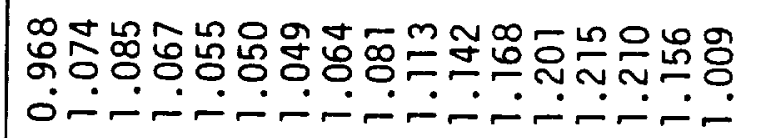 \\
\hline$\stackrel{5}{\grave{i}}$ & 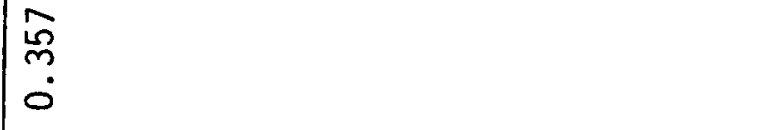 \\
\hline$\neq 0$ & $\mid \begin{array}{ll}n \\
2 \\
i \\
0 \\
0\end{array}$ \\
\hline 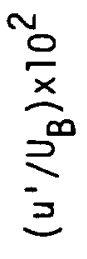 & 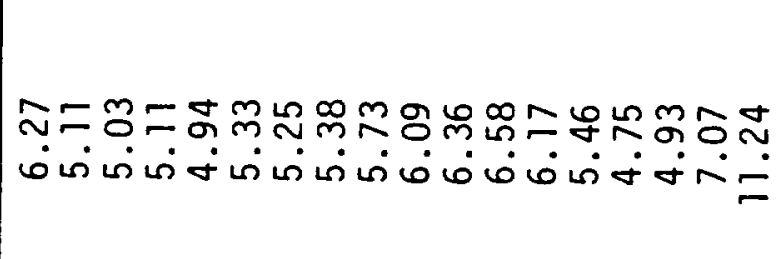 \\
\hline$\stackrel{\Omega}{\Omega}^{\infty}$ & 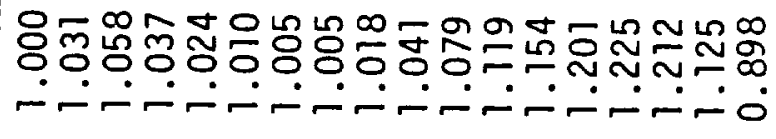 \\
\hline 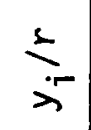 & 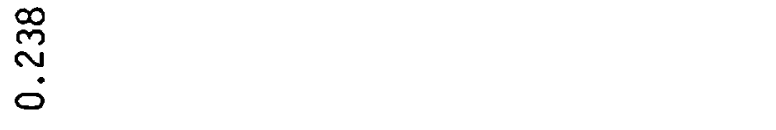 \\
\hline$\neq 0$ & $\begin{array}{l}\text { D্ } \\
\stackrel{0}{0}\end{array}$ \\
\hline$\frac{\xi}{2}$ & 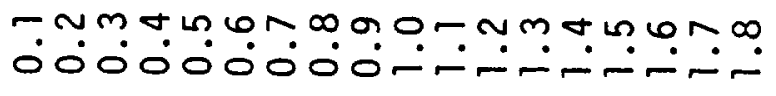 \\
\hline$\frac{0}{x}$ & $\stackrel{0}{0}$ \\
\hline
\end{tabular}




\begin{tabular}{|c|c|}
\hline $\begin{array}{l}\sim \\
0 \\
\frac{x}{2} \\
2 \\
\sum\end{array}$ & 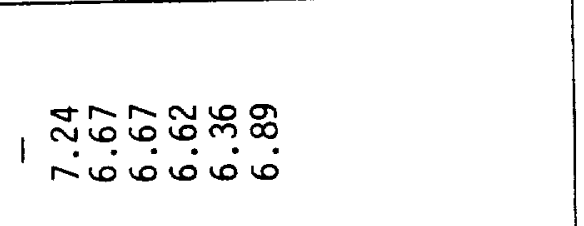 \\
\hline$\stackrel{\infty}{ٍ}$ & 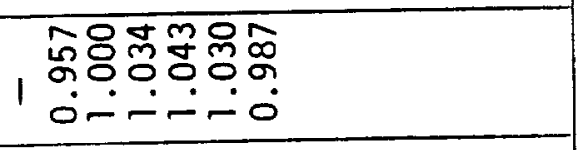 \\
\hline$\stackrel{+}{i}$ & $\begin{array}{l}\hat{\sigma} \\
0 \\
0\end{array}$ \\
\hline$\neq$ & $\begin{array}{l}\text { gे } \\
\text { g. }\end{array}$ \\
\hline 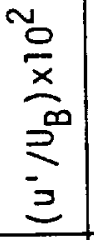 & 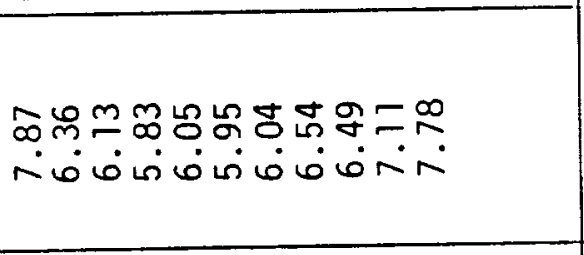 \\
\hline$\sum^{\infty}$ & 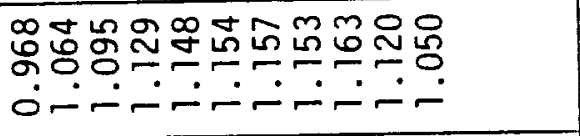 \\
\hline$\stackrel{5}{i}$ & ? \\
\hline$\geqslant$ & $\bar{\sigma}$ \\
\hline $\begin{array}{l}\frac{v}{0} \\
\frac{x}{\infty} \\
\sum \\
\vdots \\
\geq\end{array}$ & 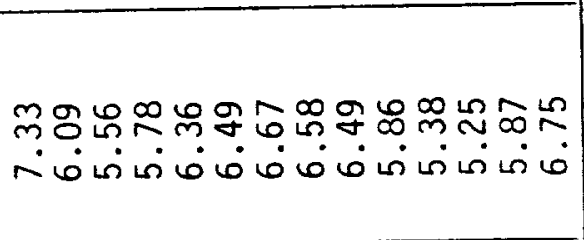 \\
\hline$\stackrel{\infty}{\supseteq}$ & 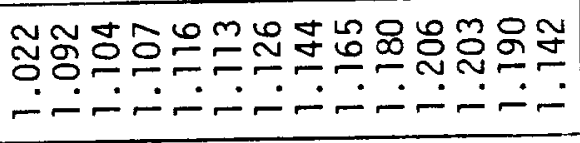 \\
\hline$\stackrel{5}{\therefore}$ & $\begin{array}{l}\Sigma \\
\sigma \\
\dot{0}\end{array}$ \\
\hline$\stackrel{1}{>0}$ & $\begin{array}{l}\stackrel{0}{N} \\
\dot{0} \\
\end{array}$ \\
\hline$\frac{1}{2}$ & 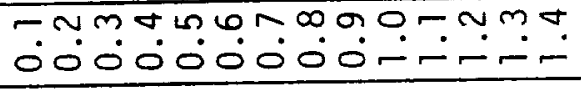 \\
\hline$\frac{\partial}{x}$ & $\stackrel{\circ}{\dot{0}}$ \\
\hline
\end{tabular}


APPENDIX 4

DEFINITION OF SYMBOLS

$\begin{array}{ll}\text { Roman Characters } \\ C_{p} & \text { Pressure coefficient (figure 12) } \\ d & \text { Pipe diameter } \\ \dot{m} & \text { Mass flow rate } \\ p & \text { Static pressure } \\ P_{r e f} & \text { Static pressure one diameter upstream of pipe bend } \\ R & \text { Radius of curvature of the bend } \\ r & \text { Internal radius of pipe }=\frac{1}{2} d \\ R e & \text { Reynolds number } U_{B} d / v \\ U & \text { Streamwise mean velocity } \\ U_{B} & \text { Bulk velocity } 4 \dot{m} /\left(\pi \rho d^{2} \text { ) }\right. \\ u^{\prime} & \text { R.m.s. streamwise velocity fluctuation } \\ x & \text { Distance measured along the pipe and bend centreline } \\ y & \text { Distance measured horizontally from centreline (figure 1) } \\ z & \text { Distance measured vertically from centreline (figure 1) }\end{array}$

Greek Characters

B Half angle of beam intersection

$\delta \quad$ Boundary layer thickness

$\theta \quad$ Bend angle (figure 1)

$\phi \quad$ Angle substended at pipe centreline (figure 12)

$\checkmark \quad$ Kinematic viscosity

$\circ \quad$ Density 


\section{REFERENCES}

1. Goldstein, S. (ed), (1938). Modern developments in fluid dynamics. Oxford.

2. Bradshaw, P. (1973) Effects of streamline curvature on turbulent flow. AGARDograph 169.

3. Prandti, L. (1952). Essentials of fluid dynamics. Blackie, London.

4. Ward-Smith, A.J. (1971). Pressure losses in ducted flows. Butterworth,

5. Humphrey, J.A.C., Taylor, A.M.K.P. and Whitelaw, J.H. (1977). Laminar flow in a square duct of strong curvature. J. Fiuid Mech. 83, 509.

6. Humphrey, J.A.C., Whitelaw, J.H. and Yee, G. (1981). Turbulent flow in a square duct with strong curvature. J. Fluid Mech. 103, 443.

7. Taylor, A.M.K.P., Whitelaw, J.H. and Yianneskis, M. (1981). Measurements of laminar and turbulent flow in a curved duct with thin inlet boundary layers. NASA Contractor Rep. 3367.

8. Rowe, M. (1970). Measurements and computations of flow in pipes. J. Fluid Mech. 43, 771 .

9. Agrawal, Y., Talbot, L. and Gong, K. (1978) Laser anemometry study of flow development in curved circular pipes. J. Fluid Mech. 85, 497.

10. Boadway, J.D. and Karahan, E. (1981) Correction of laser Doppler anemometer readings for refraction at cyl indrical interfaces. DISA Information 26.

11. Durst, F., Meliing, A. and Whitelaw, J.H. (1976). Principles and practice of laser-Doppler anemometry. Academic Press, London. 


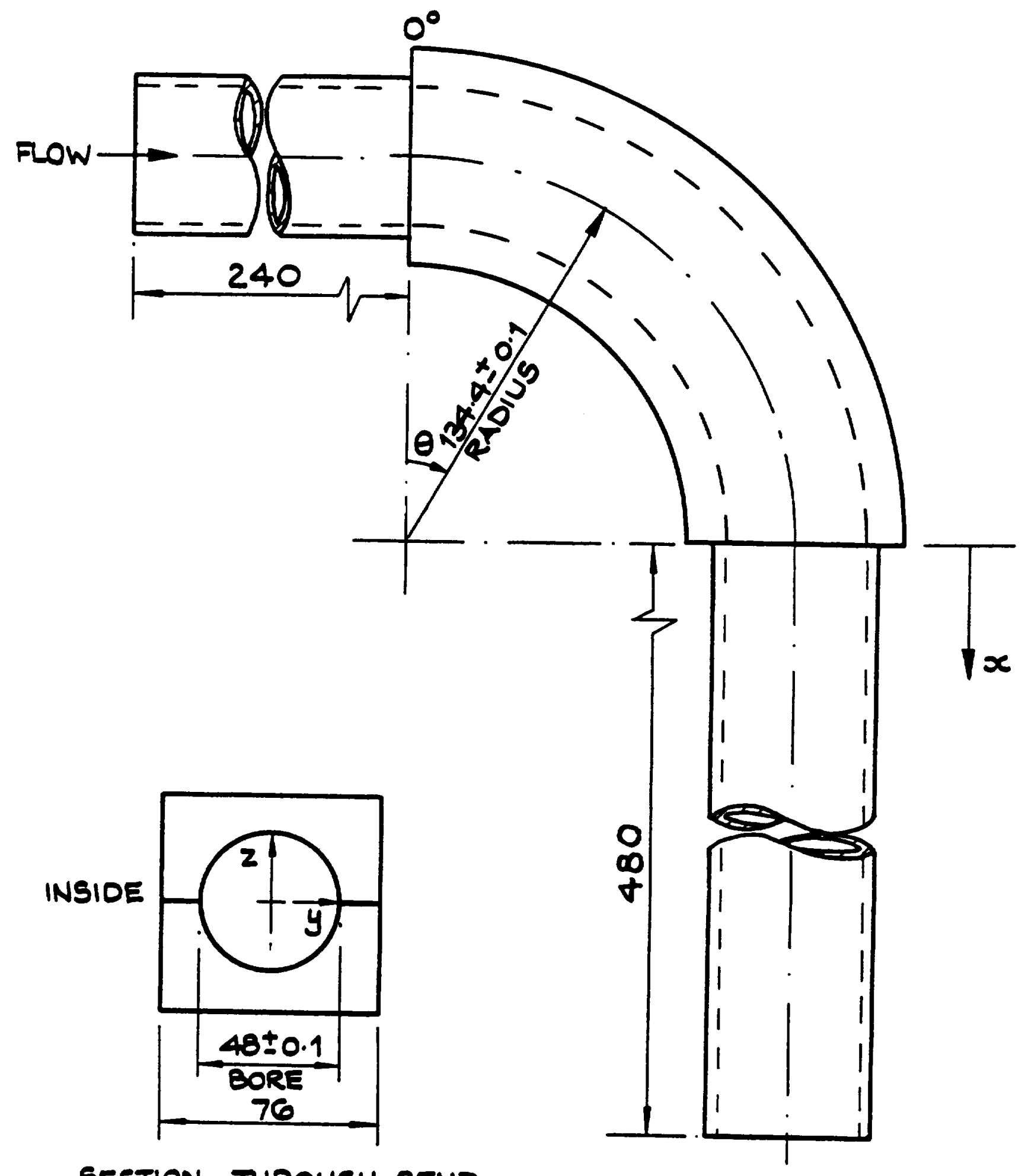

SECTION THROUGH BEND

Figure 1 Bend dimensions and co-ordinate system (Dimensions in $\mathrm{mm}$ ) 

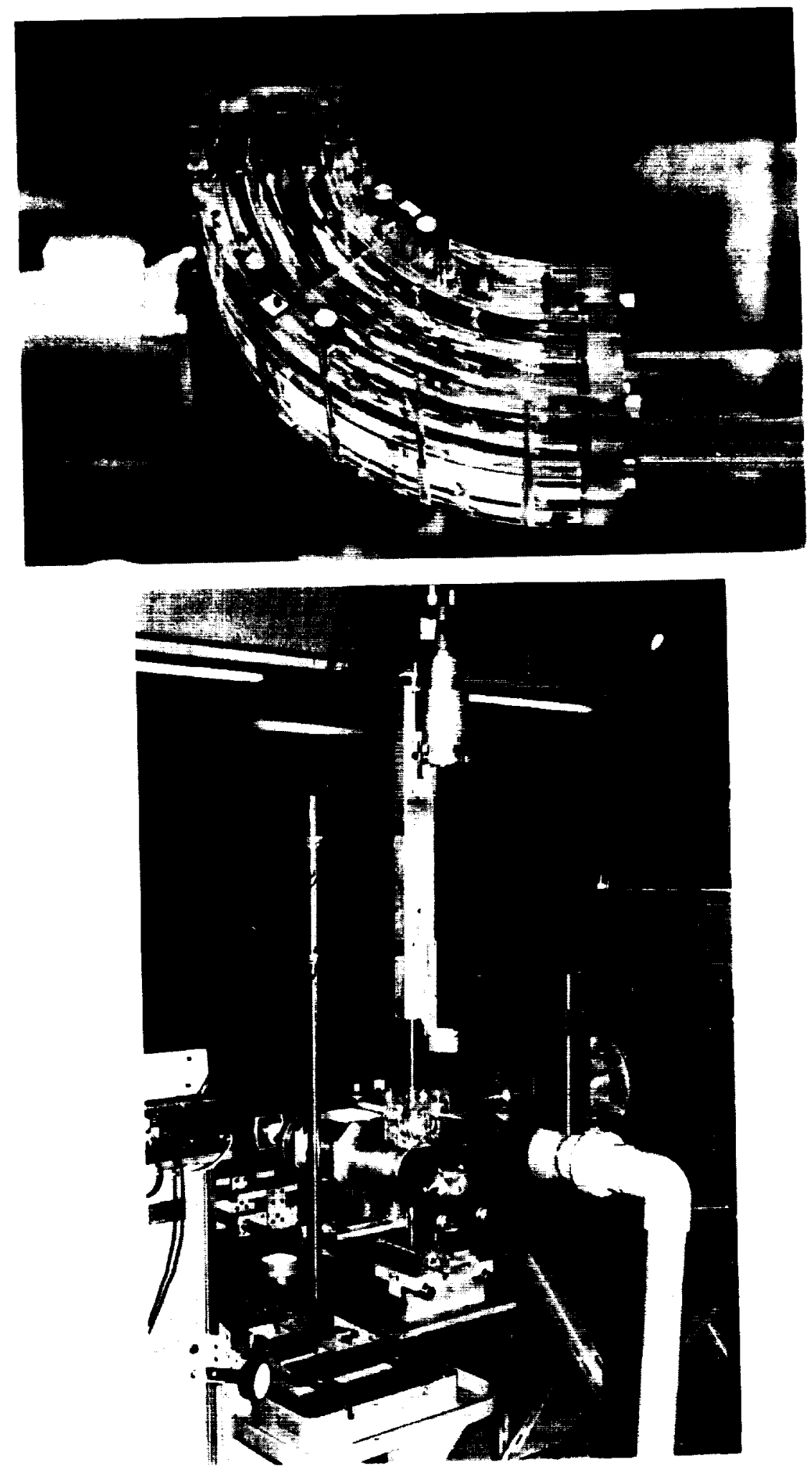

Figure 2 Views of the test bend and instrumentation 


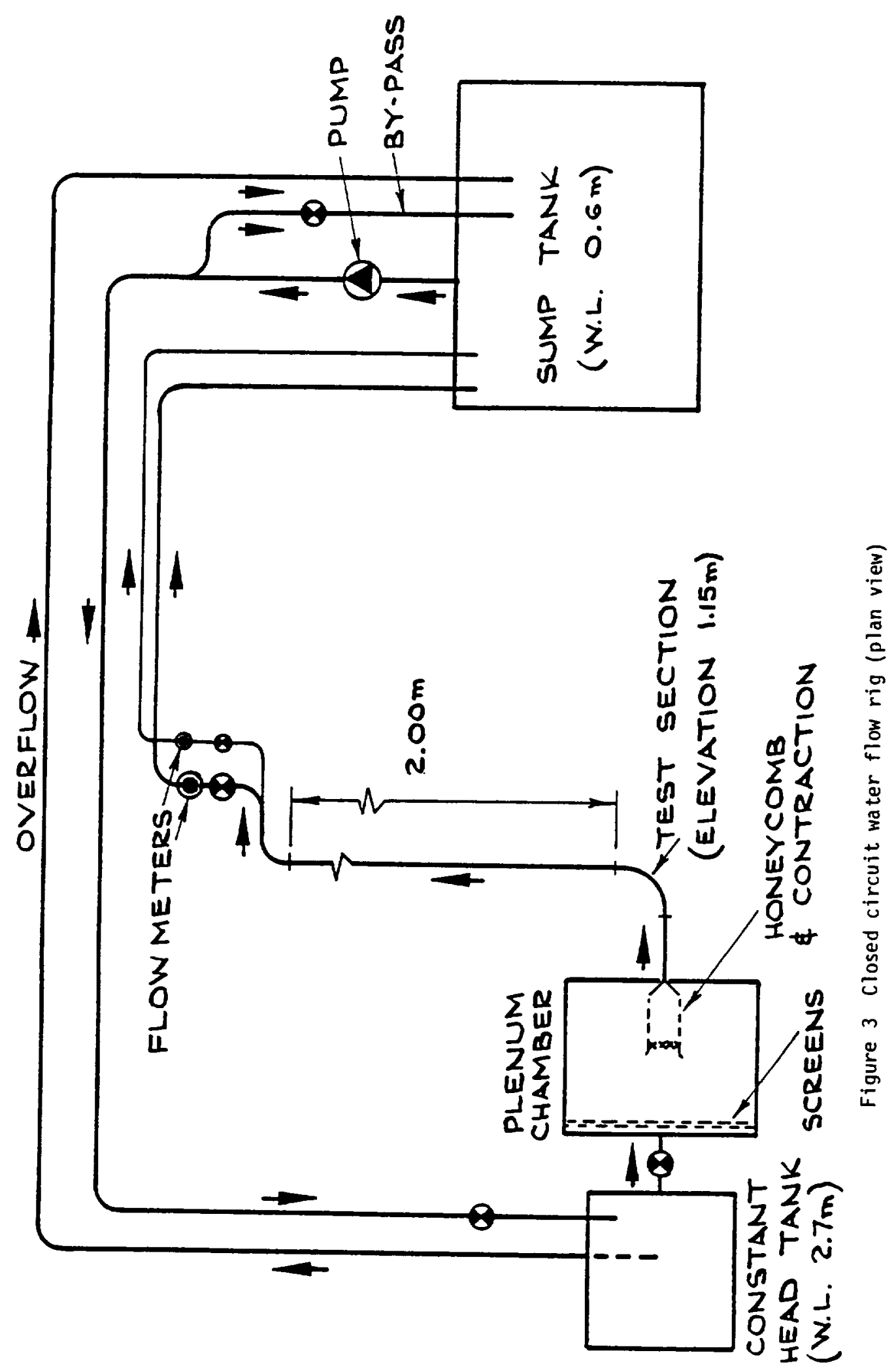




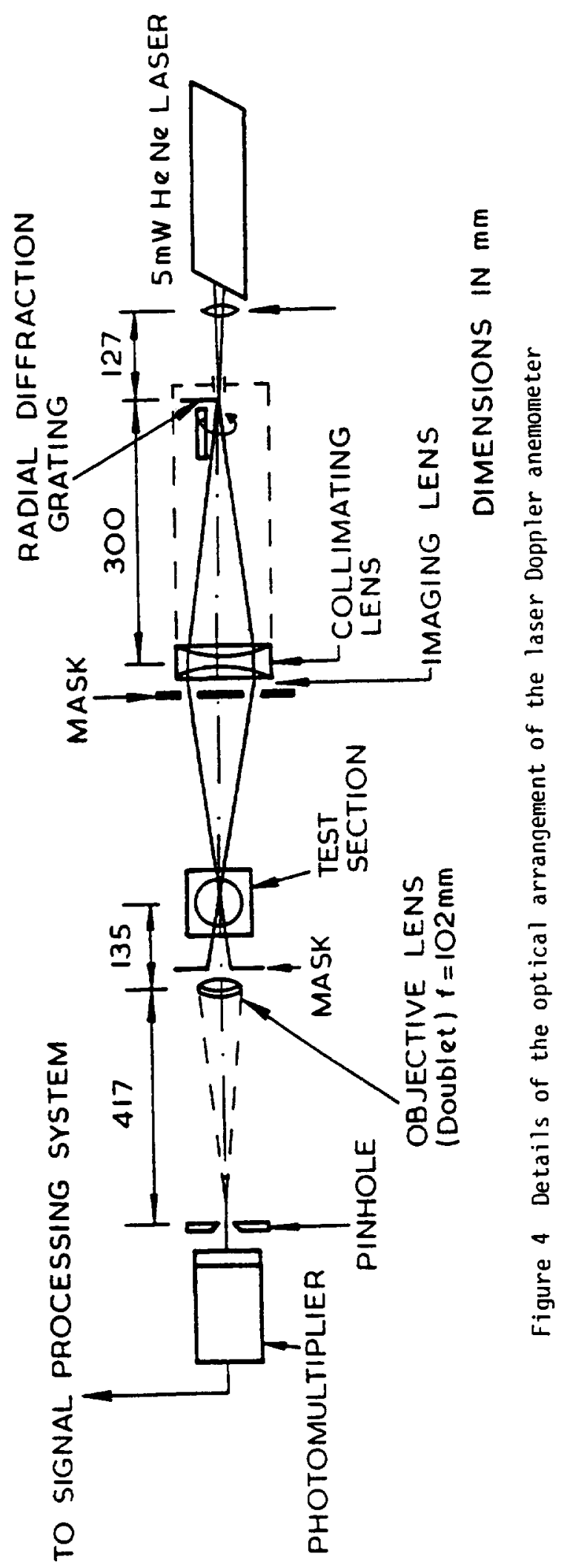




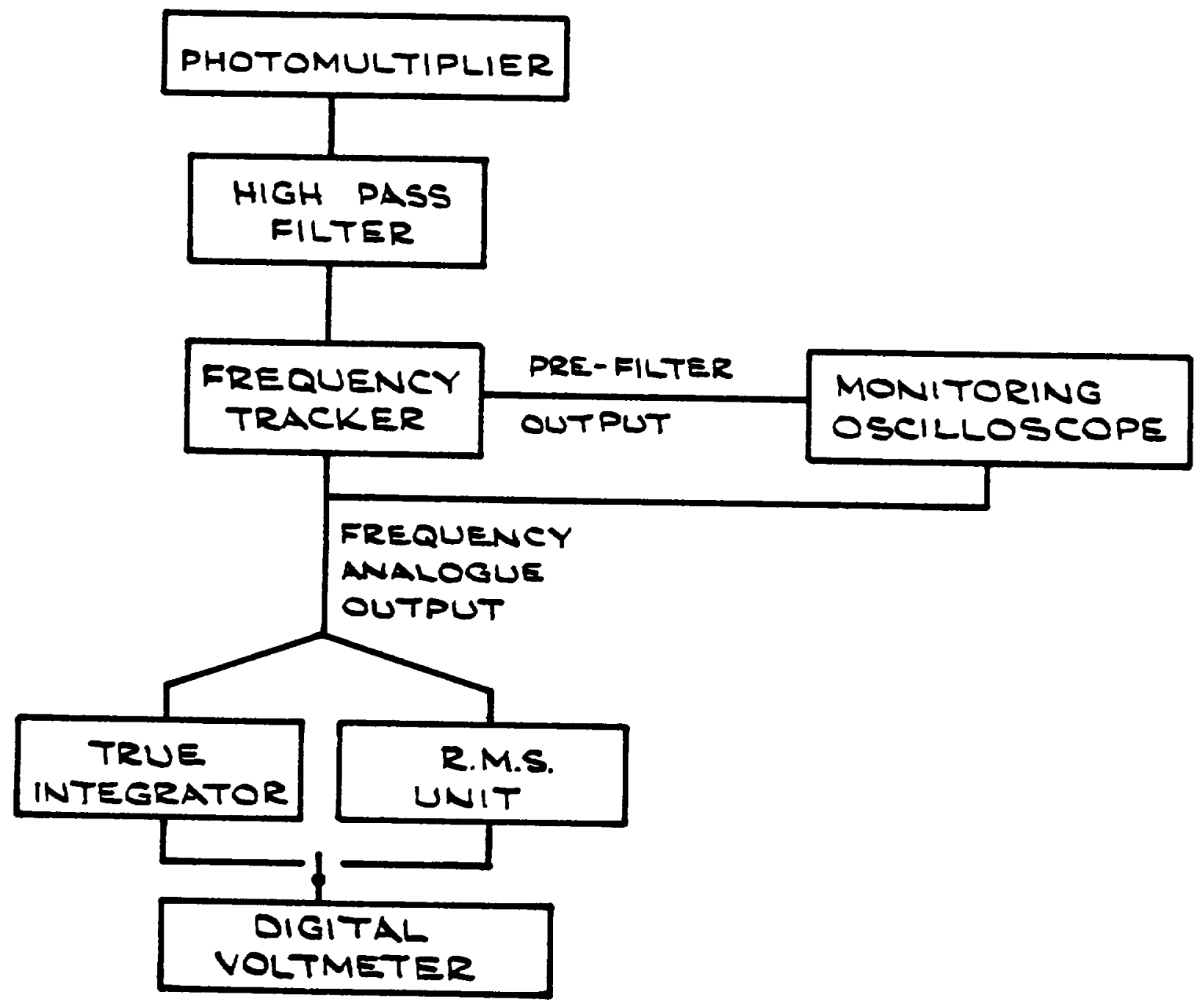

Figure 5 Block diagram of Doppler signal processing system 


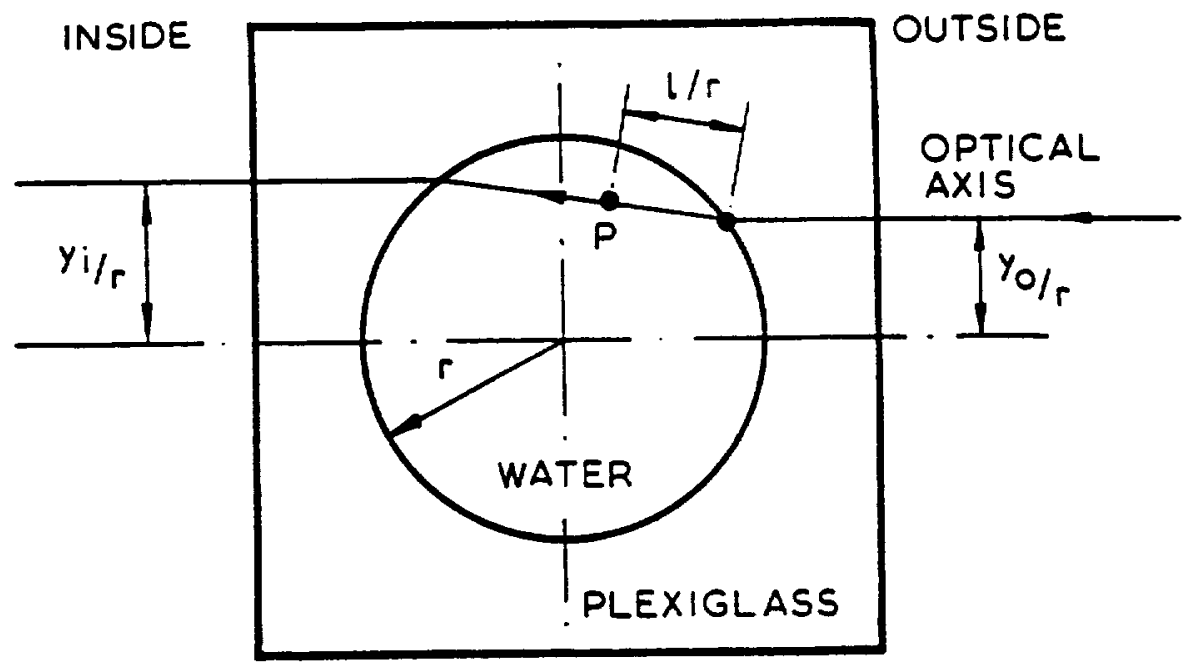

SECTION A-A

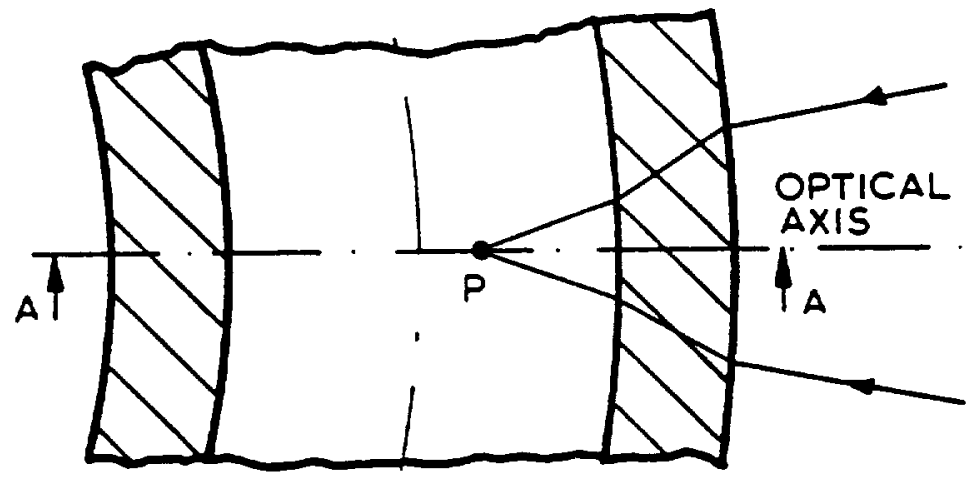

Figure 6(i) Beam paths through test section. Bend section in $\theta-y$ plane. Point $P$ marks location of scattering volume

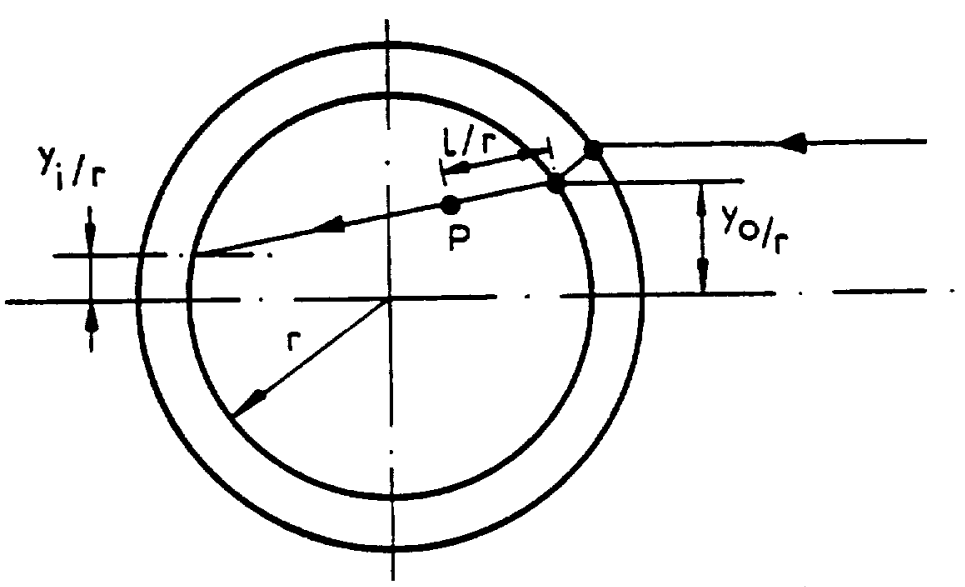

Figure 6(ii) Cross-section through upstream and downs tream tangents 


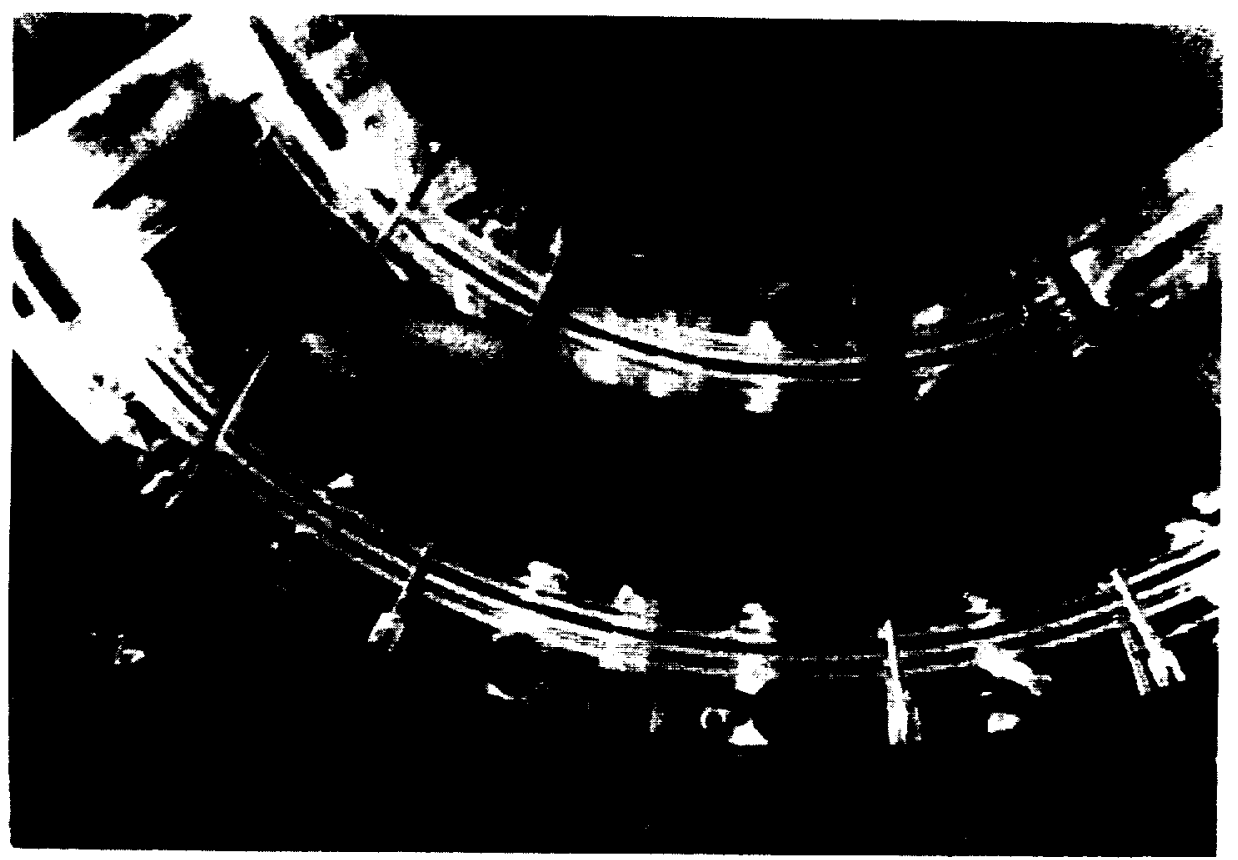

Figure 7.1 Flow visualization: $\operatorname{Re}=1093$. Flow from top left to top right; wire inserted at $\theta=15^{\circ}, y / r=0, z / r=1.0$

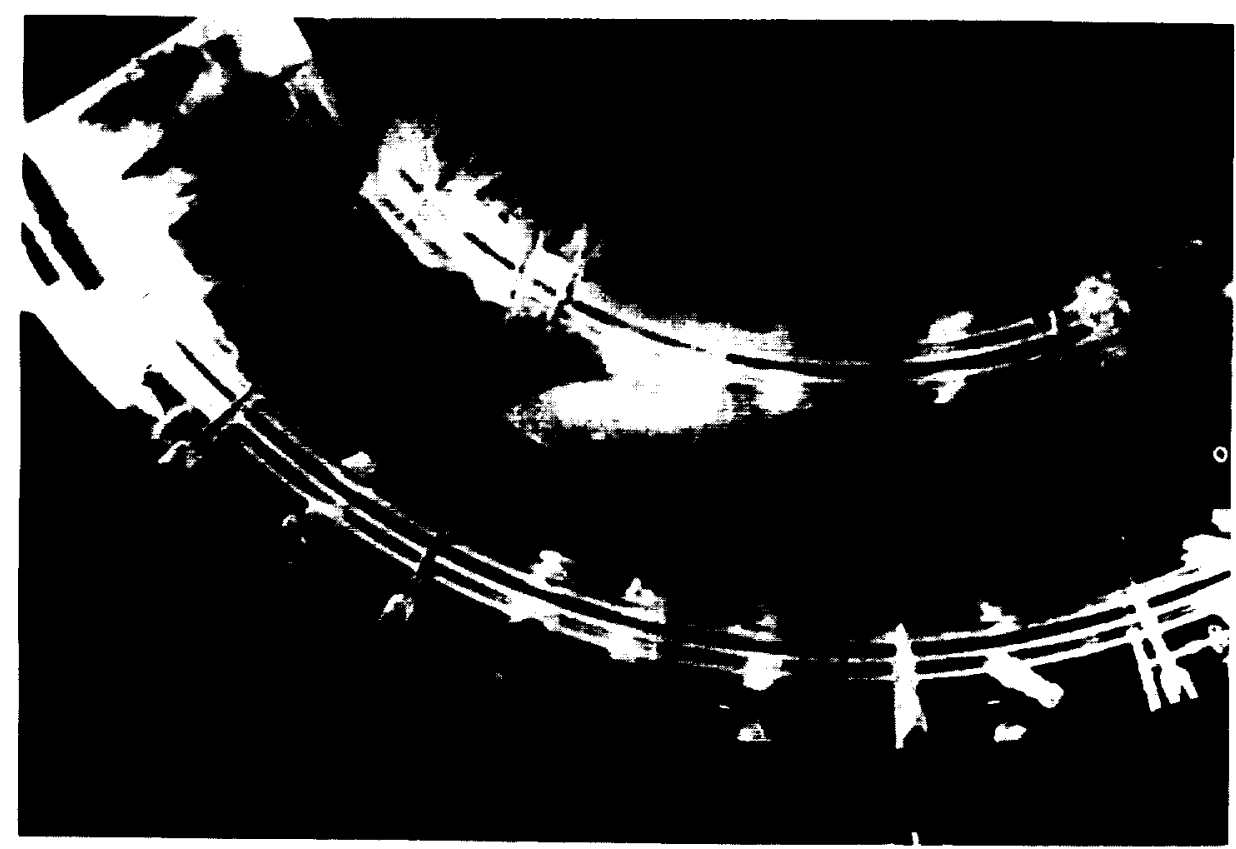

Figure 7.2 Flow visualization: $R e=1093$. Flow direction from top left to top right; wire inserted at $\theta=30^{\circ}, y / r=0$, $z / r=1.0$. 


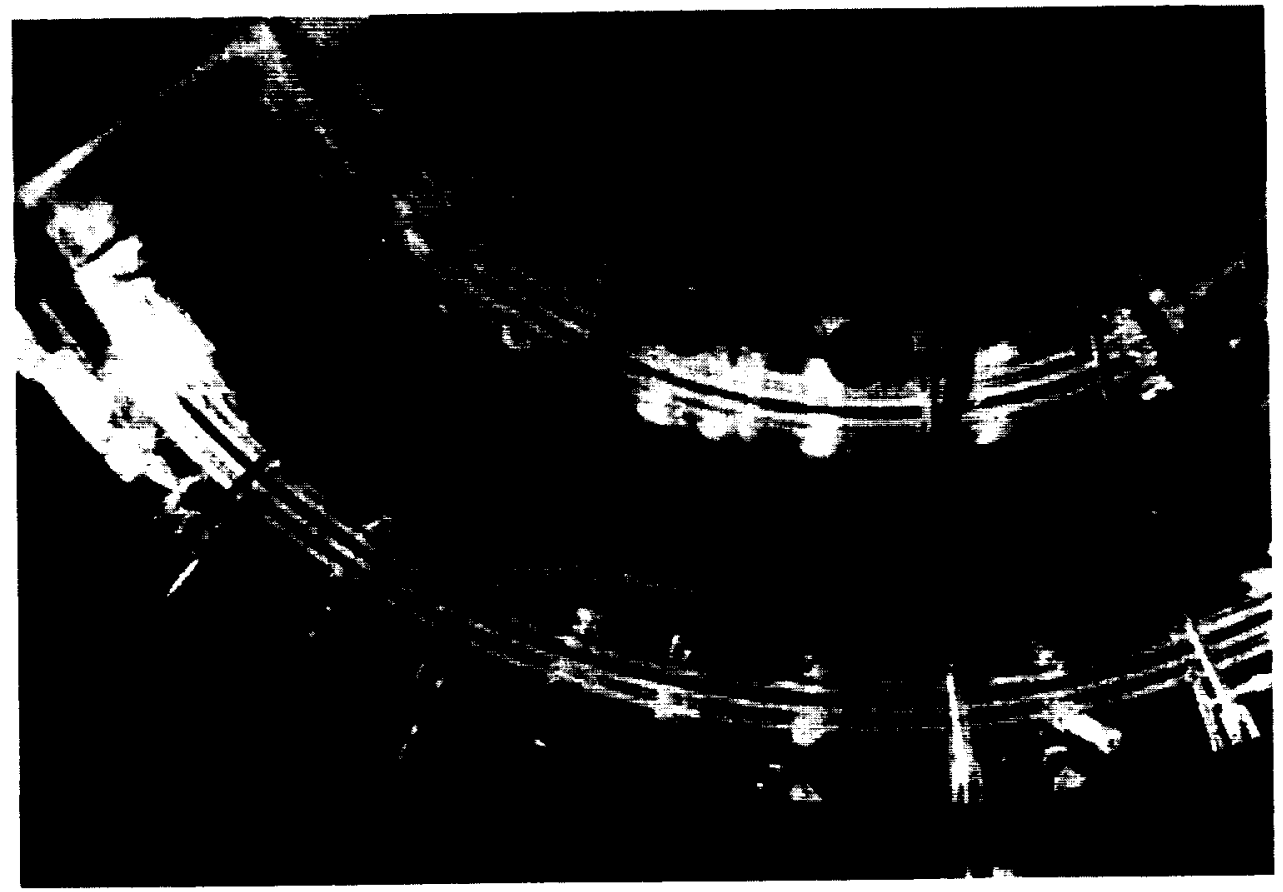

Figure 7.3 Flow visualization: $R e=1093$. Flow direction from top right to top left, wire inserted at $\theta=30^{\circ}, y / r=1.0$, $z / r=0$ 


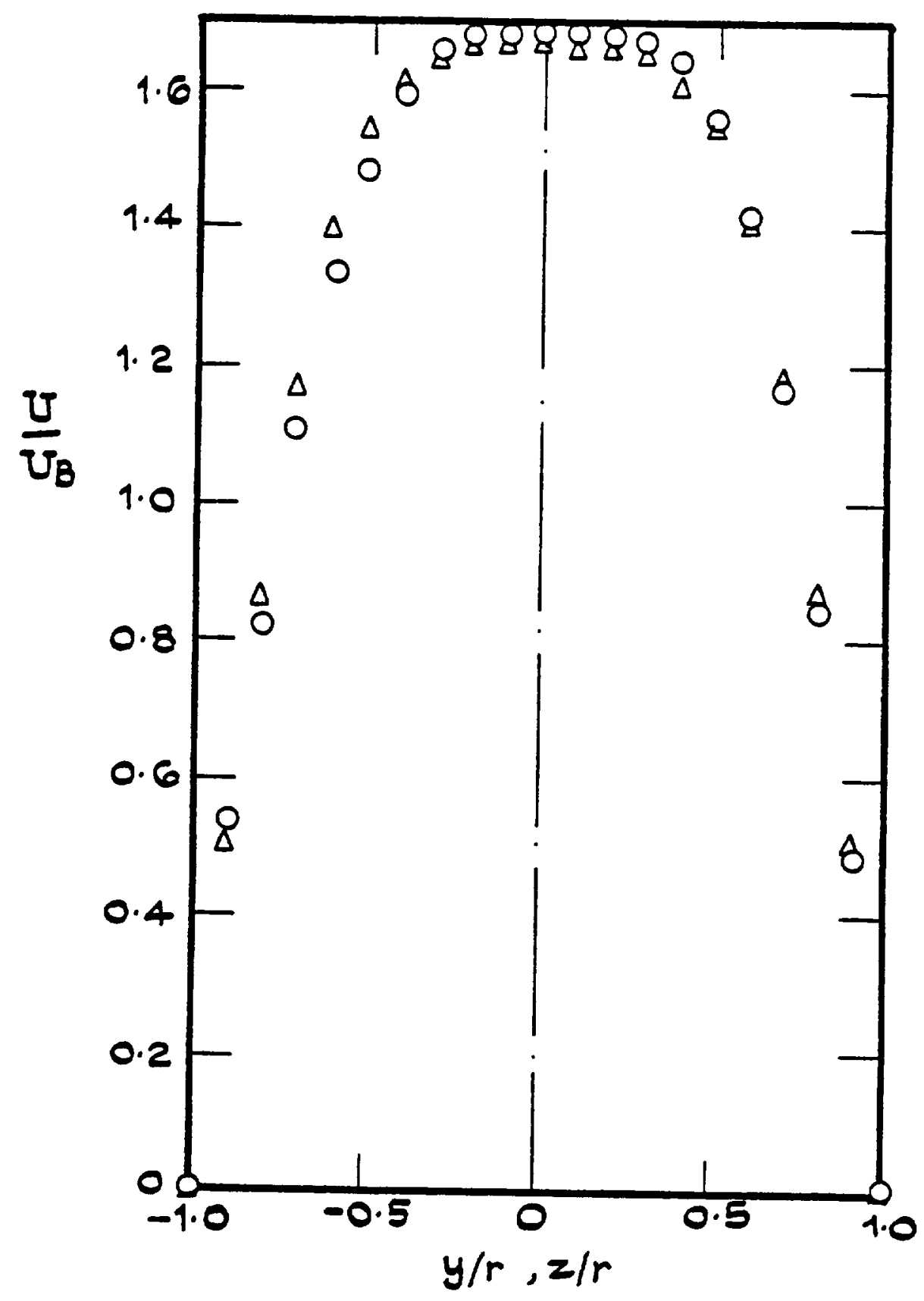

Figure 8 Horizontal, $O$, and vertical, $\Delta$, profiles of mean velocity in the laminar approach flow 0.58 diameters upstream of the inlet plane. $R e=500$ 

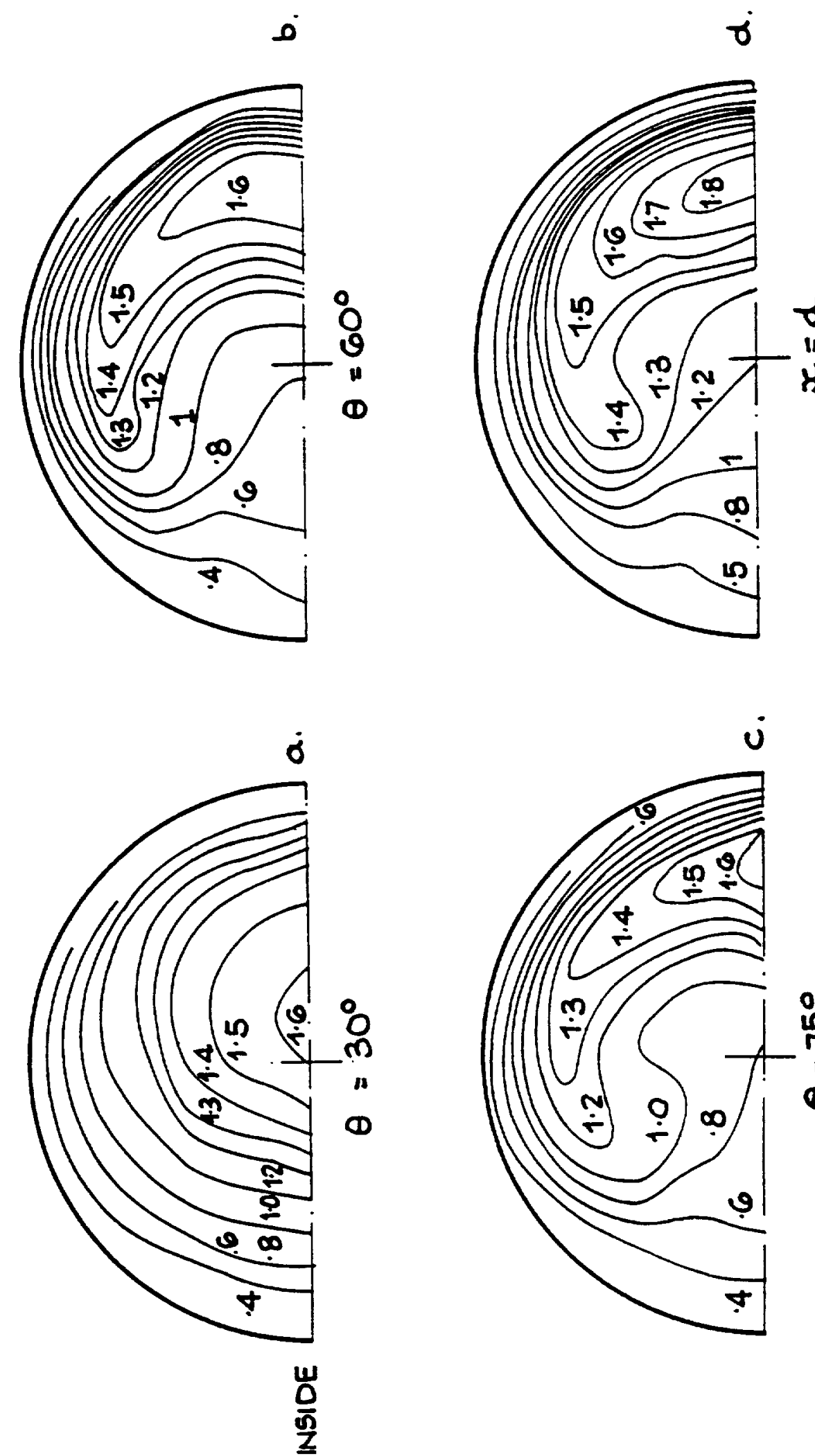

융

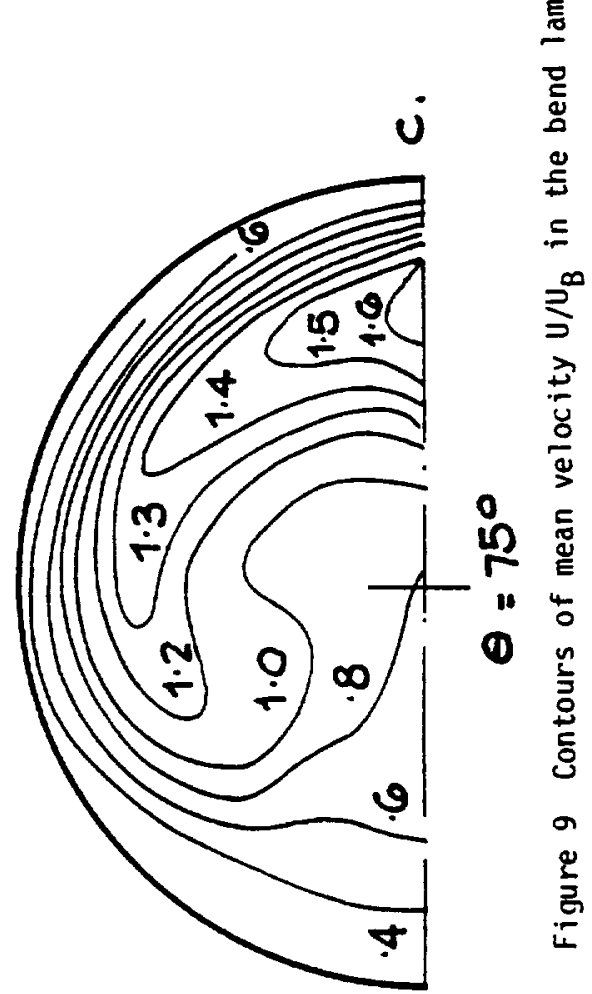




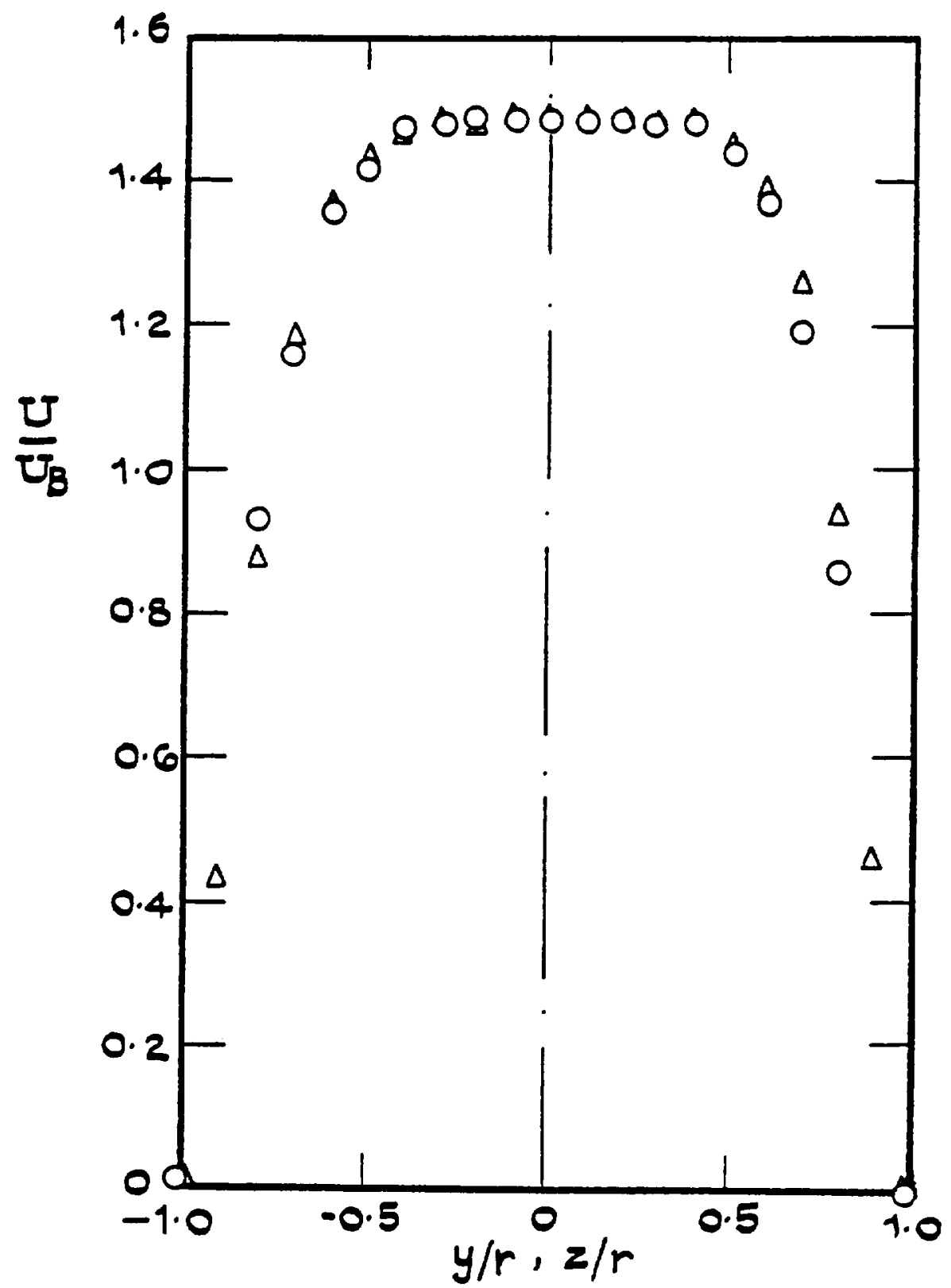

Figure 10 Horizontal, $O$, and vertical, $\Delta$, profiles of mean velocity in the laminar approach flow 0.58 diameters ups tream of the inlet plane, $\mathrm{Re}=1093$ 

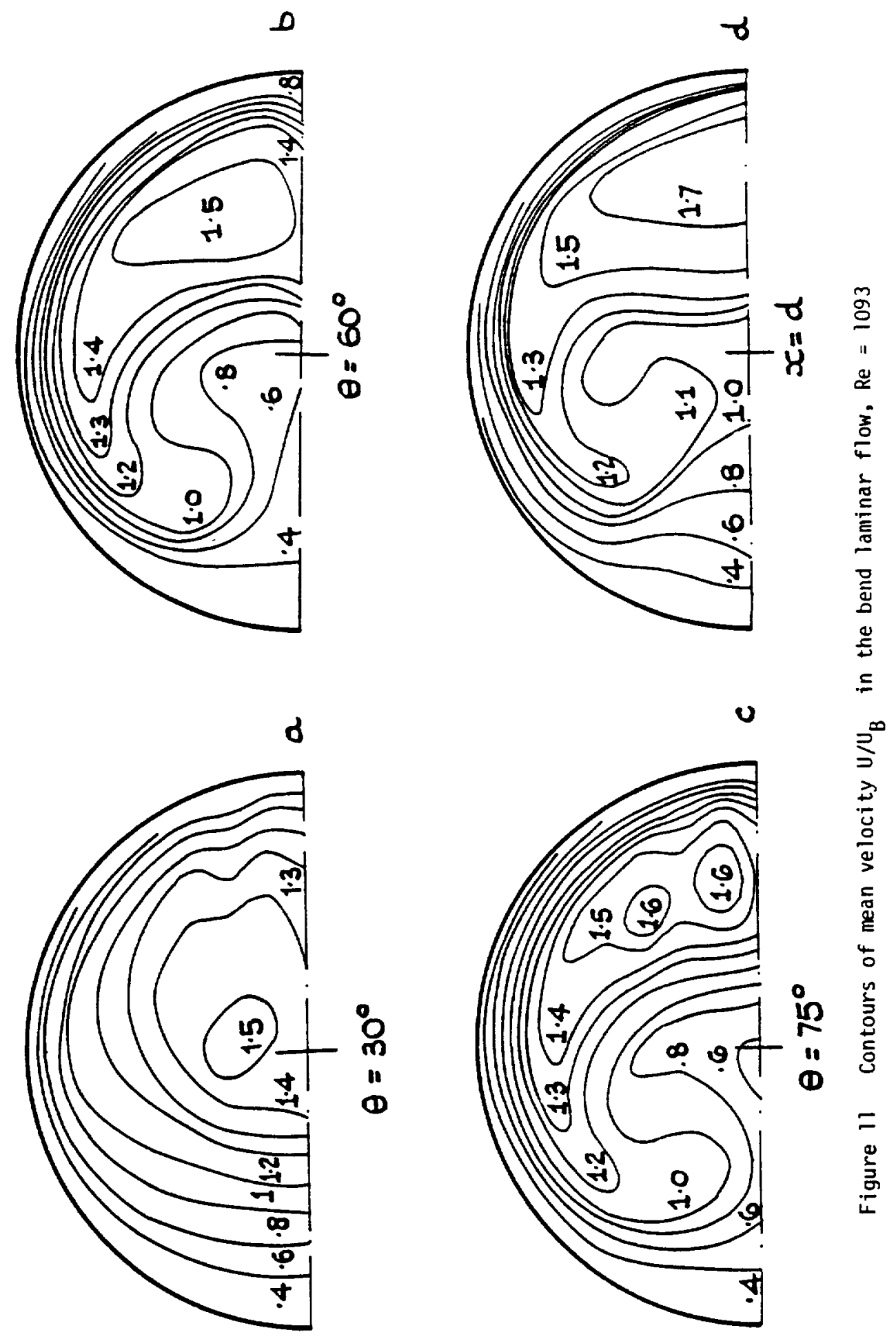

$\frac{\text { un }}{\underline{0}}$ 


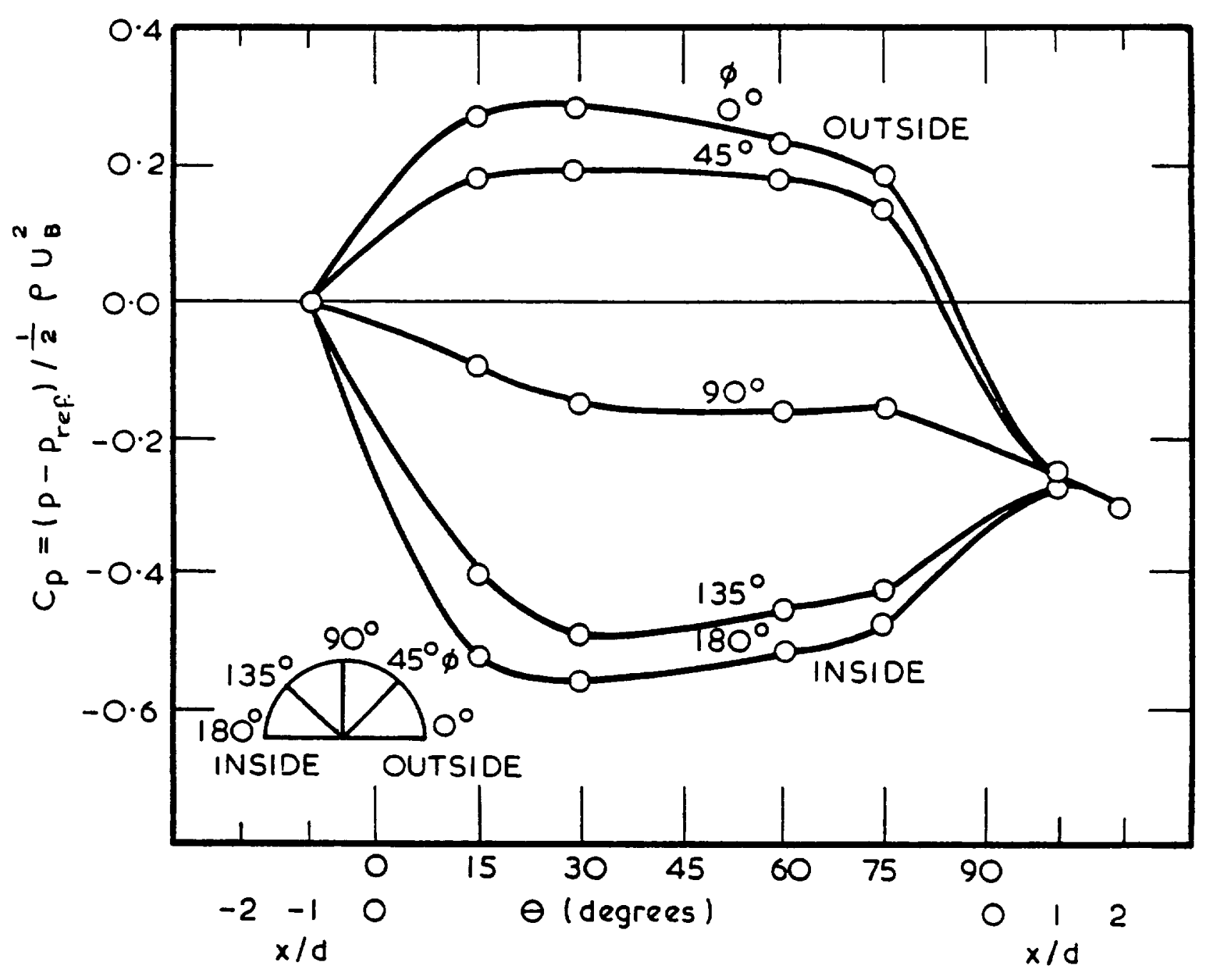

Figure 12 Wall static pressure variation. Turbulent flow, $\operatorname{Re}=43000$ 


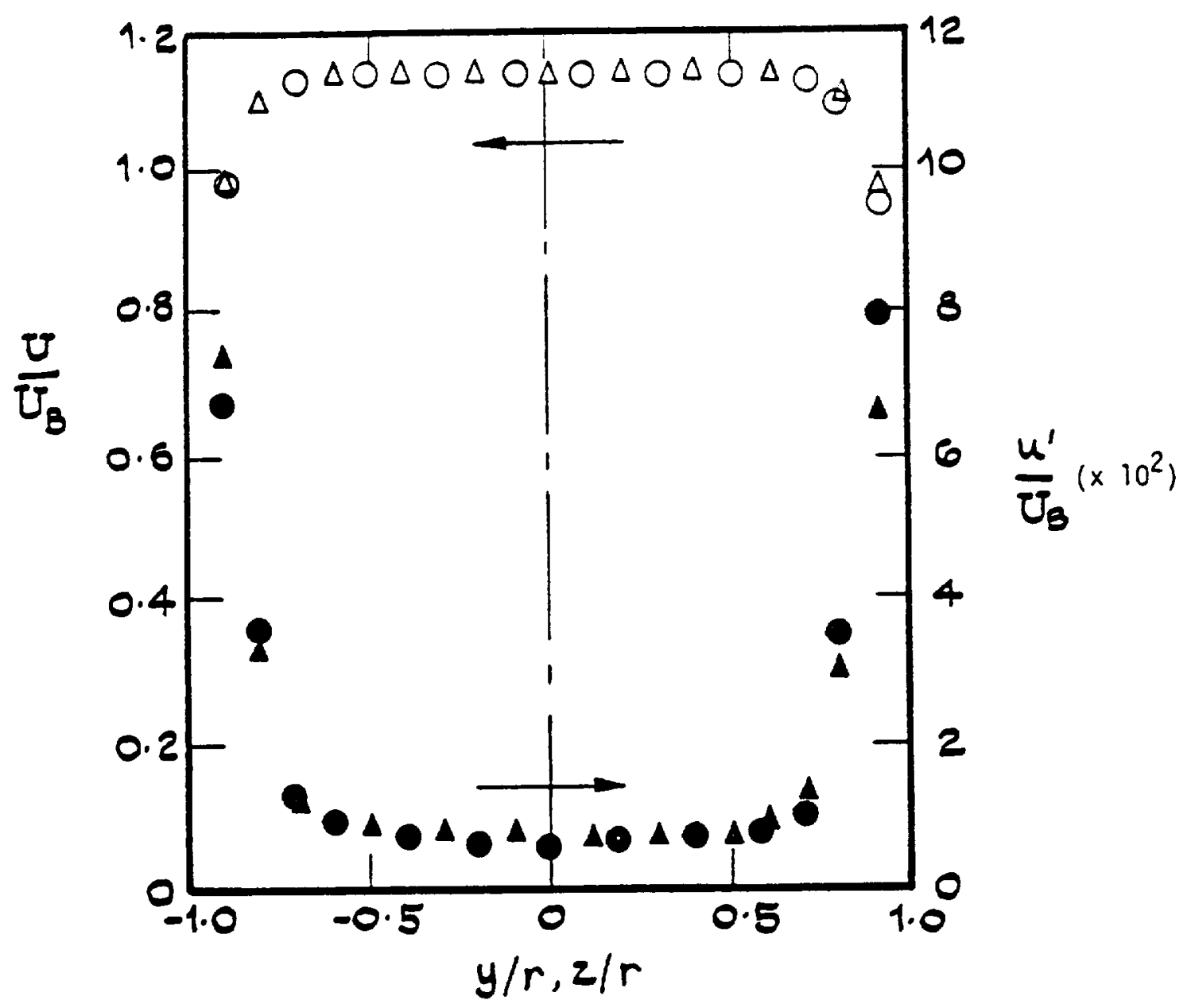

Figure 13 Profiles of mean velocity $U / U_{B}$ and turbulence intensity $u^{\prime} / U_{B}$ in the turbulent approach flow 0.58 diameters upstream of the bend. $O$ horizontal, $\Delta$ vertical. Re $=43000$ 

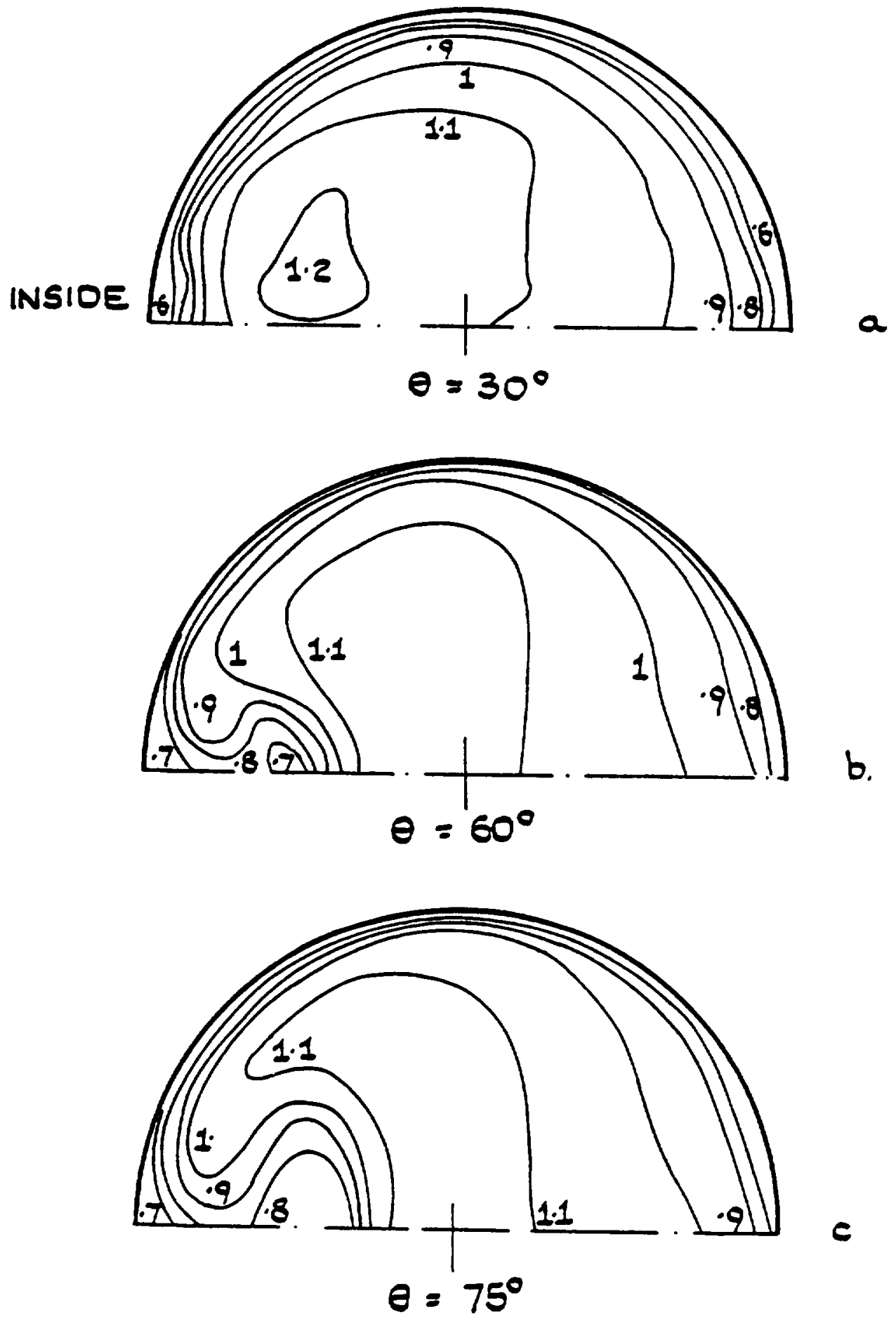

Figure $14(a)-(b)$ Contours of mean velocity $U / U_{B}$ in the bend.
Turbulent flow, $R e=43000$ 

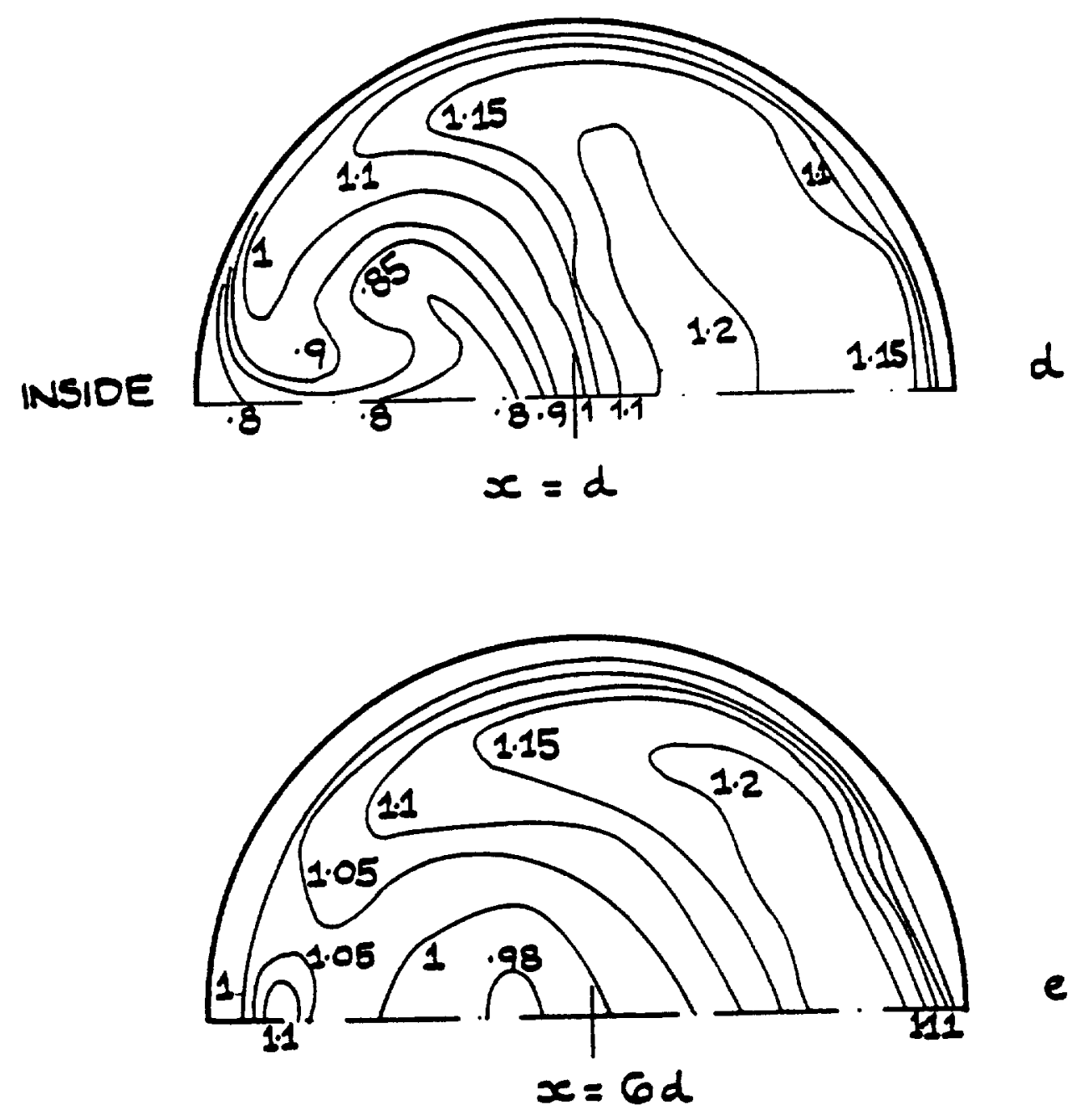

Figure $14(d)-(e)$ Contours of mean velocity $U / U_{B}$ downstream of the
bend. Turbulent flow, Re $=43_{000}$ 

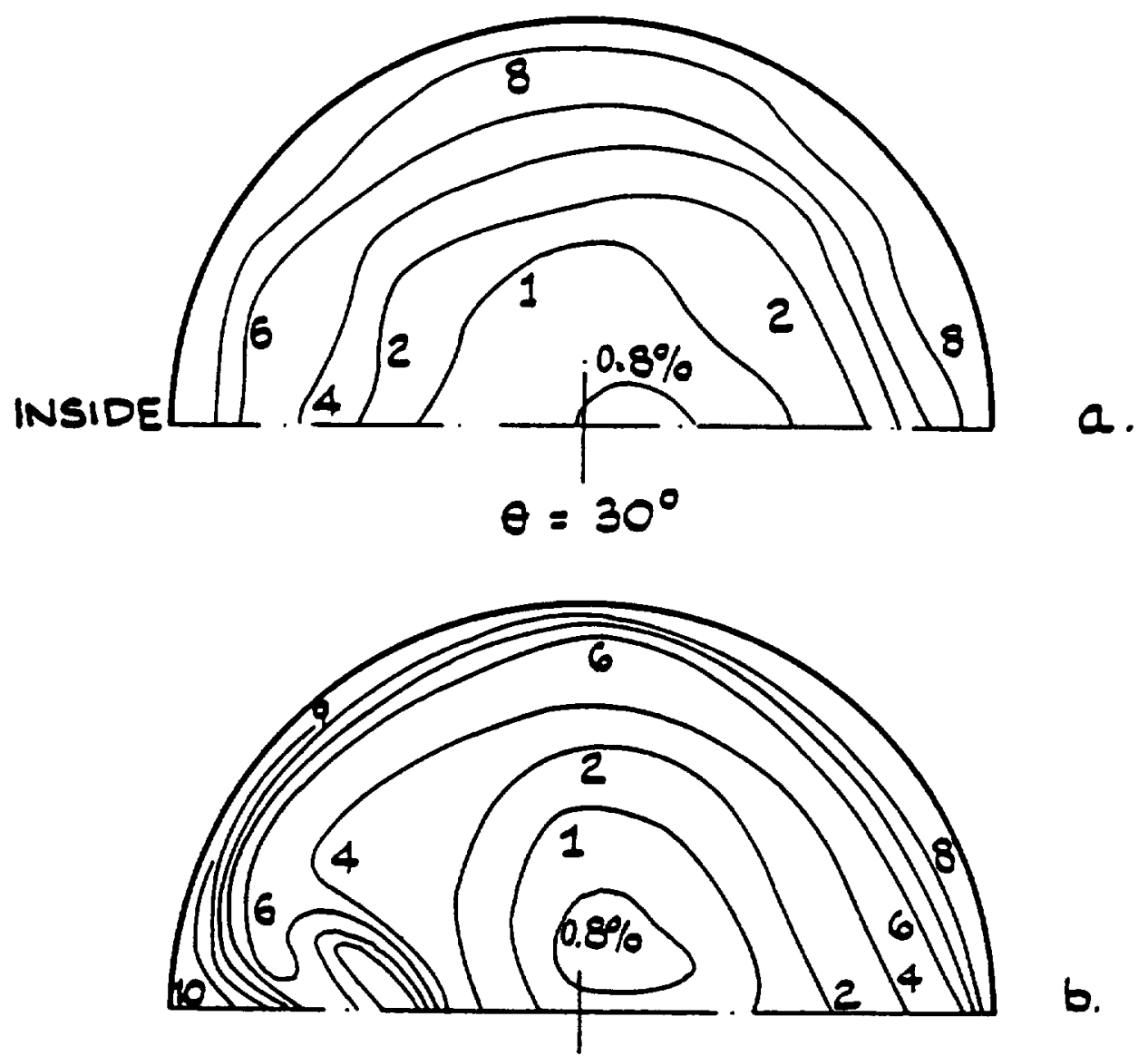

b.

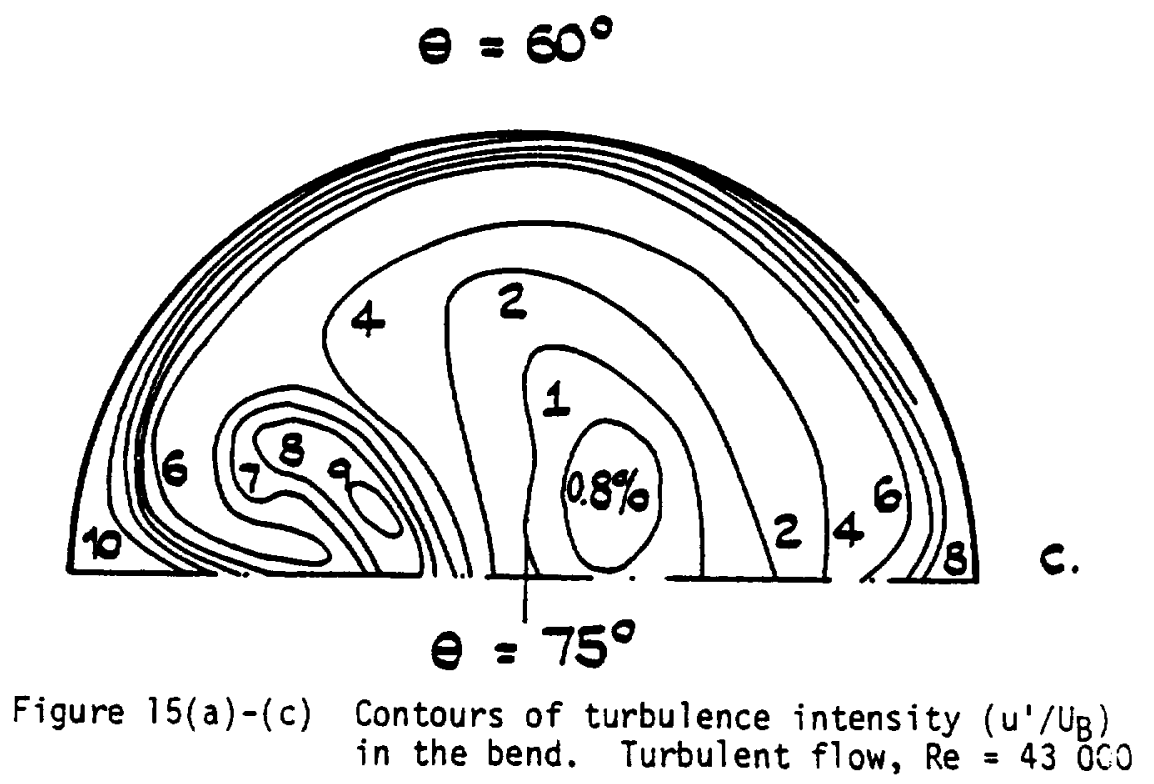



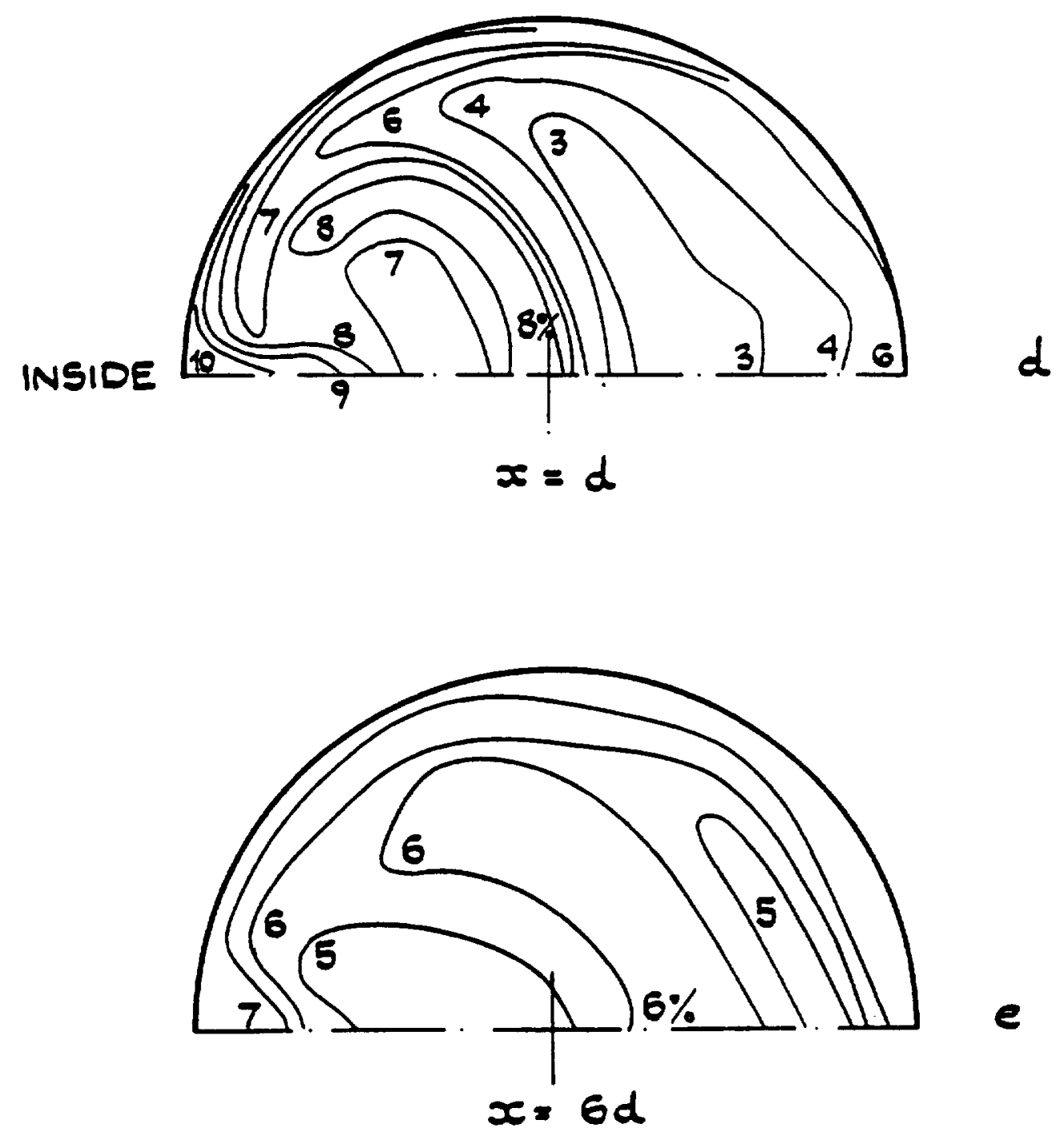

Figure $15(d)-(e)$ Contours of turbulence intensity $\left(u^{\prime} / U_{B}\right)$ downstream 


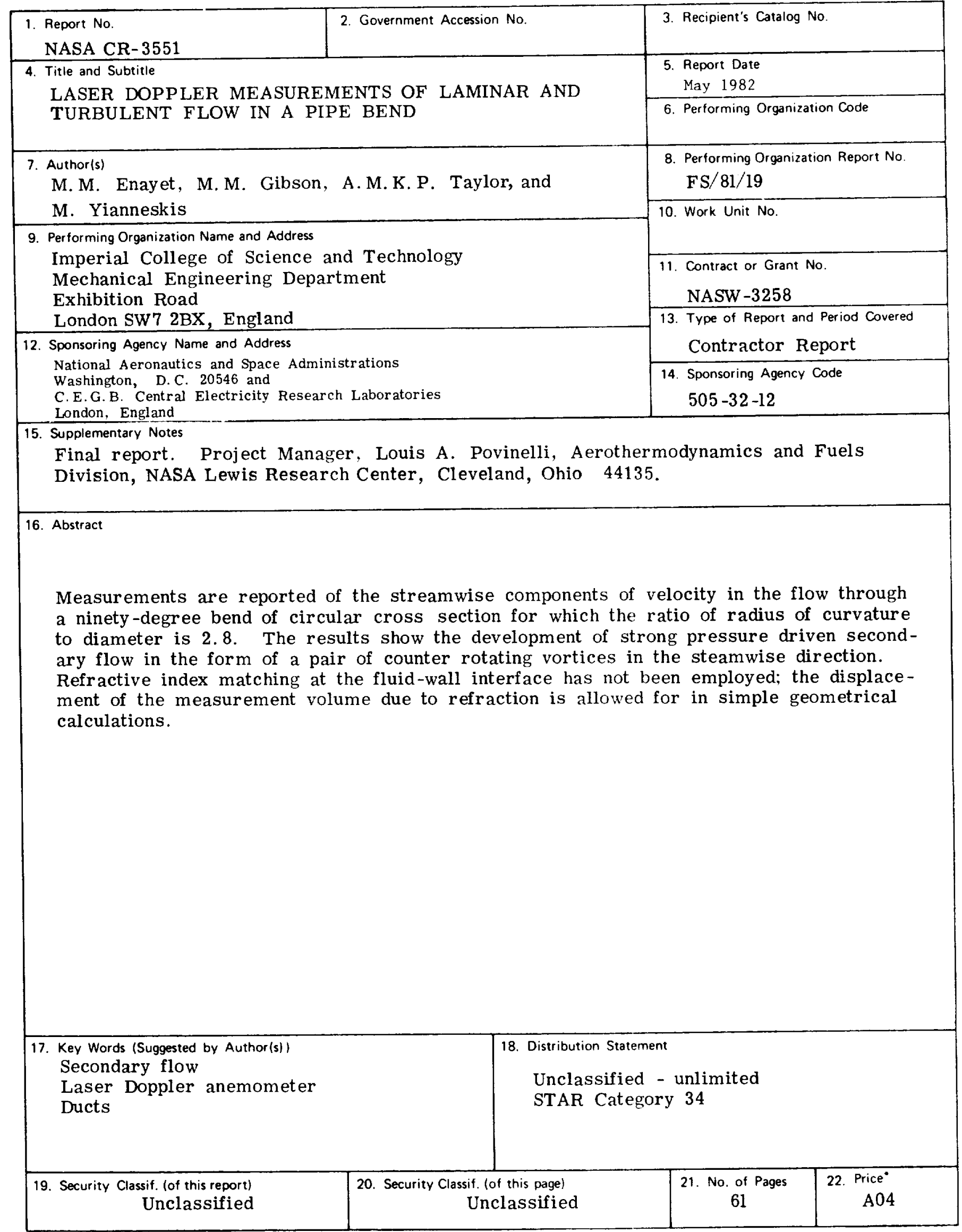

* For sale by the National Technical Information Service, Springfield, Virginia 22161 